\title{
ASSESSMENT OF LIGHT WATER REACTOR ACCIDENT MANAGEMENT PROGRAMS AND EXPERIENCE (U)
}

by WSRC Contact - K. K. Norkus

Westinghouse Savannah River Company

Savannah River Site

Aiken, South Carolina 29808

Other Authors:

R. J. Hammersley

Fauske and Associates, Inc.

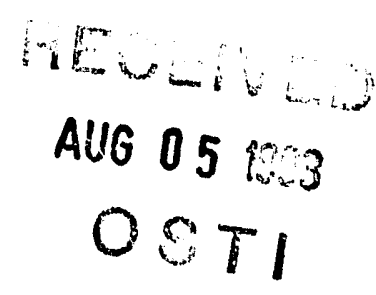

This paper was prepared in connection with work done under Contract No. DE-AC09-89SR18035 with the U.S. Department of Energy. By acceptance of this paper, the publisher and/or recipient acknowledges the U.S. Government's right to retain a nonexclusive, royalty-free license in and to any copyright covering this paper, along with the right to reproduce and to authorize others to reproduce all or part of the copyrighted paper.

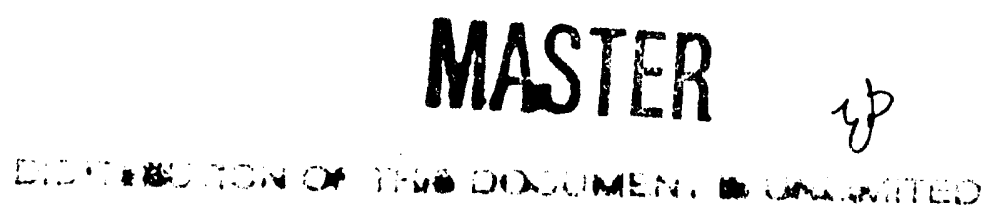




\section{DISCLAIMER}

This report was prepared as an account of work sponsored by an agency of the United States Government. Neither the United States Government nor any agency thereof, nor any of their employees, makes any warranty, express or implied, or assumes any legal liability or responsibility for the accuracy, completeness, or usefulness of any information, apparatus, product, or process disclosed, or represents that its use would not infringe privately owned rights. Reference herein to any specific commercial product, process, or service by trade name, trademark, manufacturer, or otherwise does not necessarily constitute or imply its endorsement, recommendation, or favoring by the United States Government or any agency thereof. The views and opinions of authors expressed herein do not necessarily state or reflect those of the United States Government or any agency thereof.

This report has been reproduced directly from the best available copy.

Available to DOE and DOE contractors from the Office of Scientific and Technical Information, P. O. Box 62, Oak Ridge, TN 37831; prices available from (615) $576-8401$.

Available to the public from the National Technical Information Service, U. S. Department of Commerce, 5285 Port Royal Rd., Springfield, VA 22161. 
PROJECT:

DOCUMENT:

TITLE:

TASK:
ACCIDENT MANAGMENT PROGRAM

WSRC-RP-92-10

ASSESSMENT OF LIGHT WATER REACTOR ACCIDENT

MANAGEMENT PROGRAMS AND EXPERIENCE (U)

REVIEW OF UTILITY, NRC AND INDUSTRY ACCIDENT MANAGEMENT PROGRAMS AIVD EXPERIENCE
At the

P. K. Norkus

Technical Review

Js $\bar{s}, t x$

T. E. Britt, Lead Engineer

Accident Management

153 Zut

L. A. Wooten, Manager

Safety Analysis Group

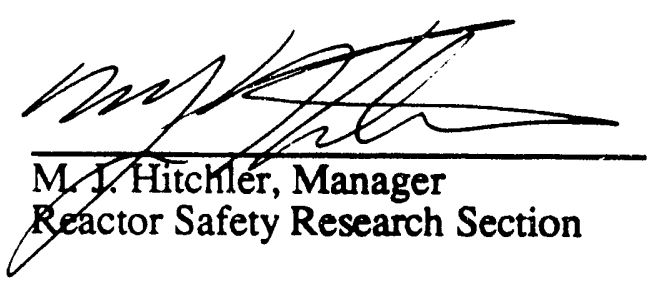

$\frac{2 / 28 / 92}{\text { Date }}$

$\frac{3 / 1}{\text { Date }} / 9 \alpha$

$\frac{3 / 25 / 92}{\text { Date }}$

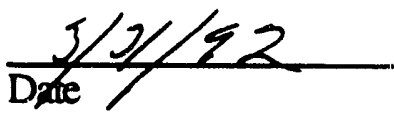




\section{IABIR OF COITEAIS}

Pace

I. REPORT OBJECTIVE. . . . . . . . . . . . . . . . . . . . 1

II. BACKGROUND ON ACCIDENT MANAGEMENT . . . . . . . . . . . . . . . 2

III. REVIEW OF ACCIDENT MANAGEMENT LITERATURE. . . . . . . . . . . . . 5

III.1 Review of NRC and Regulatory Documents . . . . . . . . . . 5

III.2 Review of Utility Accident Management Literature . . . . . 31

III.3 Review of Industry Documents . . . . . . . . . . . . . . 59

III.4 Accident Management Bibliography . . . . . . . . . . . 72

IV. ASSESSMENT OF APPROACHES FOR DEVELOPING

ACCIDENT MANAGEMENT PROGRAMS. . . . . . . . . . . . . . . . . . . 75

IV.1 Regulatory Approach . . . . . . . . . . . . . . . . 75

IV.2 Commonwealth Edison Approach. . . . . . . . . . . . 77

IV. 3 Assessment of Industry Approach . . . . . . . . . . . . . . 82

V. SEVERE ACCIDENT TECHNOLOGY DEVELOPMENTS . . . . . . . . . . . . . 84

V.1 NRC Technology Developments. . . . . . . . . . . . . 84

V.2 Utility Technology Developments. . . . . . . . . . . . . 86

V.3 Industry Technology Developments . . . . . . . . . . . . . 92

VI. REFERENCES. . . . . . . . . . . . . . . . . . . . 95 


\section{LIST OF TABIRS}

Table No.

1 Chronology of Key Regulatory Documents

Regarding Severe Accident Management. . . . . . . . . . . . 6

2 Generic Accident Management Strategies

("A" Strategies). . . . . . . . . . . . . . . . . . 20

3 Generic Mitigative Accident Management

Strategies ("B" Strategies) . . . . . . . . . . . . . . . . 25

4 Summary of Procedures in the French Approach to Incident and Accident Management . . . . . . . . . . . . . 54

5 Summary of Key Elements of the Severe

Accident Management Scheme for Loviisa. . . . . . . . . . . . 60

6 Summary of Personnel Resources for Accident-

Management Evaluation . . . . . . . . . . . . . . . . . 69

7 Summary of Comparison of EPRI and CECo

Accident Management Evaluation Processes. . . . . . . . . . . 83

$8 \quad$ NRC Consequence Assessment Procedure Overview . . . . . . . . 88

$9 \quad$ NRC Protective Action Assessment Procedure

Overview. . . . . . . . . . . . . . . . . . . . 89 
Fieure No.

$1 \quad$ NRC Severe Accident Closure Plan - Interfaces

of Key Elements... . . . . . . . . . . . . . . . . . . . . . 9

Logic Structure of Accident Management "A" Strategy . . . . . 23

NRC Process for Developing an Accident Management

Plan. . . . . . . . . . . . . . . . . . . . . . . 29

4 Development of Integrated IPE and Accident

Management Effort... . . . . . . . . . . . . . . . 33

5 Development of Integrated IPE and Accident

Management Effort (Continued) . . . . . . . . . . . . . 34

6 Conceptual Approach to Accident Management Program

Definition in Parallel with IPE .............. . 35

7 Commonwealth Edison Evaluation Process for

Identifying and Documenting IPE and AM Insights. . . . . . . 37

8 Overview: Framework for Identifying and

Documenting IPE and AM Insights in Paralle1. . . . . . . . . 39

9 Detailed Process for IPE and AM Insights. . . . . . . . . . 40

10 Some Possible Pathways for Example Sequence . . . . . . . . . 64

11 Overview of Industry Guidance (NUMARC) for

Evaluation Process. . . . . . . . . . . . . . . . . . . 66

12 Industry Guidance: Breakdown of Accident

Management Capabilities . . . . . . . . . . . . . . . . 67

13 NRC Assessment Tool Overview. . . . . . . . . . . . . 87

14 Accident Management Analytical Tools Proposed by EPRI . . . . . . . . . . . . . . . . . . . . . . . . . . . 94 


\section{REPORT OBJECTIVE}

The objective of this report is to provide an assessment of the current light water reactor experience regarding accident management programs and associated technology developments. This assessment for light water reactor (LWR) designs is provided as a resource and reference for the development of accident management capabilities for the production reactors at the Savannah River Site. The specific objectives of this assessment are as follows:

1. Perform a review of the NRC, utility, and industry (NUMARC, EPRI) accident management programs and implementation experience.

2. Provide an assessment of the problems and opportunities in developing an accident management program in conjunction or following the Individual Plant Examination process.

3. Review current NRC, utility, and industry technological developments in the areas of computational tools, severe accident predictive tools, diagnostic alds, and severe accident training and simulation. 


\section{BACRGROUND ON ACCIDENI MANAGDIOANT}

It is useful to first provide a working definition of "accident management". The same broad general definition of accident management that is being most frequently employed by the NRC as well as the utility industry as represented by NUMARC will also be used in this document. That is, accident management refers to actions taken during the course of an accident by the plant operating staff and technical staff, to perform the following:

- prevent the accident from progressing to core damage,

- terminate core damage if it begins,

- maintain the integrity of the containment as long as possible, and

- minimize the effects of off-site releases.

Advanced preparations that help to ensure effective response for potential accidents are also considered part of accident management. The objective of such advanced preparations is to assure that the total plant capabilities are considered and made available in the eventuality of a severe accident. Accident management is not limited to actions taken to cope with an accident after there has been core damage. However, accident management is meant to be limited in this conception to the phases of an accident beginning when operator intervention is necessary to prevent the accident from proceeding to core damage. This is equivalent to saying that accident management is meant to focus on conditions beyond the design basis for the plant. In the case of light water reactors, accident management would be implied by the emergency operating procedures followed by supplemental accident management strategies currently being planned or considered and the emergency response guidance which exists for all commercial LWRs.

The appropriate interfacing and interactions between these several sets of guidance is a key activity for producing an integrated accident management program. For LWRs emergency operating procedures (EOPs) and emergency response guidance already exist. This can be contrasted to the situation at 
the production reactors where emergency operating procedures of the same type and detail as LWRs are not currently available.

The NRC in SECY-89-012 has identified five key areas for consideration in preparing an accident management program. The LWR utility industry to date has generally endorsed these five elements with some modifications. The five elements provided in SECY-89-012 are as follows:

1. Organization: The assessment and as required modification of the respective plant's decision making authority and lines of communication.

2. Codified Guidance: Written descriptions of accident management strategies that provide guidance in the event of a severe accident.

3. Training: Operators, technical support staff, and management training regarding severe accident issues and symptoms, or ganizational needs and changes, and potential actions and activities during a response to severe accidents.

4. Calculational Aids: Guidance and tools for the technical support staff and managers for diagnosing and planning appropriate responses to severe accidents.

5. Plant Instrumentation: An assessment of the instrumentation needs and their availability during severe accidents.

The LWR utility experience to date has generally endorsed the content of first four elements and identified the need to expand the area of plant instrumentation to cover a broader scope of plant status information. For example it is anticipated that it will be necessary for accident managers to know which components are out of service, the number of mechanical maintenance personnel on site, the status of key spare parts for crucial equipment in the store room and other general information regarding the total set of capabilities and resources on site. This is consistent with the concept of assuring that the total plant capability is considered when planning possible responses as part of an accident management program.

The broad definition of accident management as stated here and the five basic elements for an accident management program identified are consistent with the philosophy for accident management development espoused for the 
Savannah River Site at the Savannah River Laboratory (Haas, 1990). Thus these broad perspectives will be used as a point of reference in the technology survey and documentation provided in the balance of this report. 


\section{REVIET OF ACCIDENT MANAGETIENT LITERATURE}

The purpose of this section is to provide a review of NRC, utility and industry accident management programs. A bibliography is provided of avilil. able references on the subject of accident management. The key documents are abstracted in the following sections.

\section{III.1 Review of NRC and Regulatory Documents}

A chronology of key regulatory documents regarding severe accident management is provided in Table 1 . This table provides a convenient reference of the key documents and a brief statement of the major requirements or purpose of each. This chronology provides a description of the evolution of the regulatory position on severe accident management that has occurred to date. Each of the documents in Table 1 plus additional regulatory documents are discussed in this subsection.

\section{NRC Severe Accident Policy Statement}

The first document in Table 1 is the NRC Commissioner's policy statement on severe accidents regarding future designs and existing designs. This document was published in August, 1985 in the Federal Register and it establishes the policy of requiring a systematic evaluation of each nuclear power plant regarding its vulnerability to severe accidents. The systematic evaluation is called an Independent Plant Evaluation (IPE) which may use an existing probabilistic risk assessment (PRA) or perform a new one. In either case the goal is to assure that insights are identified to assure no undo risk to public health or safety due to the operation of that facility. Furtherwore, a key point in the policy statement is the identification of the need of a commitment by utility management to the pursuit of excellence in risk management.

These requirements are not binding to the Savannah River Site reactors as they are not governed by NRC regulations. The SRS reactors are governed by DOE rules. SRS may choose to evaluate the SRS reactors performance 


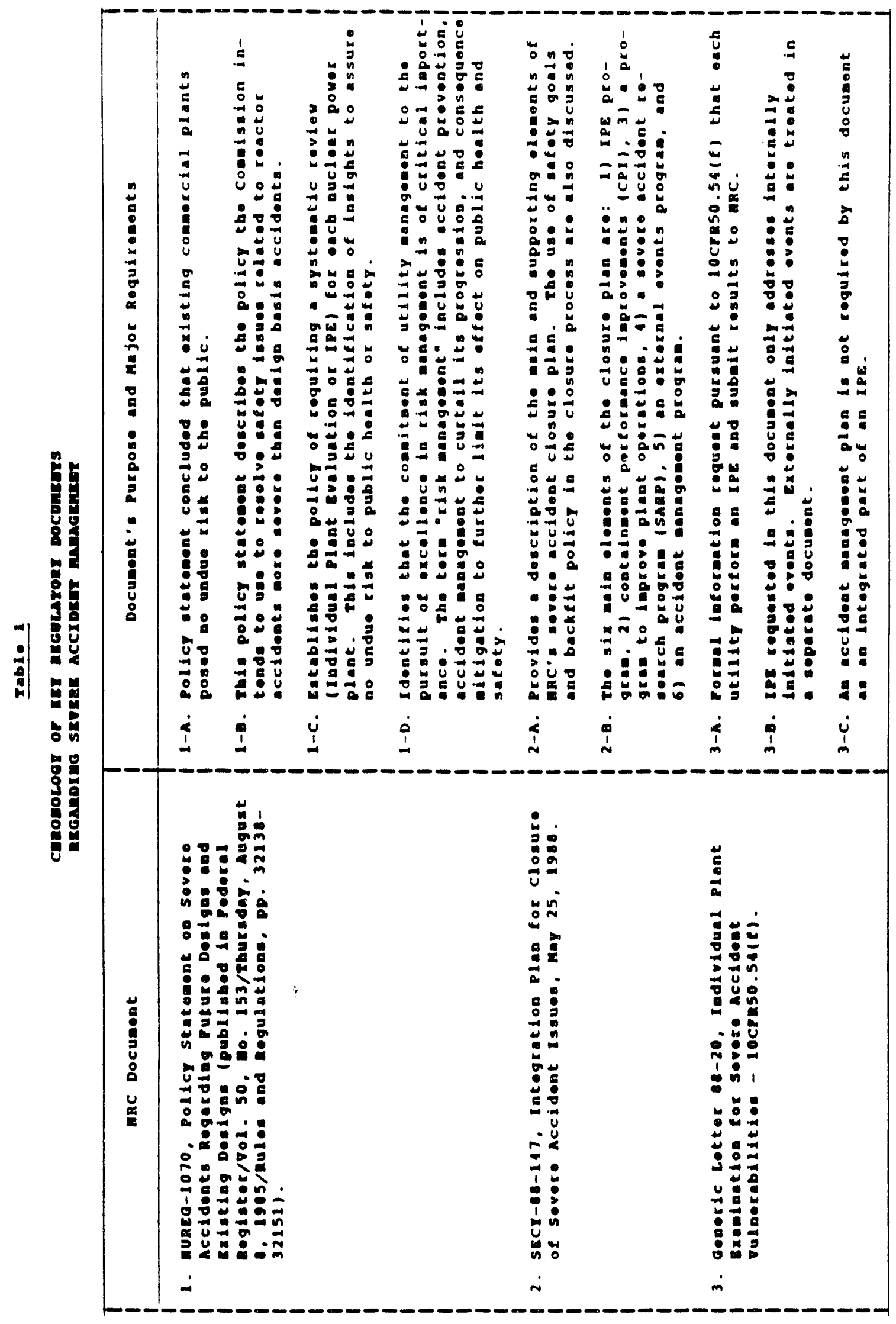




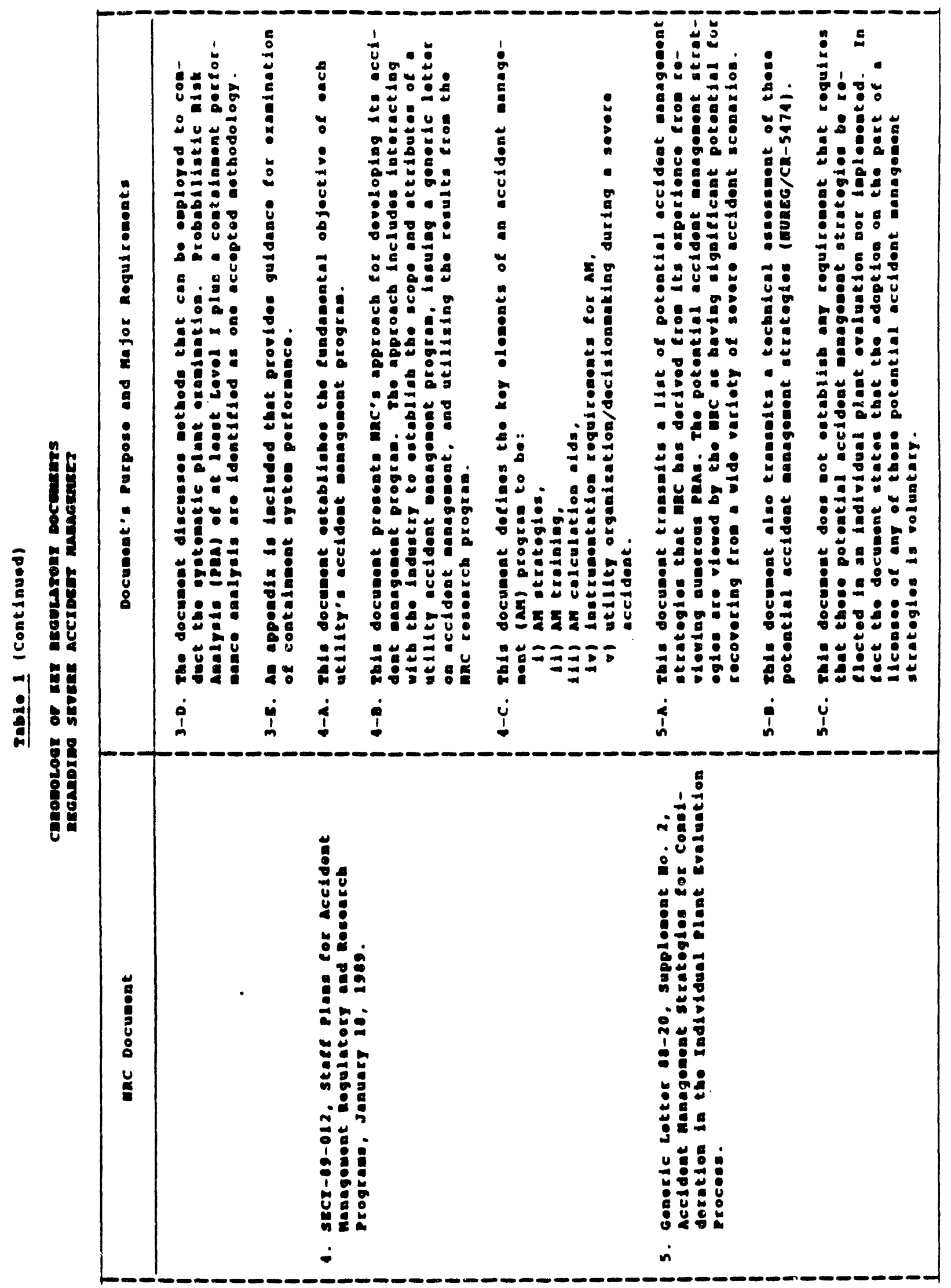


against NRC rules but SRS is not obligated to meet NRC requirements. Risk management is identified as being of critical importance in the NRC Commissioners Policy Statement. Risk management is defined as including: accident prevention, accident management to retard severe accident progression, and the mitigation of consequences to further limit the accident's effect on public health and safety. These objectives of accident or risk management are worthy of consideration for the Savannah River site as well.

\section{Integration Plen for Clopure of Serpre Accidonte (SBCY-88-147)}

The NRC has issued an integration plan for closure of severe accidents (SECY-88-147) and has subsequently updated this plan. The main elements of the closure program are presented in Figure 1 . There are six major elements in the NRC closure plan and they include the following:

1. Examination of existing plants for severe accident vulnerabilities.

2. Development of generic containment performance improvements with respect to severe accidents to be implemented if neces sary for each of the six containment types (LWR designs).

3. Upgrading of staff and industry programs to improve plant operations.

4. A severe accident research program.

5. A program to define how and to what extent vulnerabilities to severe accidents from external events need to be included in the severe accident policy implementation.

6. A program to ensure that licensees develop and implement accident managenent programs at their plants.

Incorporated, as appropriate, in each of these elements is an increased emphasis on human factor considerations and the realistic performance of systems.

When Figure 1 is reviewed regarding its technical applicability to the Savannah River Site it is observed that several of the elements are 


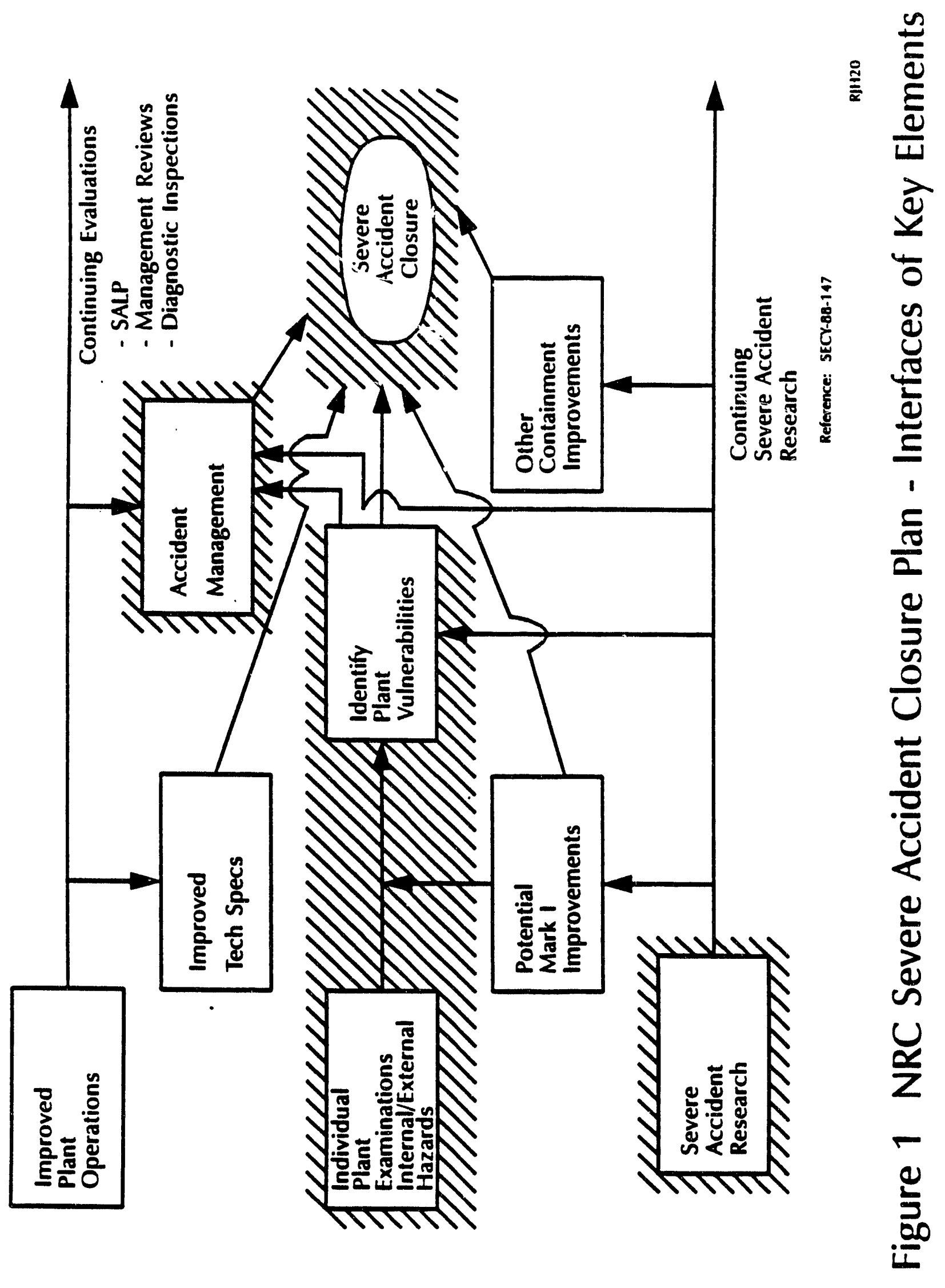


applicable (cross hatched elements). A probabilistic risk analysis has been conducted for the Savannah River Site reactors. This is a key input to the accident management program and can serve as an input for the development of potential plant vulnerabilities and the identification of key plant performance and accident management insights. The crosshatched elements are the main steps that are coupled with the definition of an accident management program which are required for closure of severe accidents. These specific elements of the NRC severe accident closure plan are directly applicable for the Savannah River site reactors and are currently in different stages of completion by the NRC. Severe accident research as well as improved plant operations are ongoing activities whose intermittent results need to be reviewed for effectiveness and applicability for the Savannah River site.

Accident management is a key addition to the elements used to help assure public health and safety. Broadly defined, accident management includes the measures taken by the total plant staff to 1) prevent core damage, 2) terminate the progress of core damage if it begins and retain the core within the reactor vessel, 3) falling that, maintain containment in. tegrity as long as possible, and lastly 4) minimize the consequences of offsite releases. Preparatory and recovery measures can be taken by the plant operating and technical staff that could prevent or significantly mitigate the consequences of a severe accident. Such preparatory and recovery measures are generally referred to as accident management. Furthermore, accident management includes the measures that may be taken before an event occurs which include improved training for severe accidents and hardware or procedure modifications that facilitate the implementation of accident management strategies.

The NRC intends to focus its efforts for commercial LWR plants on developing the regulatory framework under which the industry programs will be developed and implemented. Thus accident management programs will be developed and implenented by the individual licensees and the NRC will provide an independent assessment of the accident management capabilities and strategies. 
This approach is fully applicable to the Savannah River Site as well as its current application to the commercial light water reactors. The other major elements of the NRC's integrated plan for closure of severe accident issues will help provide technical basis for developing the elements of an accident management program. The technical basis for commercial LWR reactors is also being supplemented by severe accident research performed by the industry and individual utflities. The NRC points out that a key element to severe accident closure would be the implementation of an accident management program for each plant. Since information on severe accident phenomena and effective accident management strategies will continue to be developed by both the NRC and Industry, each licensee should have an accident management program whose framework is such that it can be expanded or modified to accommodate new information as it becomes avallable. This is a particularly useful attribute for the Savannah River accident management program since significant research is expected to continue both as part of the commercial SARP and the new production reactor activities.

In SECY-88-147 the NRC describes the closure process as follows:

"In sumary, the steps which each licensee is expected to take to achieve closure on severe accidents for its plants are as follows:

- Complete the IPE's; identify potential improvements, evaluate and $\mathrm{fix}$ as appropriate.

- Develop and implement a framework for an Accident Management Program that can accommodate new information as it is developed.

- Implement any Comission-approved generic requirements resulting from the staff Containment Performance Improvements Program; this should constitute closure of containment performance generic issues.

While prograns for improved plant operations and research in the area of severe accidents will continue, completion of the above by a Iicensee is considered to constitute "closure" of the severe accident issue for the plants in question. Specific issues that may arise in the future as a result of ongoing research will be treated on a case-by-case basis and will not affect the closure process." 
BRC Generic Ietter 88-20

Generic Letter 88-20 formerly requests that an IPE be performed by each utility for all of their plants to identify severe accident vulnerabilities and that the results be submitted to the NRC. The general purpose of the examination is for each utility to 1) develop an appreciation of severe accident behavior, 2) to understand the most likely severe accident sequences that could occur at its plant, 3) to gain a more quantitative understanding of the overall core damage probabilities and fission product releases, and 4) as necessary reduce the overall probabilities of core damage and fission product releases by modifying, where appropriate, hardware and procedures that would help prevent or mitigate severe accidents. These general purposes for such an examination as requested of the commercial LWR utility's are also applicable to the Savannah River site and are being accomplished by the ongoing PRA. Performing a PRA is consistent with one of the methods of examination as identified by the NRC in Generic Letter 88-20.

Generic Letter 88-20 also discusses accident management. Severe accident prevention and mitigation is identified as an important aspect of reactor safety and an important aspect of that is the total organizational involvement. Operations personnel clearly have key roles in the early recognition of conditions or events that may lead to core damage. The availability of guidance specifying corrective actions and training of operators and emergency teams can have a major beneficial influence on the course of events in the case of a severe accident. Subsequent to the Three Mile Island accident, commercial LWR utilities developed symptom based emergency operating procedures to assure additional directions are available to operators during abnormal events and accidents. The emergency operating procedures have been inplemented and requisite training is provided for utility personnel regarding their use.

The operators at the Savannah River Site will have a major role in responding to severe accidents. The conclusions to be drawn from an IPE for severe accident vulnerabilities will depend upon the credit taken for the survivability of equipment in a severe accident environment and they will 
also depend upon operators either taking beneficial action during or prior to the onset of severe core damage or on the operators not taking specific actions that would have adverse effects. Therefore, the results of an IPE will be an essential ingredient in developing a severe accident management program for a given plant.

Generic Letter 88-20 did not require utillties to develop an accident management program as an integral part of their IPE. Guidance on the development of an accident management program is under development by both the LWR utility industry (NUMARC) and the NRC. The current NRC guidance on accident management is to define the scope and content of acceptable accident management programs and to identify a plan of action that will ultimately result in incorporating any plant-specific actions deemed necessary, as a result of a utility's IPE, into an overall severe accident management program. The regulators encourage utilities not to delay in implementing actions which are identified that would benefit emergency operating procedures or similar formal guidance while the specific scope and content of their accident management plans are being further developed.

Generic Letter 88-20 includes three appendices. The first appendix provides guidance on the examination of containment system performance (back-end analysis), the second appendix provides criteria for selecting important severe accident sequences, and the third appendix provides a brief discussion of accident management. Appendix 3 on accident management provides some general suggestions regarding the elements of an accident management program. The elements evolve around the organizational structure of the utility that operates the plant. Plant instrumentation and equipment are another key element that needs particular attention regarding severe accident behavior and finally procedures and training are identified as important elements. The NRC research program for closure of severe accident provides ongoing input for the development of accident management strategies and programs (see SECY-89-012 for more specific and complete discussion of the NRC staff plans for accident management programs). 
Staff Plans for Accident Management Regulatory and

Research Prograns (SECY-89-012)

This is the principle document regarding the content of a utility's accident management program and it has been referenced by individual utilities, regulatory contractors, and industry wide organizations. The fundamental objective of the NRC's proposed accident management program is stated in this document as follows:

"Each NRC 11censee shall implement for each nuclear plant an "Accident Management Plan" which provides a framework for evaluating information on severe accidents, including that developed through conduct of the Individual Plant Examinations (IPEs), for preparing and implementing severe accident operating procedures, and for training operators and managers in these procedures."

This fundamental objective is applicable to all types of reactor designs given they are potentially susceptible to severe accidents. Thus this fundamental objective is useful as a basis for the Savannah River site accident management program.

The NRC also identifies four subsidiary objectives which should be addressed by LWR licensees when their accident management plan is developed. The four subsidiary objectives include the following:

1. Development of technically sound strategies for maximizing the effectiveness of equipment and personnel in both preventing and mitigating potential severe accidents.

2. Assuring that installed instrumentation and equipment that will be required for diagnosing and controlling severe accidents are identified and assessed regarding their availability and capabilities during a severe accident.

3. Assure that nuclear plant staff and management receive appropriate training regarding severe accidents and accident management strategies.

4. Provide a technical basis for assessing the effectiveness of specific accident management strategies. 
The stated goal of the NRC's accident management program is aimed at assuring the most effective use of available utility resources to prevent and mitigate severe accidents. The utility resources include both personnel and hardware. In the case of LWR plants incremental improvements in the existing emergency procedures and training programs and additional planning for severe accidents that could strengthen the support provided to plant personnel in the case of a severe accident are the kind of changes anticipated. Harduare changes are specifically identified by the NRC as not being the central aim of the NRC accident management program. The central aim is to assure the effective use of the existing plant capability. Such an approach is certainly applicable for the javannah River Site as well. LWR plants improved such emergency procedures and training programs (Post, 1983; Shurman, 1983) in compliance with regulatory requirements established after the accident at Three Mile Island. The potential also exists that the accident management program implemented at Savannah River may identify a number of recommendations for improving the effectiveness of currently available resources such as emergency procedures.

Five attributes or elements are identified in SECY-89-012 for consideration as part of a utility's accident management plan. These elements are viewed as vehicles for incorporating improvements to the current utility capabilities. These five elements have been largely endorsed though somewhat modified by both the regulatory contractors and utility organizations. These five elements are as follows:

1. Accident Management Strategies: Strategies which extend the use of current plant capabilities or operating and emergency procedures may be Identified on the basis of a plant's PRA. The strategles could greatly enhance the plant operators ability to cope with potential severe accidents. The identification and definition of such strategies is one element of an accident management program.

2. Calculational Aids: Calculational aids may be identified to provide guidance to plant personnel and management for diagnosing the progress of severe accidents. Additionally, calculational aids can be provided for planning and assessing appropriate responses to potential severe accidents. Calculational aids would be valuable during pre-planning and development of accident management strategies as well as during an actual severe accident. The identification and 
preparation of calculational aids is another aspect of an accident management program.

3. Accident Management Organization: Each utility's accident management plan should include a review and as appropriate modification of the utility's organization and lines of communication. The plant's decision making authority and mechanisms should be reviewed for completeness and applicability during a severe accident. The organization and lines of decision making and communication should be reviewed and modified as appropriate as part of an accident management program.

4. Instrumentation: Licensees are expected by the NRC to review instrumentation changes that may be required in their plants to implement accident management strategies or calculational aids. The ability to monitor a plant's condition and response to strategies should be assessed as part of the accident management program.

5. Accident Management Training: The entire range of personne 1 (operators, technical support staff, maintenance personnel, etc.) and managers responsible for responding to potential severe accident should be trained regarding the other elements identified for an accident management plan.

The NRC's regulatory mechanism for obtaining improvements in commercial LWRs accident management capabilities will be through the issuance of a generic letter. The generic letter is expected to be issued in 1992. SECY89-102 includes as Attachment 2 a proposed outline for the generic letter on accident management. The NRC has stated that it plans to circulate the generic letter on accident management to utilities through NUMARC and to the public for comment prior to issuance. The generic letter on accident management will provide general guidance and identify a need for each utility to obtain appropriate improvements regarding their ability to cope with potential severe accidents. However, the stated NRC position is to remain flexible regarding the implementation of potential accident management improvements. The details of the development and implementation of plant-specific accident management plans will be pursued with each licensee by the NRC on an individual basis. This flexibility will also be useful for the Savannah River site because of their unique design and mission.

The NRC research activities will be focused on assessing the feasibility of various accident management strategies. The assessment of 
potential accident management strategies will also examine the potential circumstances under which selected operator actions could worsen the accident consequences or adversely impact the ability to achieve a long term, stable state. The NRC will assess such feasibility based on the technical information provided by its SARP and Containment Performance Improvements programs as stated as part of the NRC closure plan for severe accidents. Additionally, as research becomes avallable from other countries or perhaps from utility organizations it too will be used for assessing the feasibility of various accident management strategies. For example the external flooding of an RPV could provide a means for maintaining its integrity which would be a useful strategy. Research from several programs in both thr United states and Europe is being performed to address lower head failure mechanisms. As this research is conducted and reported it can be used to assess such an accident management strategy.

Another means of addressing the potential concern of adverse consequences of proposed strategies has been employed by Commonwealth Edison. This includes the active pursuit of "good" practices and plant capabilities that should be continued and maintained in a plant regarding its ability to respond to severe accidents. For example procedures or hardware that can be used to extend or replenish various resources (like water supplies, battery life, or alr supplies) should be identified and highlighted for inclusion in an accident management program and associated training. Thus as the acci. dent management program is developed the features in terms of hardware and procedures that provide the plant with its ability to withstand postulated severe accident sequences will be identified and recorded. This provides a mechanism and information resource for minimizing changes in the future which may reduce a plant's capability to cope with a severe accident.

Lastly, the NRC notes that ongoing severe accident and related research will concentrate on all consequences of potential actions. It is currenty expected by the NRC, as stated in SECY-89-012, that the ultimate guidance to the operating staff is to always add water during the course of a severe accident. This can serve as a very practical, useful, and directly assessable objective for accident management programs and managers. The addition of water is a cornerstone of the generic guidance being provided to the 
utility industry in the form of EPRI's Technical Basis Report (see Section III.3).

SECY-89-012 also includes an appendix (Appendix 1) which discusses the need for each utility to systematically identify and implement effective measures including strategies, revised procedures and hardware to optimize the plants accident management resources. These measures should addresses three global strategies which the NRC has identified from operational experience and PRA insights that have a significant potential for reducing a plant's risk. The three global strategies identified in Appendix 1 of SECY89-012 are as follows:

1. Strategies for conserving and rerienishing limited resources during the course of an accident. These resources would include such things as battery capacity, cooling water supplies, and compressed air.

2. Strategies for using plant systems and components for innovative applications during a severe accident. This would include enabling crossties with support systems or the use of fire systems as an example. This category of strategies would also include the use of alternate electrical power sources (AC or DC) to meet critical safety needs during a given accident scenario.

3. Strategies for defeating interlocks and overriding component protective trips given an emergency situation. Examples of these types of strategies would include defeating interlocks and overrides which are implemented to provide margin for the protection of key components.

These three global strategies, and as appropriate others that may be identified, should be applied to each of the applicable major safety functions for a given plant: reactivity control, coolant inventory control, heat removal and containment performance. Likewise the three global strategles should be applied to principal support functions: electrical power, equipment cooling, and air systems. In the context of performing an Individual plant Examination each utility should be alert to identify and implement effective measures associated with these strategies. Appendix 1 of SECY-89-012 provides a table of examples of potential measures that further demonstrate the application of these three global strategies. 
The fundamental NRC objective of an "Accident Management Plan" is to provide a framework for evaluating information on severe accidents for preparing and implementing severe accident guidance and for training plant personnel. A similar objective could also be selected for the Savannah River Site. T'kewise, the five elements (strategies, calculational aids, organization, instrumentation, and training) proposed in SECY-89-012 for an accident management plan are also suitable for consideration at the Savannah River Site. Their specific implementation must be formulated to reflect the unique design of the Savannah River Site and their safety features.

\section{Generic letter 88-20. Supplement No. 2: Accident Kanagenent Strategies for Consideration in the IPE Process}

Supplement No. 2 to Generic Letter 88-20 transmits a list of potential accident management strategies that the NRC derived from its experience during the review of numerous PRAs. The potential accident management strategies identified by the NRC are included in NUREG/CR-5474 (Assessment of Candidate Accident Management Strategies) which is an enclosure to Supplement No. 2. This enclosure provides a technical assessment of the set of potential accident management strategies identified by the NRC. This list of potential actions is sometimes referred to as the "A" strategies.

As discussed above, Appendix 1 of SECY-89-C12 lists three global accident management strategy categories. These categories involve conserving or replenishing limited resources, the innovative use of plant systems or components, and defeating appropriate interlocks during emergency situations. Potential accident management strategies included in Supplement. No. 2 and the enclosed NUREG/CR-5474 are grouped by these three global strategies. Table 1 of NUREG/CR-5474 is reproduced as Table 2 in this report. The applicability of the individual strategies which are grouped under these three global strategies to the Savannah River Site will be assessed as part of the anticipated follow on effort to this literature survey report. An approach implied in this figure for conducting this survey is exemplified in Figure 2 which is a portion of the figure provided 


\section{Table 2}

\section{GENERIC ACCIDENT MANAGEMENT STRATEGIES ("A" STRATEGIES)}

(Reference: NUREG/CR-5474, Table 1)

I. Conservirg and Replenishing Limited Resources

- Refill refueling water storage tank (RWST) with borated water, or condensate storage tank (CST) with condensate. Assure adequate supply of boron on site.

- Maintain emergency core cooling system (ECCS) suction to condensate systems to avoid pump failure due to high suppression pool temperature.

- Throttling containment sprays to conserve water for core injection.

- Conserve battery capacity by shedding non-essential loads.

- Use of portable battery chargers or other powcr sources to recharge batteries.

- Enable emergency replenishment of gas supply, or otherwise ensure operability of air operated components.

- Enable early detection, isolation, or otherwise mitigate the effects of an interfacing systems loss of coolant accident (LOCA).

II. Use of Systems/Components in Innovative Applications

- Strategies to enable emergency use of available pumps to accomplish safety functions.

- Use of diesel fire systems for injection to the containment sprays, a BWR core, or the PWR steam generators (SGs).

- Use of control rod drive (CRD) pumps in BWRs or charging pumps in PWRs for core injection.

- Use of alternate injection (e.g., hydro test pump) when reactor coolant pump (RCP) seal cooling is lost (seal failure concern).

- Enable emergency crosstie of service water and closed (component) cooling water (CCW) to residual heat removal (RHR) in BWRs or feedwater in PWRs.

- Use of condensate, or startup pumps for feedwater injection.

- Strategies (and hardware) to enable emergency connection of available AC power sources to meet critical safety needs.

- Use of diesel generator or gas turbine generator to drive CRD pumps for core injection. 
Table 2 (Continued)

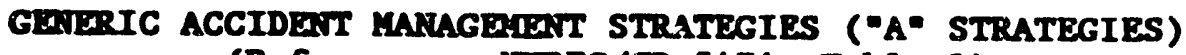

(Reference: NURBG/CR-5474, Table 1)

- Enable emergency crosstie of AC power between two units or to onsite gas turbine generator

- Strategies to enable emergency connect of injection systems to alternate water sources.

- Ensure appropriate recirculation switchover and cope with the fallure to switch over in LOCA.

- Enable emergency connection of service water or feedwater systems to rivers, reservoirs or municipal water systems.

- Strategies for Reactivity Cortrol.

Initiate standby liquid control system (SLCS) in case of potential core damage and guard against boron dilution when core injection is restored.

- Ensure abundant supply of borated makeup for long-term eccident sontrol.

III. Defeating Interlocks and Component Protective Trips in Emergencies.

- Renpen main steam isolation valves (MSIVs) and turbine Lypass valves to regain the condenser as a heat sink.

- Extend reactor core isolation cooling (RCIC) availability by either raising the turbine exhaust pressure trip set point, or overriding the trip function.

- Enable emergency bypass of protective trips for diesel generators and injection pumps. 
in NUREG/CR-5474. The approach implied in this figure for assessing candidate accident management strategies and their applicability to other designs is as follows:

Step 1: Select safety objective or functional requirement. For example "maintain core cooling" would be one functional requirement.

Step 2: Identify potential challenges to the selected functional requirement. Examples in Figure 2 for challenges to maintaining core cooling are insufficient coolant, injection system unavailable, power loss, and loss of heat sink.

Step 3: Apply each global strategy to each challenge as a means of Identifying specific strategies that are applicable to the selected plant. For example, if one were to consider the challenge of insufficient coolant, strategies that would result from considering the three global strategies would include conserve coolant, resupply injection, or use of alternate sources.

Lastly, it should be noted that Supplement No. 2 to Generic Letter 88. 20 does not establish any requirements for licensees to take these specific accident management strategies into account as part of the IPE or to implement any of the potential strategies transmitted by that document. Rather, adoption of any accident management strategy (on the part of a licensee) in response to Supplement No. 2 is voluntary. This declaration in supplement No. 2 maintains the principle of flexibility established regarding accident management consideration by the NRC in its plan for development of accident management programs. The issuance of the potential accident management strategies in Supplement No. 2 and their technical assessment by the NRC is provided solely as an informational resource for use by utilities in their own prograns.

\section{Workshop on Severe Accident Ynnare:ant for FiRs}

The U.S. NRC sponsored a workshop on severe accident management for PWRs (Kastenberg, 1991) that involved a broad cross-section of U.S. experts. The objectives of the workshop were to address uncertainties regarding proposed accident management strategies. The "An strategies presented in 


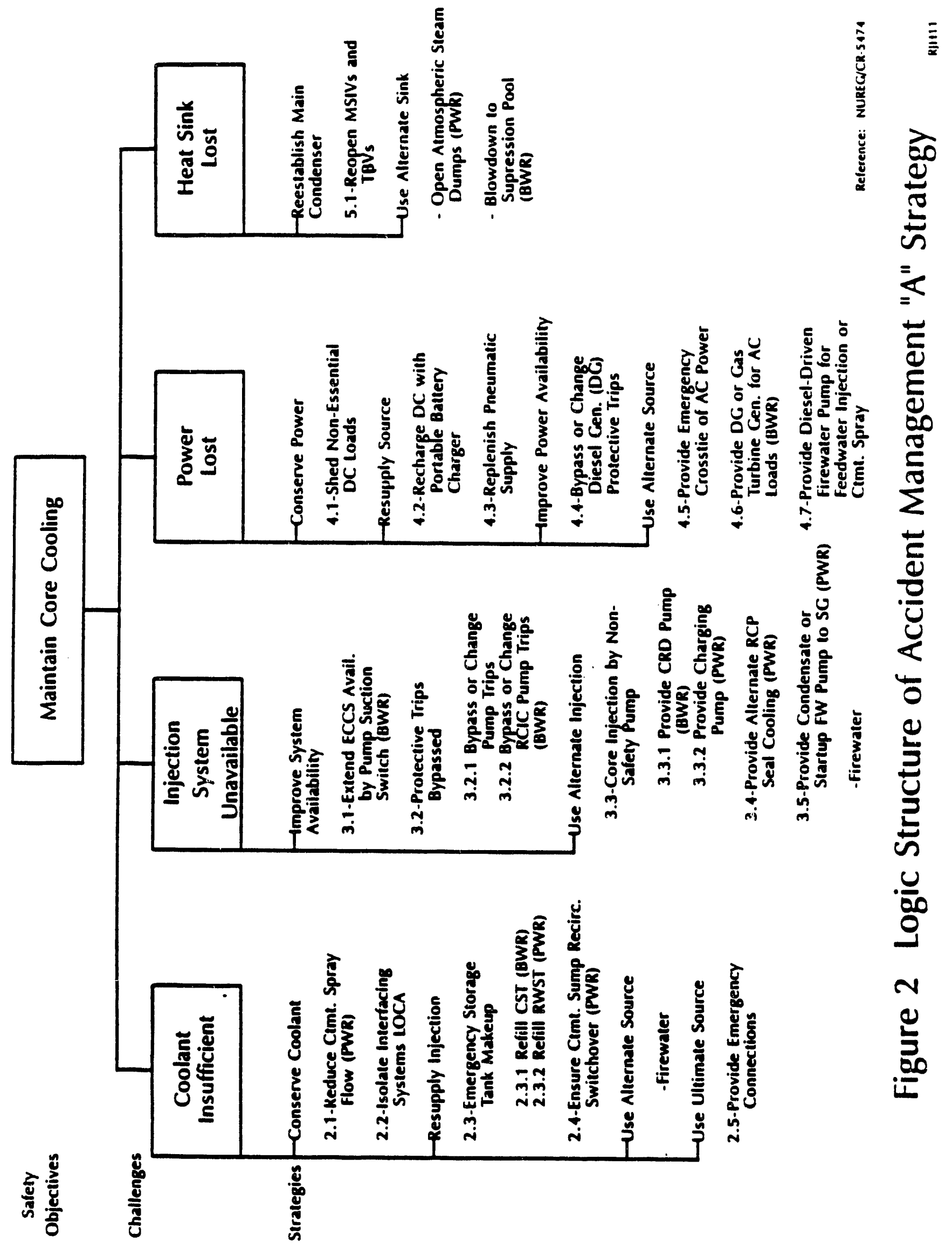


Table 2 of this report were assessed as well as the "B" strategies. The "B" strategies are provided in Table 3. The workshop's objectives were to answer the following set of questions for each proposed strategy:

A. What are the necessary conditions for a coolable state? What is the uncertainty regarding such a state? How will the state be defined?

B. What are the possible management strategies that will yield a coolable state, or a new transition state?

C. What are the possible negative consequences of these strategies and what are the uncertainties?

The specifics of the answers to these questions produced at the workshop relate to PWR designs. However, this set of questions will also be useful for assessing the impact of uncertainties once a set of proposed accident management strategies is formulated for the Savannah River Site.

It is significant to note that as a result of the workshop it was generally agreed that water should be added as soon as it is made available to the operators. If the severe accident progression is still in-vessel when water is made avallable, then the water should be added to the vessel. If the severe accident progresses has reached an ex-vessel stage, then again water should be added. If the water supply is limited, it was generally agreed that water should be directed to the vessel first since it would eventually end up ex-vessel. Thus, consensus is continuing to grow within the technical community that the addition of water is a central strategy for aceident management.

The Savannah River Site can benefit from this workshop by employing its approach for assessing the uncertainties in potential accident management strategies for the Savannah River site. Furthermore, the "B" strategy concepts of fission product release mitigation and transport control outside containment should be pursued for Savannah River specific application. 
Table 3

GERERIC MITIGATIVE ACCIDENT MANAGERAT STRATEGIES

("B" STRATEGIES)

\author{
Prevent Vesse1 Pailure: \\ use RCS pumps to force flow through the core \\ depressurize and inject coolant into the RCS \\ remove RCS heat using steam generators (secondary feed and bleed) \\ remove RCS heat using PORVs (primary feed and bleed) \\ flood cavity to cool vessel \\ Prevent Contaioment Fallure by Slow Overpressurization: \\ use containment sprays to remove containment heat \\ use fan coolers to remove containment heat \\ flood cavity before or after vessel fallure to delay or prevent \\ core/concrete interaction \\ use recombiners or ignitors to control combustible gases \\ vent containment to relieve pressure \\ Brevent Contaif ent Failure by Rapid Overpressurization: \\ depressurize RCS to prevent direct containment heating \\ flood cavity before or after vessel fallure to break up and \\ cool core debris \\ vent containment to control combustible gases \\ (pre-vessel fallure and/or post vessel failure) \\ Prevent Basenat Yelt-Through: \\ flood cavity to cool core debris before vessel fallure \\ and/or after vessel fallure \\ Brevent Failure pue to Missiles: \\ dry vessel to eliminate in-vessel steam explosions \\ maintain RCS at high pressure to prevent steam explosions \\ Mitigate Fission Protuct Release: \\ Control Transport Out of RCS: \\ use auxiliary pressurizer spray to scrub fission products \\ before they are released through the PORV \\ flood cavity before and/or after vessel fallure \\ Control Transport Outside Containment: \\ flood leak location \\ reestablish containment isolation \\ depressurize containment to reduce driving force across leak \\ depressurize RCS (steam generator tube rupture) \\ flood steam generator secondary (SGTR) \\ flood break location (interfacing system LOCA)
}




\section{Systenatic Process for Developing and Assessing}

Accident Managesent Plans (NUREG/CR-5543)

The key regulatory documents discussed above and summarized in Table 1 describe the chronological development of the regulatory position on accident management for LWRs. As part of the regulatory research on severe accidents another document (NUREG/CR-5543) has been produced. This document describes a four phase approach for developing criteria recommended for use in assessing the adequacy of accident management plans. This document was produced to assist the NRC in assessing accident management plans as developed by individual licensees. Two phases of the approach have been completed and provide a prototype process that could be used to develop an accident management plan. Predicated upon the process defined in this document, a preliminary set of assessment criteria has been derived. These preliminary criteria will be refined and improved when the remaining steps of the approach are completed, that is, after the prototype process is validated through application. Since this four phase process is still being formulated and the first two phases were published in the second quarter of 1991, currently there is no experience base regarding the implementation of such a process. Nevertheless, this document provides one mechanism for developing an accident management plan and will be reviewed below.

This document is written from the perspective provided by instructions from both the Commission and the NRC Executive Director of Operations that the NRC and its contractors should work with the nuclear utility industry to define the scope and content of accident management plans and to develop guidance on these plans. In accordance with these instructions the office of Nuclear Regulatory Research is conducting a research program to establish those attributes of a plant severe accident management plan that are necessary to ensure effective response to credible severe accidents and recommend criteria that can be used to assess the adequacy of accident management plans. These are the objectives and goals of NUREG/CR-5543. In this document accident management plans are defined as those plans and actions undertaken by nuclear plant staff prior to an accident to ensure that adequate plant hardware and capability exists. Furthermore, the plans and 
actions should ensure that plant personnel with responsibilities for accident management are adequately prepared to take effective on-site actions to prevent or mitigate the consequences of a severe accident. Thus this document describes an approach composed of four phases that has been developed to identify the important attributes of a severe accident management plan and based on these attributes, to produce assessment criteria. The primary objective for each of the four phases is as follows:

Phase 1. Identify the general attributes that an implemented accident management plan should include.

Phase 2. Integrate the identified general attributes into a prototype process that includes the steps necessary to develop and implement an accident management plan.

Phase 3. Validate the capabilities of the process through an application that uses information expected to be avail. able at a nuclear power plant.

Phase 4. Identify criteria, based on the important characteristics of the validated process that could be used to assess the adequacy of accident management plans.

To date phases 1 and 2 of the approach have been completed and a preliminary set of criteria as called for in phase 4 has been developed based on the prototype process. It should be recognized, however, that the information provided in this document has not been completely reviewed nor has it been approved by the NRC staff.

The authors of this document identified nine attributes based upon a review of the NRC regulatory position on accident management (as described in Table 1 above) that in their view should be contained within an implemented accident management plan. These nine general attributes are presented in Table 3 of NUREG/CR-5543 and are repeated here for easy reference :

1. Adequate information to understand the capabilities and potential limitations of the plant, including both equipment and personnel. 
2. A clearly identified set of accident management strategies that will effectively prevent or mitigate undesirable accident sequences.

3. Procedures and guidelines implemented at all appropriate levels in the organization for executing the strategies.

4. Engineered methods (necessary systems and equipment) identified for the proper implementation of strategies.

5. Indication that adequate plant status information is available to monitor all plant safety functions and is available to select and to assess the effectiveness of all strategies.

6. Clearly delineated lines of decision making, authority, and responsibility.

7. Provisions for adequate training of all personnel involved in accident management.

8. Validation of the performance of the implemented accident management plan.

9. A formal mechanism in place to identify and incorporate new information into the implemented accident management plan as it becomes available.

It is interesting to observe that the last attribute implies the concept of a "living" accident management plan. This would parallel the concept of a "living" PRA and implies a commitment on the part of a licensee to continuously review information and research results with the goal of assuring that the accident management plan is current. In the case of a "living" IPE the information that is reviewed relates to changes in plant configuration and procedures. In the case of a "living" accident management plan the scope of the review and information sources has to be expanded to include regulatory and industry sponsored research as well as the experience of other utilities in this regard. In concept the approaches of maintaining both a "living" IPE and a "living" accident management plan are applicable to all types of reactors including those at Savannah River.

In NUREG/CR-5543 the prototype process based on the set of nine attributes 1isted above is illustrated in Figure 3. This NUREG provides a detalled description of each of the eight sieps in the suggested prototype process. The eight steps are summarize: is: fillows: 


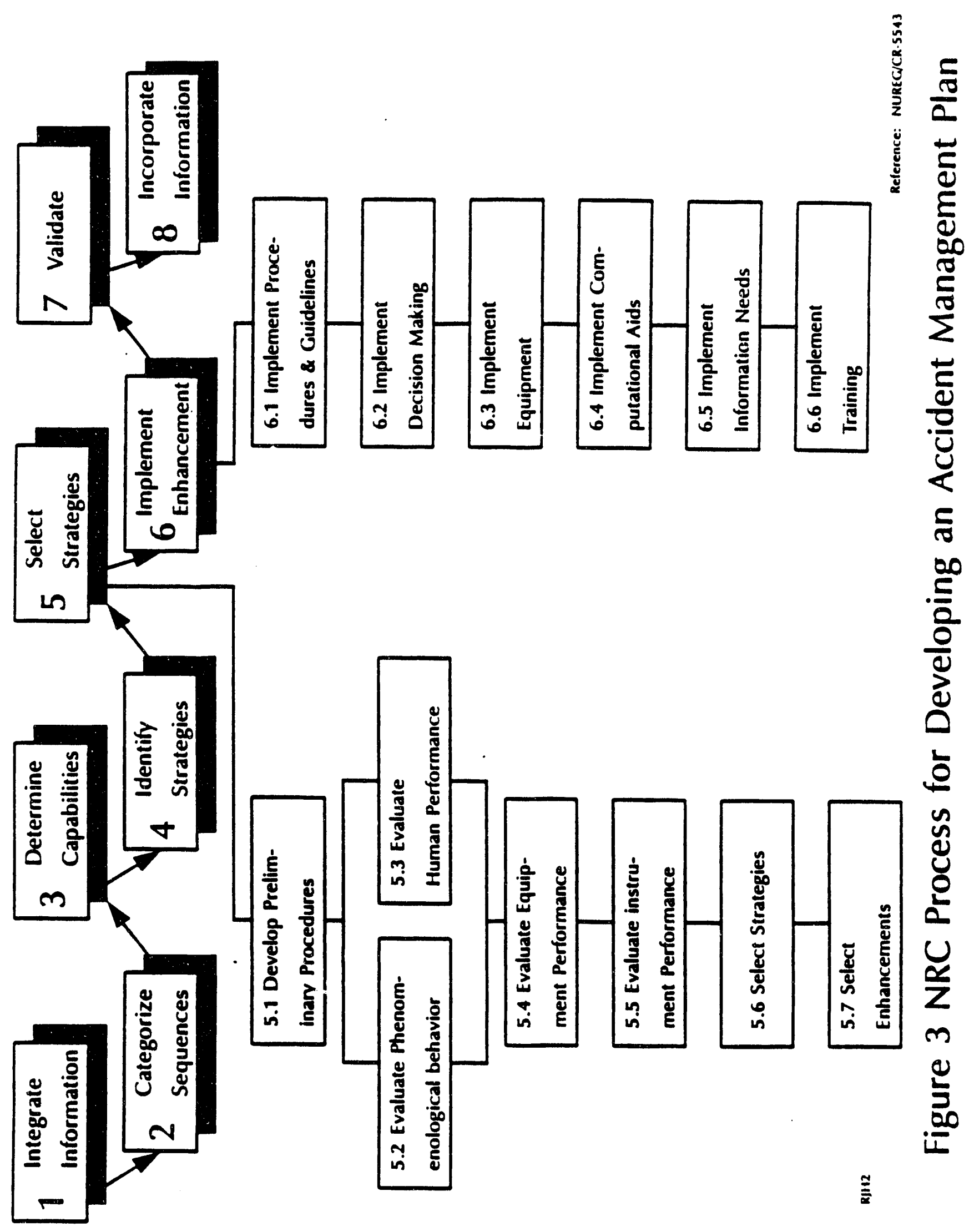


Step 1: Assemble existing information needed to understand plant capabilities and limitations during severe accidents. Examples of such information are individual plant examination (IPE) results, plant-specific design and operations information and results from severe accident research.

Step 2: Categorize the severe accident sequences identified by the IPE into groups having similar accident characteristics and challenges to safety functions. These categories will guide the remaining steps in the process in determining what plant capabilities exist to enhance accident management and what accident management strategies would be beneficial.

Step 3: Identify plant-specific accident management capabilities having the potential to be effective for the accident sequence categories identified in step 2 .

Step 4: Identify strategies that have a potential to prevent or mitigate the consequences of the categorized sequences identified in Step 2. This can be accomplished by identifying accident management actions that intervene in the sequences, placing emphasis on the use of existing plant equipment and personnel.

Step 5: Evaluate the potential strategies identified in step 4 and select those that will be most effective. Initially, develop preliminary procedures that list in detail the tasks needed to implement each potential strategy then evaluate the details of the strategy in four different but interrelated areas: phenomenological behavior, human performance, equipment performance, and instrument performance. Results of these evaluations can then be used to select strategies that will effectively address the sequence categories. Selected strategies can then be used to identify the accident management enhancement necessary for implementing all selected strategies.

Step 6: Use the information developed in the first five steps to implement the accident management enhancement.

Step 7: Validate the implemented accident management plan. The suggested methods to validate the tasks in the implemented accident management plan are the same as those identified in NUREG-0899 for implementation of the symptom-based emergency operating procedures.

Step 8: Identify and incorporate new severe accident information in the implemented accident management plan. 


\section{III.2 Reviev of Ut1lits Accident Managenent Literature}

Limited examples exist of individual utility approaches to accident management. As noted in Section III.1, although an accident management program framework has been defined by the U.S. Nuclear Regulatory Agency, a generic letter requiring accident management programs from utilities has not yet been issued. Thus, utilities have not yet been formally requested to develop accident management plans and implenent them for their plants. However, the need to eventually do so has been identified in Generic Letter 88-20 on Individual Plant Examinations. As part of the NRC's program to develop the needs and requirements regarding utility accident management programs, an ongoing interaction between the Nuclear Regulatory Commission and U.S. Utility's (NUMARC) is in progress.

\section{Commealth Edison}

Nevertheless there are a few notable examples of utility endeavors to define and implement accident management programs. One principle example of a utility actively involved in accident management plan development is Commonwealth Edison. Commonwealth Edison has recognized the need for an accident management program (Klopp, 1988) early in the IPE program and initiated an ongoing program to develop accident management in parallel with its IPE evaluations for all twelve of its nuclear units (Klopp, 1990; Lutz, 1991). An innovative approach has been formulated by Commonwealth Edison such that the development of an accident management program definition is being done in parallel with its IPE activities. Section IV.2 of this document provides a discussion of such an integrated approach.

The first step in the Commonwealth Edison program for integrating accident management into the IPE effort was to define a framework for accident management. Commonwealth Edison selected the five major elements provided in SECY-89-012 and endorsed them with some modifications as the framework for its accldent management program. Each of these five areas was broken down into their composite elements in an intuitive, forward look at what the final accident management program might entail. This is described as the "top down" examination of the accident management program elements as 
illustrated in Figures 4 and 5 . This logical-intuitive breakdown into composite elements lead to the modification of the five elements identified by the NRC. The final set of five elements in the accident management program, as envisioned by CECo includes the following:

1) Emergency response organization.

2) Training needs for the entire emergency response organization.

3) Codified accident management guidance.

4) Calculational tools for diagnosis, prediction, and decisionmaking.

5) Plant status information.

Clearly these elements are quite similar to those in the regulatory documents. The major differences from the NRC's accident management definition include: a) the expansion of the plant instrumentation area to include all plant information needs for accident management, b) accident management guidance that includes an interface with the site emergency plan, and c) computational tools that include diagnostic, predictive and decision-making tools. Once this framework was established, key aspects of each accident management program element were intuitively identified as illustrated in Figures 4 and 5 .

Due to Commonwealth Edison's large nuclear program the utility identified the desire to have a uniform and realistic assessment of each of its twelve plants. Thus, a series of guidance documents were produced and are being used by the individual analysts who are assessing the twelve CECo nuclear plants. The IPE analysts have a key role. In fact the evolution of an accident management program definition during the IPE has as its central focus the IPE analjsts. Thus the evolution of the "bottom up" definition of the accident management program is dependent upon each individual IPE analyst and their ability to identify inslghts regarding the plant's behavior or possible accident management strategies. Figure 6 illustrates the total conceptual approach that cummonwealth Edison is using to evolve its accident management program definition. The logical-intuitive "top down" definition is employed to help define the elements and serve as a check 


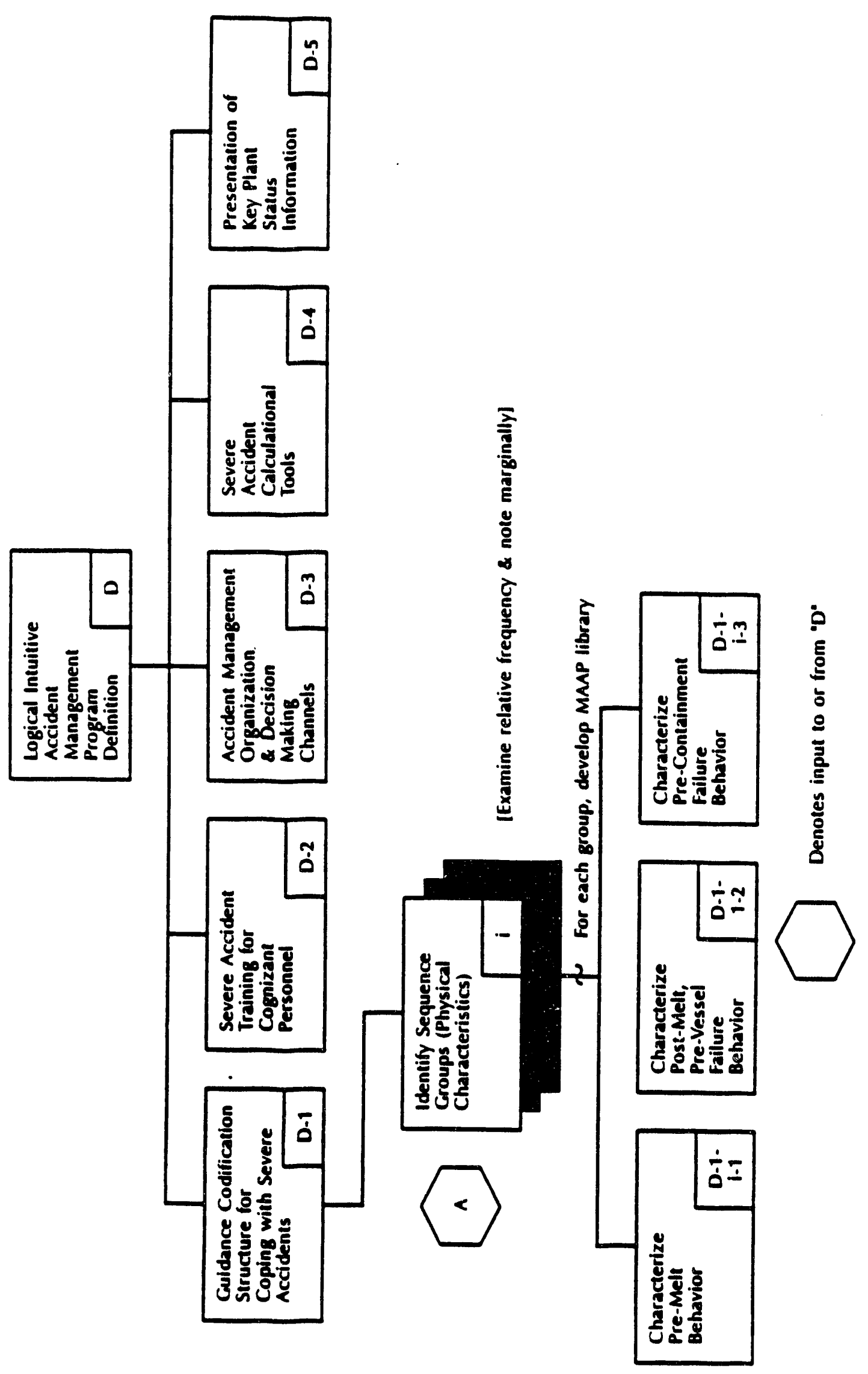

$\stackrel{ }{\bar{z}}$

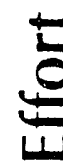

हू

कo

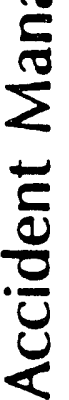

กิ

늘

8

$\frac{0}{3}$

인

E

4

$\frac{E}{2}$

$\forall$

논 


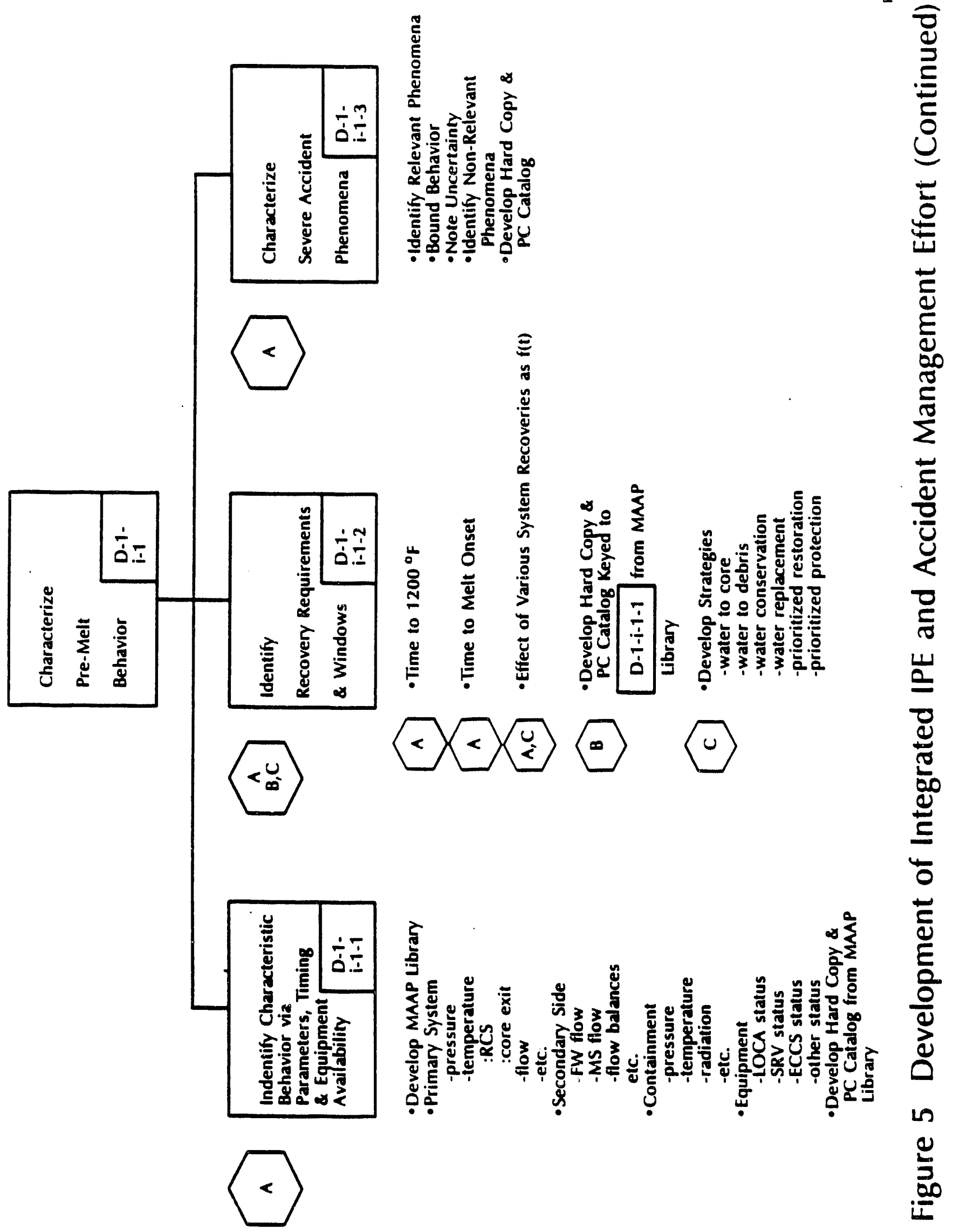


$\stackrel{8}{\square}$

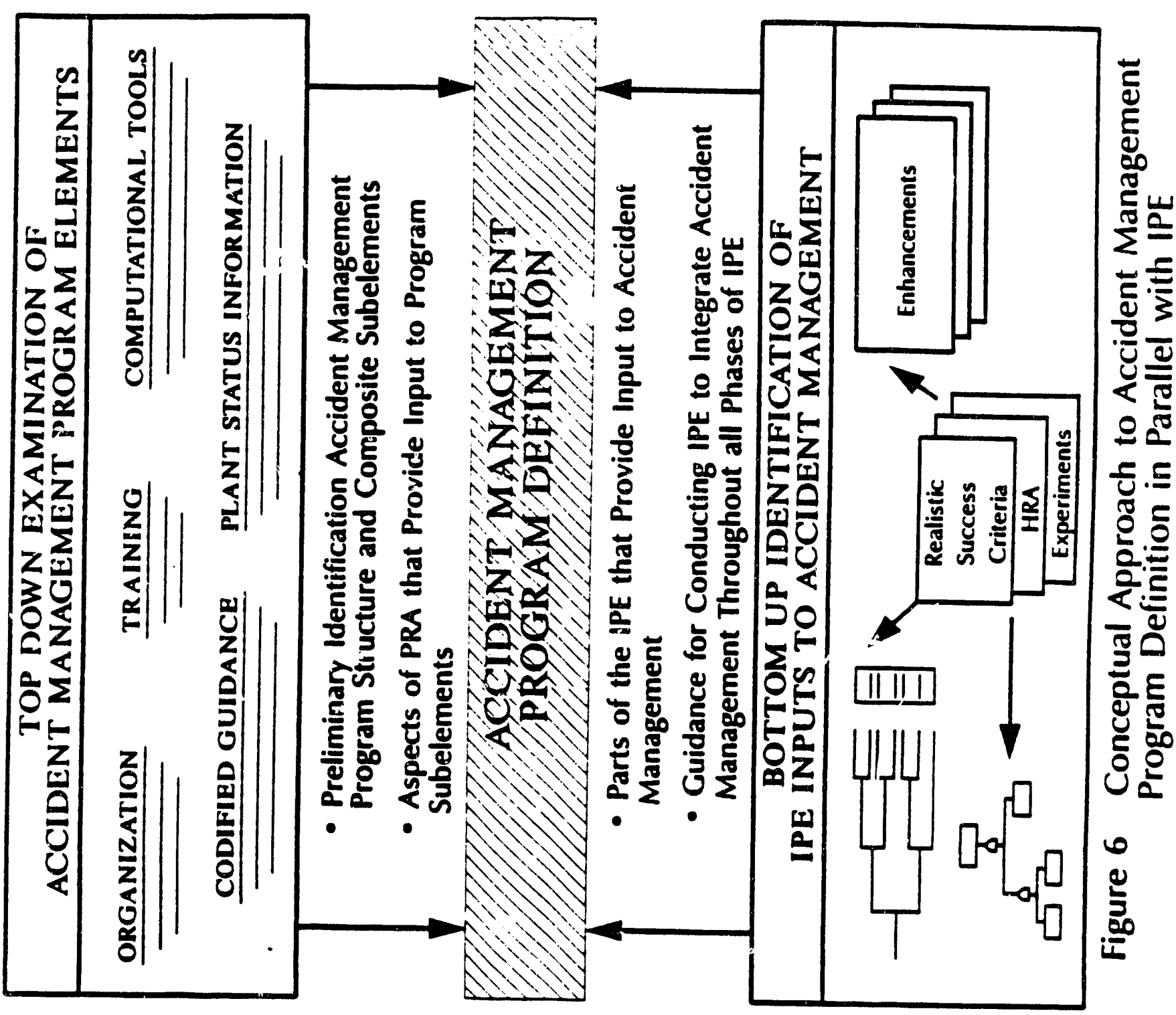


vehicle for the "bottom up" evolved accident management program definition. The "bottom up" approach exploits one of the most important elements for deriving insights from the IPE which can be used to elther impact the plant risk profile or its input to the accident management program, i.e. the IPE analysts.

In performing the several IPE work tasks, each IPE analyst will make observations which could be important to impacting the plant risk profile or the accident management program. If these observations are not elicited from the individual analysts and properly documented, a significant amount of potentially valuable information could be lost or forgotten. Thus, input from each IPE analyst is being elicited during the conduct of the IPE program for Commonwealth Edison. It is viewed as extremely important that any observations or insights be documented as they are identified in the IPE process. The "bottom up" approach is focused on a careful evaluation of each technical task involved in conducting the IPE for the CECo plants. This involves both the Level I and Level II technical tasks. In the broadest sense, Commonwealth Edison views insights as those observations regarding the current station configuration or practices which can impact the risk profile of the plant. Insights can suggest changes to enhance the capability of the plant and the plant operators to respond to an initiating event to either prevent core damage or to mitigate the consequences of core damage. Insights can also include those good aspects of the current station configuration or practices which have been identified during the IPE process, which Commonwealth Edison should not change. The philosophy of considering insights to be either potential enhancements to the plant or the identification of good practices that contribute to the plants safe operation is viewed as a key contributor to the ultimate success of the plant evaluations. The primary objective of CECo's approach is to identify all applicable insights.

In order to effect this general philosophy and satisfy its goal of a uniform and realistic assessment of each of its twelve plants Commonwealth Edison identified and codified a set of guidance tools for its IPE analysts. Figure 7 describes this information. Tools in the form of IPE and Accident Management Insights Guidelines were developed. As an appendix to these 


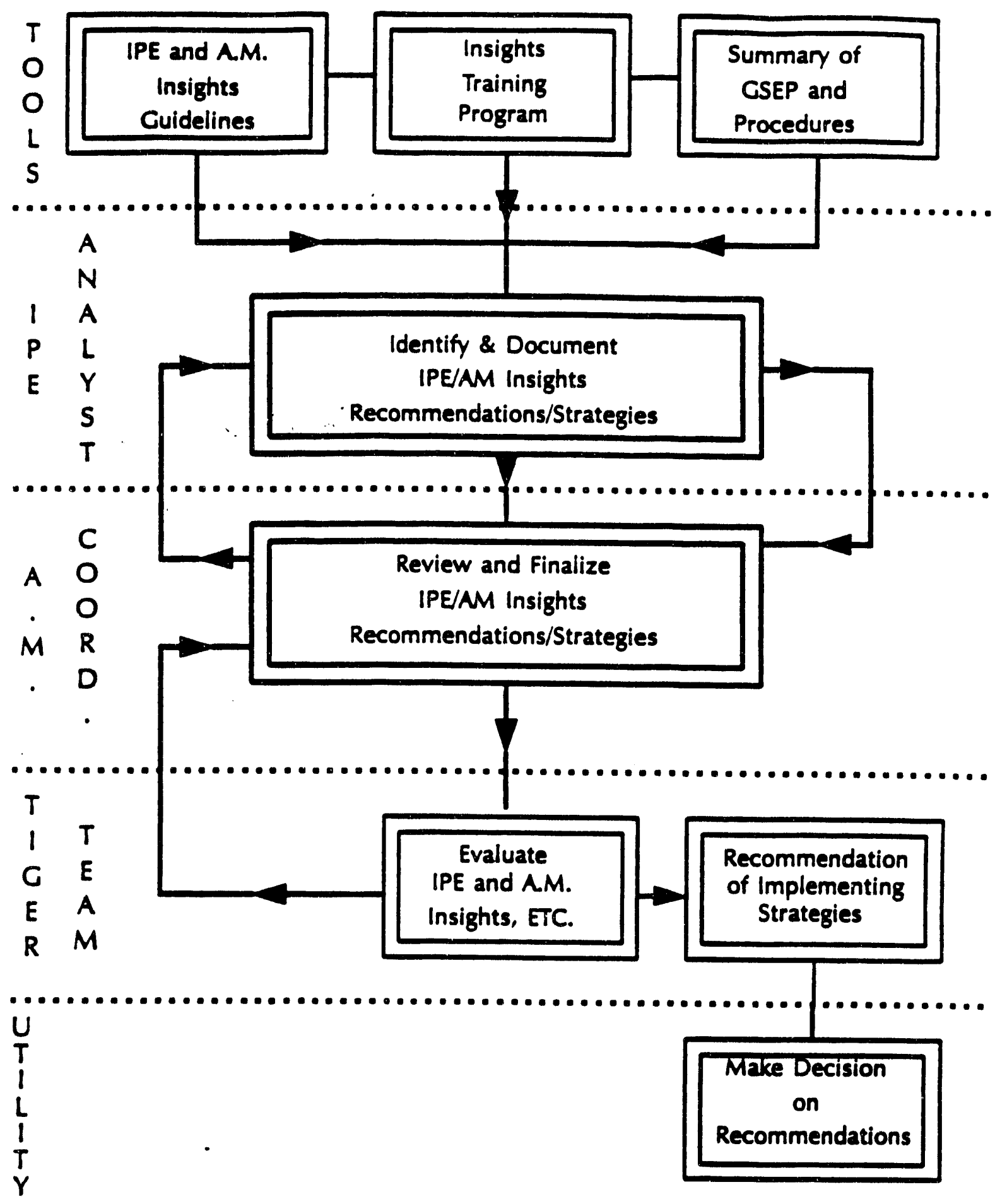

Reference: CECO

Figure 7 Commonwealth Edison Evaluation Process for Identifying and Documenting IPE and AM Insights 
guidelines a summary of the Commonwealth Edison General Site Emergency Plan (GSEP) and Emergency Operating Procedures (EOP) were included. These documents were used in the formalized training program that was provided to CECo's team of IPE analysts. The IPE analysts are the centrä. focus and vehicle for identifying and documenting insights. General guidance is given regarding the distinction between IPE and accident management insights. However, it is recognized that it may be judgmental in some cases in regards to classifying an insight as an IPE or as an accident management insight. The goal is to capture all insights and not dwell upon the category assignment. Consequently, the guidance provided to the IPE analysts is to ensure that all insights are captured. Each IPE analyst is also tasked with making recommendations or proposing accident management strategies predicated upon their experience in developing the various IPE task work products. Figures 8 and 9 depict the activities of the IPE analysts regarding the derivation and documentation of insights. In order to facilitate the IPE analyst's efforts and assure uniformity and technical accuracy of the insights and recommendations, an Accident Management Coordinator is identified for each of the Commonwealth Edison IPEs.

Once the review and finalization of insights is complete to the satisfaction of the accident management coordinator, the insights are transmitted to a "Tiger Team". A "Tiger Team" is responsible for performing an integrated evaluation of all insights, accident management strategies, and potential enhancements to operating practices. They are responsible for prioritizing the various recommendations and identifying those that merit implementation to Commonwealth Edison's management. The "Tiger Team" consists of specialists in plant operation, risk analysis and severe accident behavior. Finally, Commonwealth Edison's management assesses the recommendations and identifies those to be implemented.

For example the Zion IPE is currently in progress and the insights that have been identifled by the IPE analysts number approximately 150 prior to the event tree and source term quantifications. The process has not progressed to completion for the zion project so the eventual number of recommendations and selected insights for implementation has not yet been determined. However, the process is demonstrating its ability to capture 


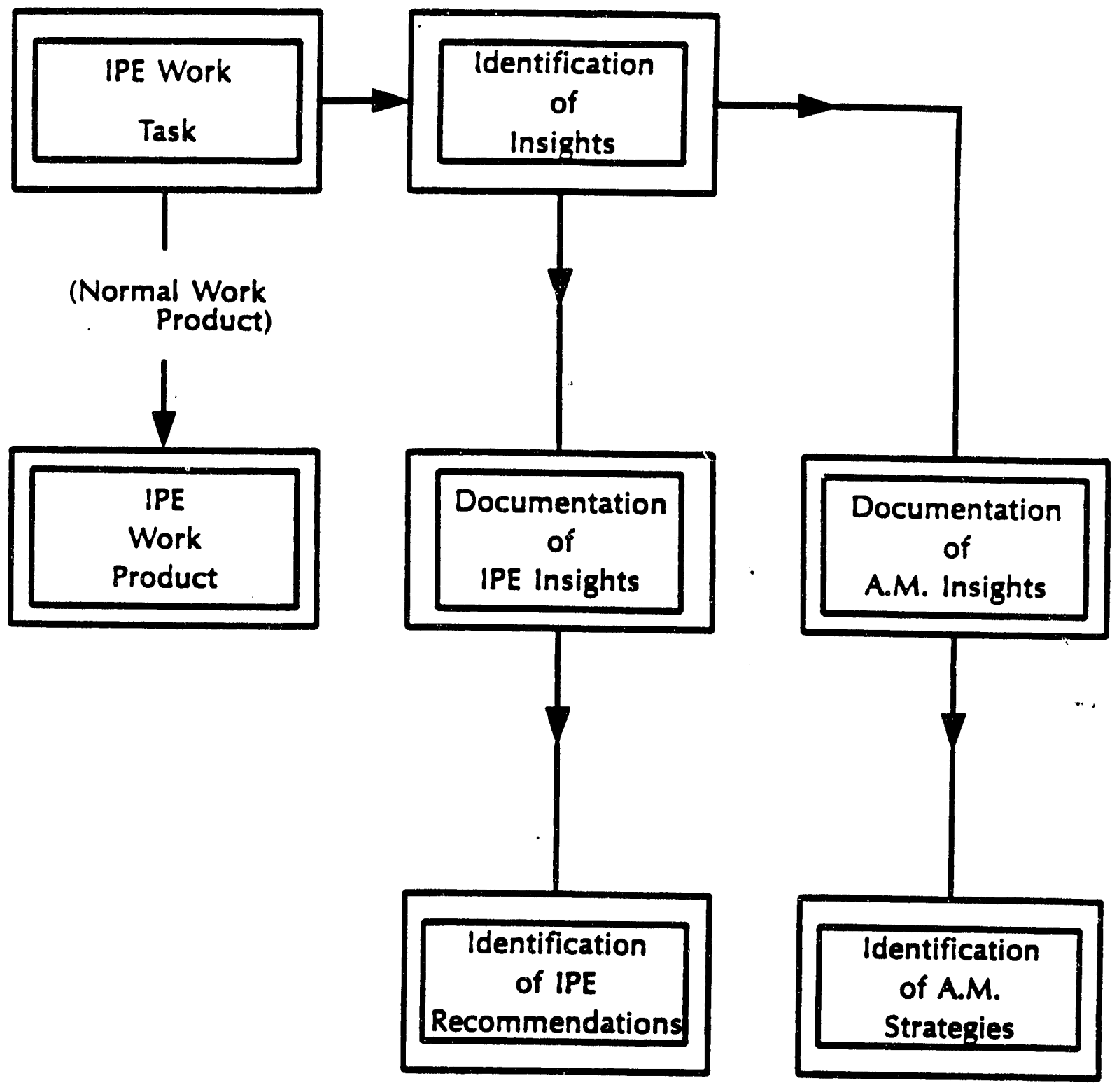

Reference: CECo

Figure 8 Overview: Framework for Identifying and Documenting IPE and AM Insights in Parallel 


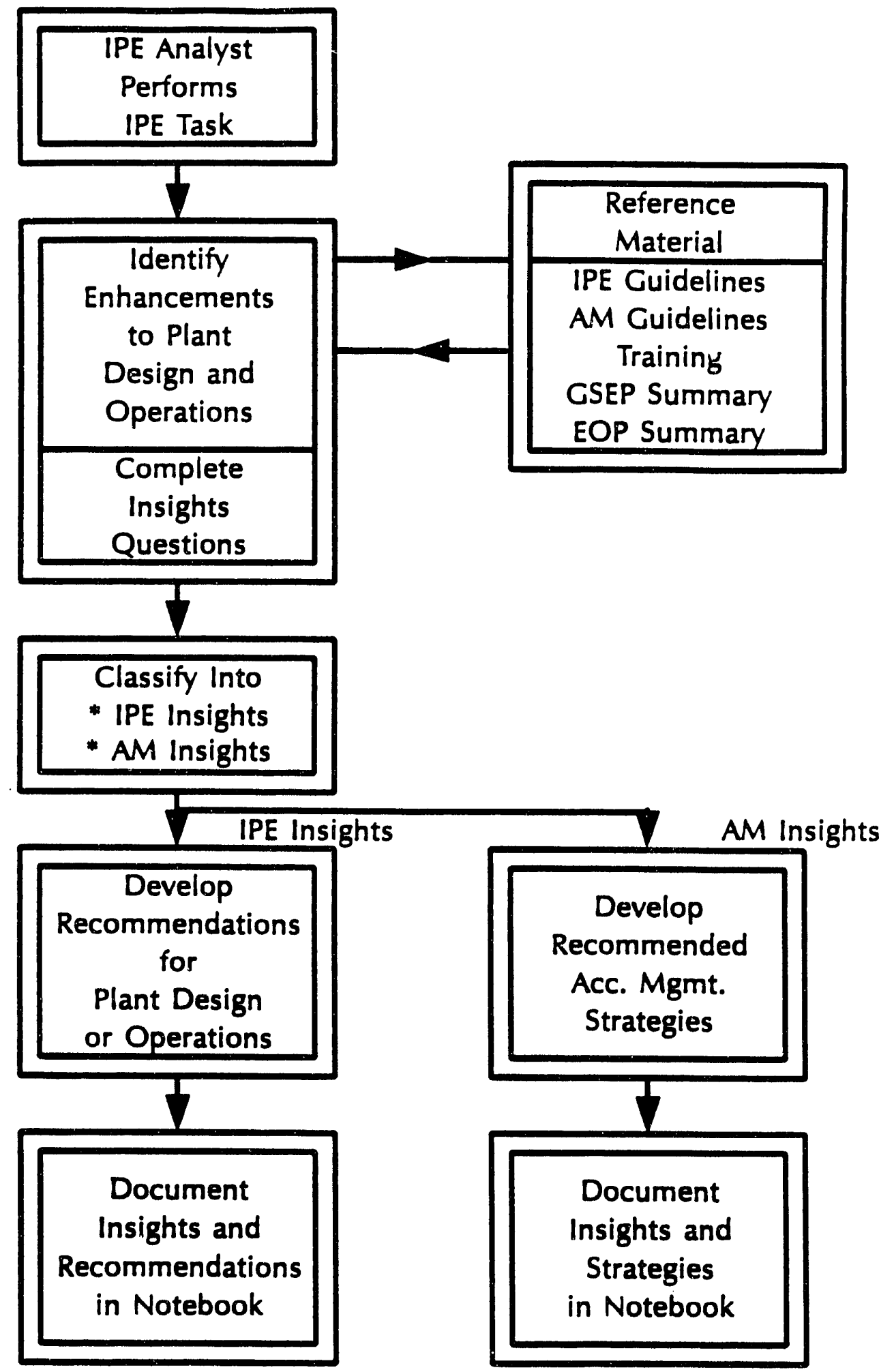

Reference: CECo 
insights and document them such that a significant data base can be developed for CECo's future use.

Another important aspect of Commonwealth Edison's accident management program is the performance of related severe accident experiments. In order to provide an expanded technical basis for potential accident management strategies and provide an appropriate perspective of the nature of the severity of postulated reactor pressure vessei and containment failure mechanisms, Commonwealth Edison has sponsored severe accident research. In particular scaled tests for direct containment heating in the Zion containment configuration have been performed and documented (Henry, 1991a). These experiments identified the importance of internal structures within the containment which are very effective in mitigating the dispersal of debris efected from the zion cavity during a high pressure melt ejection event. The structures are effective in removing core debris from the gas stream such that a significant direct containment heating load is not expected to occur in the zion plant configuration. These experimental results provided an important technical basis and perspective regarding one of the postulated early containment failure mechanisms. Additionally, experiments have been performed and documented (Henry, 1991b) to assess the potential of lower head cooling during a severe accident by externally flooding the RPV. The focal point of this experimental program was to quantify the ability of the water surrounding the RPV to remove the heat flux which could be postulated for the lower head during a severe accident. In particular the impact of reactor pressure vessel insulation relative to the accessibility of water to the outside surface of the RPV was assessed. Experimental results demonstrated the abllity to sustain a high heat flux from the outside surface of the lower head of the RPV even in the presence of RPV insulation. This technical basis is captured in the potential accident management strategy of assuring the external flooding of the RPV in order to enhance its survivability during a severe accident. Furthermore, the Zion plant's specific configuration can result in the RPV being externally flooded as a direct consequence of some postulated severe accident sequences. Thus the experimental components of the Commonwealth Edison severe accident management program have yielded results which have been implemented in both the IPE assessment and source term quantification and accident management 
strategy evolution. This approach parallels and supplements the NRC's program of exploiting severe accident research results as they become avail. able.

The importance of uncertainties regarding severe accident management strategies and responses is a subject that the LWR industry is addressing. The NRC has directed that each utility consider phenomenological uncertainties as part of their individual plant examinations (see Section III.1). The NRC has conducted workshops on severe accident management for both BWRs and PWRs whose objectives included assessing proposed accident management strategies that are necessary to establish a coolable state and in particular considering the uncertainty regarding such a state. The potential negative consequences of accident management strategies and their associated uncertainties were also discussed in this forum (see Section III.1). A central focus of the accident management philosophy being evolved by the regulators, utilities, and nuclear industry involves the use of water to reestablish cooling during a severe accident to establish a stable state. It is generally agreed that water should be added as soon as it is made available to the operators. Such a conclusion is reached even when uncertainties are considered. The experiments discissed above performed by Commonwealth Edison provide one means of expanding the technical basis and directly quantifying some of the uncertainties associated with severe accidents. As mentioned below in the subsection describing the accident management activities at the Loviisa plant, accident management strategies may be explicitly directed at eliminating ex-vessel phenomena and therefore their associated uncertainties. The approach identified at Loviisa employs external vessel cooling as an accident management strategy purposely designed, to reduce their streptibility to potential uncertainties by avoiding several potential containment sallenges. As the information base is expanded by utility, industry, and regulatory reser, uncertainties associated with a severely damaged core's response to potential accident management strategies could be reduced. The use of calculations, experiments and analyses have been used and should continue to se used to assess plant responses. The quantification of potential responses for a variety of plant conditions and degrees of core damage will also benefit the operators and plant personnel by describing the potential responses that may be observed 
in the plant. Furthermore, such assessments can assist them in assuring that the accident is progressing to a safe stable state.

In conclusion the experience to date for the single lead Commonwealth Edison plant (Zion) has been positive. All parts and aspects of the acci. dent management program definition process have been implemented and are currently functioning. The process appears to be working and successful as approximately a 150 insights have been identified even prior to the quantification steps of the IPE. The utility is pleased with the process and the NRC has been positive in its reception to the process and its preliminary results (Klopp, 1991).

\section{Duke Power}

Duke Power (Barrett, 1991) has performed IPEs for its Oconee and McGuire plants and submitted the Oconee IPE to the NRC for review. At this time the McGuire IPE is being submitted to the NRC. The Catawba IPE is in progress and is expected to be provided in late 1992. All of these IPEs address internal and external events. The IPEs include those EOP controlled operator actions that are judged to impact the results of the IPE. For example depressurization of the primary system, restoration of equipment, and the intermittent operation of safety equipment as called for by the emergency operating procedures. The definition of an accident management program has not been performed in parallel with the IPEs. The formalization of the definition and content of an accident management program still remains to be done by Duke. However, several of the aspects of an accident management program have been initiated as described below.

A key element of an accident management program will be training of plant personnel as well as emergency response personnel and management regarding severe accident behavior. All of the operators at the McCuire station have solicited and received severe accident training. Furthermore, the emergency response personnel have received severe accident training and it is currently Duke's anticipation that such training will be made available on an annual basis. The crisis management personnel have not yet received severe accident training but such training is anticipated. 
At this time no organizational changes or emergency response plan revisions are expected to be required. Rather the Duke staff expects that the existing organization and emergency response plan may be revised per IPE and accident management considerations but not significantly altered.

Equipment survivability and instrumentation performance during severe accident events have not been systematically evaluated to date. The major activity in this area relates to the issue of hydrogen control and its concomitant requirement for assessment of equipment and instrumentation survivability during potential hydrogen burns. This assessment is ongoing at this time.

Tools and calculational aids specifically for accident management applications have not yet been selected or implemented. Some preliminary activities and considerations have been initiated regarding tools and calculational aids. Duke Power anticipates using the MAAP code in it Crisis Management Center. The capability has been tested using a personal computer and accessing the central computing capabilities from the Crisis Management Center. During drills the response personnel have used calculational results in the form of plots produced by MAAP analyses performed for the IPE program to help support decisions and judgements. In particular plots which could be used to ascertain estimates of the time to core uncovery or the time to core damage have been used by the response personnel. Based on this positive application during exercises, Duke Power is currently anticipating the production of a notebook of key sequence types. Such a notebook would serve as a reference and a resource for estimating key event times for assessments performed as part of the IPE for the respective plant. Thus, during an event, the notebook could be consulted to estimate key event times by comparing the evaluation of the ongoing sequence to existing results for similar sequences provided in the notebook. At this time Duke Power is not planning an online analysis capability that is supported by a direct data link to plant data. No decision has been made whether such a capability will be pursued in the future at this preliminary state in development of Duke's accident management program. 
Regarding accident management guidance or procedures as well as calculational aids and tools, Duke is awaiting the results of the individual owners groups output based on the work being sponsored and coordinated by NUMARC and EPRI (see Section III.3).

\section{Northeast Utilities}

Northeast Utilities is conducting IPEs for its plants. Accident management is not included as an integral part of these several IPEs. Thus, development of Northeast Utilities' accident management plan and capabilities will be conducted sequentially with the IPEs.

The top priority and key component that Northeast Utilities will address following its IPEs will be severe accident training. Northeast Utilities management views the transfer of severe accident technology to plant personnel as the first phase of its accident management program given the completion of its IPE assessments. The format and content of such training is currently being considered.

The organizational structure employed by Northeast Utilities supports the goal of developing its accident management program. No explicit changes are planned in its organizational structure for this purpose. The existing structure includes a front line supervisory position responsible for development of thermal hydraulic analysis capabilities including those that would benefit accident management. Thus, the existing organizational structure provides appropriate resources and functional responsibility for supporting the development of the accident management program.

Northeast Utilities has initiated development of calculational tools and diagnostic aids for use during a severe accident event. On-line software is being produced to assist utility technical staff. This includes a user-friendly source of plant specific information which would include simplified piping schematics, system volumes and elevations, operating parameters, setpoints and valve capacities, and pump performance characteristics. Additionally, engineering calculations ("back of the envelope") to assess several types of responses during an accident or perhaps a severe 
accident are included in the on-line software. These on-line assessments include a means to estimate break size, time to core uncovery, choked flow calculations, decay heat calculations, gas flow rate calculations, RCS inventory and volume calculations, steam and water physical properties, clad oxidation and hydrogen generation rate, and hydrogen control. This set of calculational aids is viewed as a useful "toolbox" of assessment capabilities and graphical presentations that can assist the on-line assessment of a real time event. By using these capabilities in combination, diagnostic assessments of a plant condition can be performed.

A second calculational aid that Northeast Utilities has sponsored as part of their research and development program in partnership with Fauske \& Associates, Inc. is a MAAP Accident Response system (MARS) computer program. MARS is a user-friendly nuclear plant severe accident management/predictor system that has been implemented for the Millstone-1 plant. The MARS software was structured to provide insights into the current and possible future states of the Millstone-1 plant during accident conditions. MARS is structured to employ on-line Millstone-1 plant process computer information to perform engineering calculations that define the necessary variables required to initialize the MAAP code. Representative Millstone-1 accident simulations can be performed following initialization based on the given plant state to provide the predictive plant response at a rate faster then real time. The Millstone-1 plant process computer information required and employed by MARS is the same type of information that is available from the Northeast Utilities office Facilities Information system (OFIS). The MARS program for the Millstone-1 plant is complete and was installed at Northeast Utilities in the summer of 1991. The MARS software has been configured for several applications:

1. An accident management tool to support personnel in the EOF, TSC or other Northeast Utilities organizations,

2. Accident management planning support, and

3. Training of operators, support staff, engineering staff, and management. 
Current PWR emergency procedures are divided into two sets of procedures. One are optimal procedures for events that have been diagnosed and are responding as expected and the other are functional recovery procedures for events that have not been diagnosed or are not responding as expected. While these procedures go well beyond the design basis they do not address severe accident issues. The approach that Northeast Utilities will use for its PWRs to develop severe accident management will be to rely on the individual owners groups (Westinghouse and Babcock \& Wilcox) activities which will follow the NUMARC and EPRI programs on accident management. Northeast Utilities expects modifications to the existing emergency operating procedures (EOPs) with a focus most likely on the station organization and support from corporate resources. This expectation is based on the rationale that severe accidents often require inputs from several organizations (technical and political) and would overburden the operators. The revised EOPs may have interfaces into the station emergency organization to provide continuity with such organizations. Thus, as is the case with Duke Power as discussed above, the actual development of accident management programs including strategies and calculational and diagnostic tools is expected to be led by the individual owners groups based on the materials produced per the NUMARC and EPRI activities.

\section{Swedish State Power Board}

A second example of a utility endeavor to define and implement accident management strategies is provided by the Swedish State Power Board efforts for the Ringhals Units 2, 3 and 4 (Bastien, 1988). Symptom based procedures have been developed for Ringhals to improve the ability of nuclear power plant operators to respond to severe accidents that may lead to core melt and reactor vessel fallure. These severe accident procedures together with the existing Ringhals emergency operating procedures constitute an integrated package of consistent operator actions for dealing with both the short term and long term effects of severe accidents. The impact of the recommended operator actions has been evaluated based on Ringhals specific analyses performed with the MAAP 3.OB computer code. 
The existing Ringhals emergency response procedures have been implemented based on the generic guidance provided by the Westinghouse Owners Group Emergency Response Guidelines (ERGs), revision 1 . These procedures are a combination of event based guidance and symptom based guidance with the objective of placing the plant in a safe shut down condition prior to the occurrence of significant core damage. These procedures stop short of providing operator guidance for events which progress to and beyond significant core overheating. The basic assumption in the ERGs is that eventually the operator will be successful in applying the recommended actions which are primarily geared to prevent or minimize core damage. The existing procedures were augmented to provide operator guidance for the mitigation of radiological consequences of accidents involving significant core overheating. The development of the severe accident procedures involved three distinct steps: development of a severe accident strategy, analysis of a plant response to a range of severe accidents, and development of detailed operator response instructions.

Based on numerous feasibility studies of the response of the Ringhals plants to severe accidents and the approach taken in Europe to consider the addition of systems for severe accident mitigation, two systems were chosen for implementation at the Ringhals plants. The design basis of these sys. tems was a complete station blackout with coincident loss of all feedwater. The two systems were retained prior to the initiation of the development of severe accident procedures; their value for the mitigation of consequences of a wide range of severe accidents was verified during the development of the severe accident procedures. The Ringhals plant includes a filtered containment venting system that provides a containment pressure relief path which will automatically open at the containment design pressure and also automatically close at some lower pressure. The containment discharge stream will be filtered in a scrubber which will reduce the releases to the the environment. It is also possible to locally operate the pressure relief system. The system is designed to be completely independent from AC power. The second severe accident mitigation system installed at Ringhals is the alternate spray system which supplies city water (pure water) to the spray headers through the means of a mobile diesel-driven pump system located outside of containment. This alternate spray system is to be operated by 
the operator only and it does not receive any automatic actuation signal. It is also completely independent from $A C$ power.

Based upon the availability of these severe accident mitigation systems, the main parameters selected for control in the severe accident procedures are the containment water level and the containment pressure. Prior to reactor vessel failure the containment level must be established to allow quenching of corium if it falls into the reactor cavity given vessel failure. Furthermore if the containment water level is maintained it may be possible to quench molten debris within the reactor vessel and preclude vessel failure all together. However, this aspect of the containment water level control was not considered during the development of the Ringhals severe accident mitigation procedures. When the reactor vessel has failed, a containment water level allowing corium decay heat removal either by vaporization or by emergency core cooling system recirculation needs to be maintained. The normal containment spray system (injection mode) and the alterncte spray system as described above are possible systems to achieve the desired containment leve' depending upon their availability. During the development of the Ringhals severe accident management procedures the operation of the alternate spray system was assessed regarding its limited use due to a concern of introducing pure water (non-borated) in the sump. The concern related to limiting the surp boron dilution to prevent the core from returning critical, should the recirculation system be eventually used to provide in-vessel core cooling. This concern would be applicable given that only limited core damage had occurred such that the core's rod-like configuration was still principally intact. That constraint on alternate spray operation becomes irrelevant after reactor vessel failure or significant core damage because the corium no longer has a critical geometry. That means that 1008 pure water (non-borated water) can be used to cool the core debris. This is a useful observation which was made during the development of the Ringhals severe accident management procedures in the late 1980's. The issue of the use of borated water as an extended source of cooling water is currently being considered in the development of accident management strategies for commercial reactors in the United States. The possibility of debris bed porosity plugging by deposited boron or other contaminate salts 
during water boiloff is viewed as an issue warranting additional consideration and possibly research. The plugging of the debris bed by deposited salts could interfere with the coolability of such a debris bed.

Based upon these considerations, two series of severe accident procedures were developed for the Ringhals plant:

- A series (BERG-1) which addresses the short term period until reactor vessel failure has been diagnosed.

- A series (BERG-2) which addresses the long term after reactor vessel failure until the inherent containment heat sinks will be sile to ascommodate decay heat.

Each of these series is made up of two procedures.

The selection between the two procedures in each of the two series of procedures depends upon the containment hydrogen concentration. Should the containment hydrogen concentration be less then 108 in dry air, a systematic containment depressurization by steam condensation is acceptable because the possible hydrogen burn that may be initiated may not induce a containment pressure spike of sufficient magnitude to challenge the containment integrity or to actuate the containment vent system. Thus, those actions will not result in creating additional radioactivity releases from the containment. On the other hand, if the hydrogen concentration exceeds 108 in dry air, a more cautious approach to containment pressure reduction is required. A more cautious approach is required due to the possibility of a hydrogen burn which may result in the automatic actuation of the containment vent. The Technical Support Center personnel are required to make the necessary evaluations to select between a given procedure in either of the series of procedures. Additionally, the Technical Support Center personnel are responsible for the transition from one series (the short term period) to the other series (the long term period). This places the burden on the Technical Support Center personnel of diagnosing the fallure of the reactor vessel. The relevant parameters identified by the Ringhals evaluation to be used by the Technical Support Center to diagnose a reactor vessel fallure include: reactor coolant system pressure, containment pressure, containment 
hydrogen concentration and fission product inventory. Analyses and evaluations of the implementation of these two series of procedures has shown that it is not critical that the Technical Support Center personnel identify reactor vessel fallure immediately after its occurrence. A delay of an hour or more does. not significantly change either the course of the operator actions specified in the procedures or the severe accident progression. This can be viewed as a natural consequence of the commonality of the goals of the two sets of procedures, i.e., to maintain adequate containment water level and minimize containment pressure.

The development of the severe accident procedures for the Ringhals plant along with the addition of the ultimate spray system and the containment vent system provide a high degree of assurance that optimal accident management would be performed at the Ringhals PWR unit in the unlikely event of a severe accident. The additional systems provide diverse and redundant means of minimizing the release of radioactivity from the Ringhals plants. The severe accident management procedures which are symptom based, provide the optimal operator response strategies for dealing with both the short term and long term effects of a severe accident. The existing emergency response guidelines have been enhanced for Ringhals to ensure the proper response for severe accidents and consistency with the operator actions in the severe accident procedures. Lastly, the capability of the Ringhals 3 simulator has been extended to include severe accidents to support real time training that includes severe accidents.

\section{EDF Approach}

"The French approach" of incident/acciden management in PWR plants (Debes, 1991) involves the following three aspects:

1. Technical management of the accident condition by applying incident/accident procedures,

2. Organizational management of the accident in setting up crisis teams,

3. On sight operations under serious accident conditions. 
These three aspects are combined into a coherent package for dealing with accident condition developments over the short and medium terms. Furthermore, the comprehensive package involves implementing a nationwide organization whose efficiency is tested by exercises.

Three kinds of procedures are employed prior to core melt or damage. These are incident (I), accident (A), and highly improbable (H) procedures. The I and $A$ procedures address design basis events which are used in the design of the safeguard functions such as safety injection, containment spray systems and the containment bullding itself. The $H$ procedures are used to address events which are highly improbable for example total loss of redundant safeguards such that remedial actions at the operator's disposal to limit consequences and maintain safe conditions are defined. Lastly, ultimate (U) procedures are provided such that the operator may still dispose of ways of limiting the consequences to the environment should the $I$, $A$, and $H$ procedures not be successful. The $U$ procedures are intended to restrict release of fission products and if possible regain control of the plant. The general aim is to maintain radioactive release within limits in terms of both quantity and time so that the specific intervention plans can be correctly implemented to protect both the public and the environment. Such releases should be kept within a few thousands of the core inventory with respect to iodine for a 24 hour period after the accident. This defines the release goal established for the $U$ procedures in the French program.

The defense and depth concept has been extended to the current plant procedures ( $I$ and $A$ ) by employing parallel operators. In the case of an incident or accident, a specifically trained Radiological protection and Safety Engineer monitors the overall state of the reactor, containment and safety systems. This individual uses a procedure which is different from that used by the operating staff. He can prescribe additional measures if required. This process provides a dual analytical capability so as to further reduce risks of operator errors.

Ultimate (U) procedures have been designed to prevent or minimize the consequences of serious accidents. This is an aspect of the French approach 
which is used as part of their accident management scheme. Several measures were submitted to the safety authorities by EDF and were accepted for use in the French approach. These several measures are as follows:

1. Procedure $U_{1}$ : Operation by state of NSSS. This procedure is designed to provide the best possible coolant conditions for the NSSS and protect the core and containment building from radioactivity when the event-based procedures are inappropriate or ineffective.

2. Procedure $\mathrm{U}_{2}$ : Isolation of defect in containment building. This procedure is designed to cope with early loss of containment integrity.

3. Procedure $U_{3}$ : Use of mobile resources to back up safety injection and containment spray systems. This is viewed as a procedure that applies in the long term phase of a severe accident. Long term phase implies time intervals in the order of weeks and months.

4. Procedure $U_{4}$ : Early release through foundation rafts. This procedure contains provisions for eliminating early release through the ground of unfiltered radioactive products into the atmosphere when meltdown through the containment base slab is assumed.

5. Procedure $U_{5}$ : Reducing pressure in the containment. If containment pressure exceeds design pressure, $U_{5}$ permits the use of a filtered vent to partially reduce containment pres sure and provide a decontamination factor of at least 10 on the effluent stream. A dedicated penetration in the containment, a valve system, a letdown system, and a sand bed filter are used for the filtered vent design.

Table 4 provides a summary of the various procedures used in the French approach.

Subsequent to the TMI-2 accident the French program has pursued the development of the state-oriented (symptom) approach. The procedures (I, A, H) are principally in the event-based approach. Thus, since 1981 improvements based on the state-oriented approach were incorporated into the eventbased procedures. Improvements are being pursued and incorporated by EDF in the long term for the general implementation of the state-oriented approach. This new approach to post-accident operation requires fitting a probe to measure the water level in the vessel to provide accurate data on the status of reactor coolant system and a basis for measured response. Prior to the 
Table 4

SURYARY OF PROCEDORES IN THE FRENCH APPROACH TO INCIDENT AND ACCIDENT MANAGDORIT

\begin{tabular}{|c|c|c|c|c|c|c|c|c|c|c|c|}
\hline \multirow[t]{2}{*}{$\begin{array}{l}\text { OPERATING } \\
\text { AREA }\end{array}$} & \multirow[t]{2}{*}{ 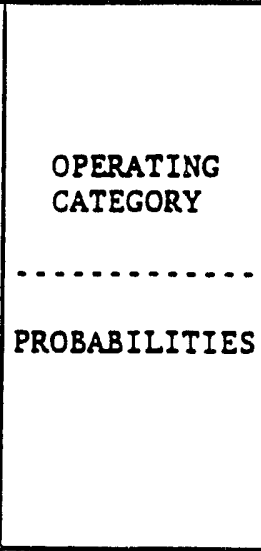 } & \multirow[t]{2}{*}{$\begin{array}{c}\text { DEFINITION } \\
\text { OF OPERATING } \\
\text { CATEGORIES } \\
\text { ACIIOI } \\
\text { RESOURCES }\end{array}$} & \begin{tabular}{|c} 
PRO \\
$\mathrm{I}$ \\
$\mathrm{N}$ \\
$\mathrm{C}$ \\
$\mathrm{I}$ \\
$\mathrm{D}$ \\
$\mathrm{E}$ \\
$\mathrm{N}$ \\
$\mathrm{T}$
\end{tabular} & $\begin{array}{c}\text { EDL } \\
A \\
C \\
C \\
I \\
D \\
E \\
N \\
T\end{array}$ & \begin{tabular}{|ll}
$C E$ & $S$ \\
$O$ & $I$ \\
$M$ & $T$ \\
$P$ & $U$ \\
$L$ & $A$ \\
$E$ & $T$ \\
$M$ & $I$ \\
$E$ & 0 \\
$N$ & $N$ \\
$T$ & $S$ \\
$A$ & \\
$R$ & \\
$Y$
\end{tabular} & $\begin{array}{|ll|}\text { IEI D D } \\
P & S \\
P & T \\
E & A \\
R & T \\
A & E \\
T & \\
I & 0 \\
O & F \\
N & \\
& N \\
B & S \\
Y & S \\
& S \\
\end{array}$ & 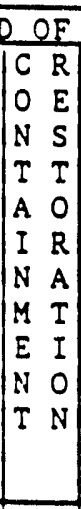 & 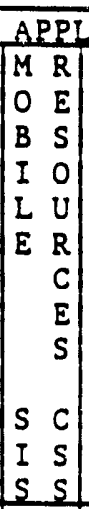 & 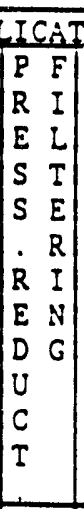 & $\mid \begin{array}{ll}\text { ION } \\
\text { R } & F \\
\text { A } & \text { L } \\
\text { I } & 0 \\
\text { N } & D \\
N & D \\
& I \\
& N \\
& C\end{array}$ & \multirow[t]{2}{*}{$\begin{array}{c}\text { RELEASE } \\
\text { LI.YIT CRITERIA } \\
\ldots \ldots . . . . . \\
\text { CONSEQUENCES } \\
\text { AT SITE LIMITS }\end{array}$} \\
\hline & & & $I$ & $A$ & $\mathrm{H}$ & $U_{: 1}$ & $U_{2}$ & $\mathrm{U}_{3}$ & $v_{s}$ & $\overline{U_{4}}$ & \\
\hline \multirow{4}{*}{$\begin{array}{c}\text { SIZING } \\
\text { deterministic } \\
\text { sequence } \\
\text { evaluation }\end{array}$} & $\begin{array}{c}I \\
1 \\
1\end{array}$ & $\begin{array}{c}\text { Normal operation } \\
\text { REGULATION }\end{array}$ & & & & & \multirow{5}{*}{$\begin{array}{l}V \\
A \\
L \\
I \\
D \\
F \\
F \\
R \\
\\
A \\
L \\
L \\
\\
S \\
I \\
I \\
U \\
A \\
T \\
I \\
O \\
S \\
S\end{array}$} & & & & $\begin{array}{l}\text { Authorizarion } \\
\text { of releases } \\
\text { spread out over } \\
\text { che year }\end{array}$ \\
\hline & $\begin{array}{c}I I \\
10^{2}: 2_{1} \ldots \ldots\end{array}$ & $\begin{array}{c}\text { Transients corres - } \\
\text { ponding to normal } \\
\text { occurences } \\
\text { PROTECFr: }\end{array}$ & I & & & & & & & & $\begin{array}{l}\text { Authorized } \\
\text { releases during } \\
\text { incident }\end{array}$ \\
\hline & $\begin{array}{c}I I I \\
\cdots 0^{-4} \& 10^{-2^{*}}\end{array}$ & $\begin{array}{c}\text { Very infrequent } \\
\text { accidents } \\
\text { PROTECTION } \\
\text { SAFEGUARD }\end{array}$ & & $A$ & & $U_{:}$ & & & & & $\begin{array}{l}0.5 \text { rem } \\
1.5 \text { rem th. }\end{array}$ \\
\hline & $\frac{\text { IV }}{10^{-0^{\prime}} \& 10^{: 4}}$ & $\begin{array}{l}\text { Hypothetical } \\
\text { accidents } \\
\text { SAFEGUARD, } \\
\text { evenutaliy H, Cl, U2 }\end{array}$ & & $A$ & $\mathrm{H}$ & $U_{1}$ & & & & & $\begin{array}{l}15 \text { rem } \\
45 \text { rem th. }\end{array}$ \\
\hline $\begin{array}{l}\text { SEVERE } \\
\text { ACCIDENT }\end{array}$ & under $10^{-6}$ & $\begin{array}{l}\text { Residual risk } \\
\text { procedures U } \\
\text { Containment } \\
\text { prorection }\end{array}$ & & & & & & $\mathrm{U}_{3}$ & $U_{5}$ & $U_{4}$ & $\begin{array}{l}\text { Limiced and } \\
\text { delayed } \\
\text { releases }\end{array}$ \\
\hline
\end{tabular}

(Reference: Debes, 1991) 
installation of such a probe only the pressurizer level was used in the event-based procedures. These general state-oriented approach procedures have been implemented in the French program on the last $1300 \mathrm{MW}$ units and will be extended on all the French units in the future. Furthermore, a general guideline has been established to cope, as best as possible, with core meltdown situations. The guideline is designed to be applied beyond the domain of the $U_{1}$ procedure when the core temperature or containment activity reach high levels. These two parameters are used to characterize a core meltdown event. This guideline will be applied by the crisis team.

The French approach includes a national crisis organization that employs a national team including nuclear safety experts. The crisis organization is put on alert and placed in contact with a data link displaying the plant's safety panel which enables it to be aware of the status of the reactor and allows a dialogue to be established with the teams at the plant. Public authorities advised by these specialist organization implement an external emergency plan which interfaces with the internal emergency plan triggered at the plant. EDF has an organization of designated personnel and experts which are also available to the national crisis team. Government orders exist which have established an organization of public authorities that are empowered in the event of a nuclear incident or accident. These organizations include authorities with responsibility for nuclear safety, radiological protection, and civil security. In terms of public radiological protection, the public authorities make decisions based on data supplied by the plant and the related ministerial bodies. It is interesting to note that information concerning the damaged unit's status is made available by a data processing link. All information assisting plant operation or monitoring its performance are therefore avallable in the crisis offices as well as at the plant. This is a common component of the accident management and response capabilities employed by utilities (Commonwealth Edison and Northeast Utilities) in the United States as well as the governmental agency's plan in Japan.

An intriguing aspect of the national crisis plan in the French program is the use of a national fleet of remote controlled robots that operate monitoring equipment which could be required under accident conditions that 
produce serious contamination. This is a unique tool (hardware) employed in the rrench program.

Lastly, the French program includes exercises which permit appraisal of the organizational ability to control accident conditions. Nationally, these exercises aim to test the efficiency of the organizational response to accident conditions. Each site participates in an exercise of this type every two years. On a national level six or seven exercises are carried out per year. The General Secretariate of the Internal-Ministry Committee for Nuclear Safety organizes an annual exercise in which the entire crisis organization of both EDF and the Public Authorities is involved. An extremely degraded scenario is employed to test the responses of persons responsible for protection of the environment and safety of the public. Journalists may be invited to participate in these exercises to verify the correct operation of the public information procedures.

\section{Lovisa Muclear Power Plant}

The approach adopted for severe accident management at the Loviisa Nuclear Power Plant (Tuomisto, 1991) in Finland is based on the integration of both "deterministic" and "probabilistic" aspects especially with regard to phenomenological uncertainties. A key aspect of the plant specific approach is to take advantage of accident management actions that reduce, in effect eliminate, much of these uncertainties. This approach is possible because of certain unique and desirable design features of Lovisa and allows both the management strategy and associated risk implications to be defined in rather simple and concrete terms.

The Lovilsa plant uses two Soviet designed VVER-440 pressurized water reactor units furnished with ice condenser containments. The primary circuit incorporate six horizontal steam generators and a highly oversized lower plenum. There are no penetrations in the lower plenum of the RPV. The containment includes a steel shell or liner which can be externally cooled by means of water spray. Based on these key characteristics, the overall accident management approach is structured around the idea of demonstrating in-vessel melt retention, absence of energetic events and 
reliable long term containment cooling. The focus of accident management at Loviisa is containment integrity. The quantitative risk goal for severe accident management is a containment failure probability of less then $10^{-2}$ per reactor year for each class of severe accident sequences they cannot be considered "negligible". With an internal target (goal) of core melt frequency of less then $10^{-4}$ per year, the "negligible" level is taken at $10^{-6}$ per year. An internal events Level 1 probabilistic safety analysis was completed for Lovisa in the summer of 1989.

A number of changes have been accomplished or are to be accomplished to reduce the preliminary estimates of the core damage frequency made in the Level 1 probabilistic safety analysis. Extensive systems have been planned to reduce the contribution of bypass scenarios to less then 58 of the core melt frequency. The approach is to rapidly reduce the primary pressure to below the secondary pressure and the systems included an upgrading of the pressurized spray system and installation of a borated source of water. Depressurization is an accident management procedure has been incorporated for the Loviisa plant.

In-vessel melt retention constitutes the cornerstone of the Loviisa accident management approach. Cooling the lower head requires a vapor venting capacity around the vessel-cavity annulus. In order to ensure the stability of the natural circulation cooling path.including the escape of steam from the submerged portion of the RPV, a system to lower the lower head insulation and the neutron shield blocks has been defined and will be implemented and at its use proceduralized. In-vessel coolability eliminates a number of potentially significant containment challenges due to melt interactions in the cavity. These challenges include excessive steam explosions, core concrete interactions, and direct containment heating.

By eliminating these potential containment challenges through in-vessel coolability, the Lovisa plant concludes that they only need be concerned with major hydrogen combustion events in the containment atmosphere as a potential containment challenge. The existence of hydrogen igniters in the current design and the plan to fully credit depressurization capability provides significant capability for managing hydrogen. The only additional 
accident management measure provided is to open the "lower" ice condenser door such as to promote natural circulation between the lower containment compartment and the containment dome. This allows for a well-mixed containment and the elimination of local hydrogen accumulations as well as good coupling to the heat sinks available by the containment boundary.

Lastly, the long term containment cooling and stabilization of an accident can be accomplished by steam condensation on the containment walls. The double wall structure allows the steel liner (inner wall) to be exposed to an external water spray. The external spray capability provides for the long term decay heat removal.

The three main critical functions of the Loviisa accident management scheme include the absence of energetic events, lower head retention, and long term stabilization. Accident management procedures are to be produced for each of these critical functions but no other detailed procedures are planned nor felt necessary. Rather guidance will be identified for use by the technical support center personnel. Loviisa relegates "loop isolation" and "securing the bypass" actions to be preventive measures such that they are not viewed as part of their accident management program. The procedures within the accident management realm begin with "depressurization". Depressurization is to be initiated at the Lovisa plant with the first indications of superheated steam at the core exit. Such a condition sets in motion the "severe accident phase" of the emergency response. Continuous monitoring of the core exit thermalcouple is employed by the Loviisa plant to assure timely action in interfacing the emergency operating procedures and accident management procedures.

The blowdown associated with a late depressurization of the RCS is not very significant for the Loviisa containment. Since the containment design does not include alr return fans, the depressurization procedures also are planned to set in motion the procedure for opening the ice condenser door. For large and intermediate break LOCAs that do not require depressurization system performance, the door opening procedure initiates when the first continuing indication of superheat at the core exit thermalcouples occurs in coincidence with a low pressure status of the reactor coolant system. 
Lowering the insulation and neutron shield assembly around the lower head of the reactor pressure vessel can be initiated automatically from the high water level in the reactor cavity. Manual backup to the automatic lowering can be made in coincidence with the need for depressurization or if deemed necessary from the readings of the thermalcouples to be installed on the reactor vessel insulation region. These temperature measurements could be of great value for an emergency response organization to get information on the location of a reactor core.

Finally, the procedure for activating the external containment sprays is based on diagnosing the increasing containment pressure above its design pressure.

Operators will be trained on the simulator for Loviisa which is to be expanded by simple models to include the above described key events in a reasonably realistic time frame. This training will take place in the presence of support engineering. Thus, training is an important component of the Loviisa accident management program. Furthermore, the expanded simulator capability constitutes a tool that will be used during the training aspects of its accident management program.

Thus for the Loviisa reactor in Finland, a comprehensive accident management program has been defined and is currently being planned and implemented in the plant. The various elements of the severe accident management scheme for Loviisa are summarized in Table 5 .

\section{III.3 Reviev of Industry Docuents}

As part of the NRC's plan for development of accident management programs (SECY-89-012) a joint effort on behalf of the NRC and the industry is being conducted. The industry is represented by NUMARC during interfaces with the NRC. Several joint industry and NRC activities on accident management are being conducted as input to the NRC generic letter on accident management. These activities include EPRI's technical basis report, vendor specific accident management guidance, NUMARC guidelines for evaluating accident management capabilities, and NRC research. The NRC generic letter 

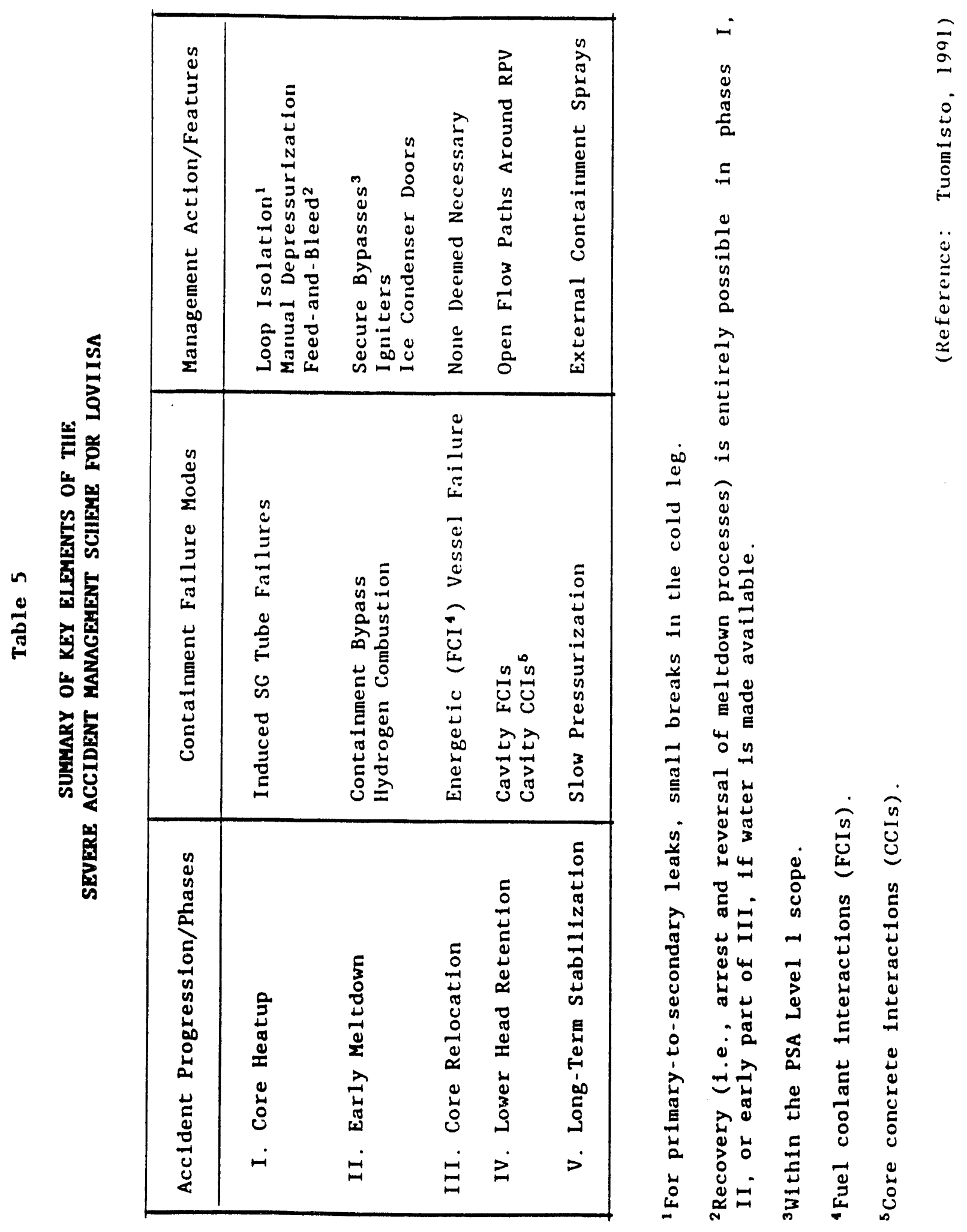
on accident management which is anticipated in 1992 and in conjunction with individual plant evaluations will be employed by utilities for the actual implementation of their accident management plans. The overall objective of industry's coordinated severe accident management effort as put forward by NUMARC is to provide for the systematic implementation of certain insights from an individual plant evaluation and other relevant information regarding severe accidents for the purpose of pre-planning and enhancing a utility's capabilities during an accident to take preventive and mitigative actions in an efficient and cost effective manner.

The nuclear utility industry has drafted a severe accident management issue resolution paper that provides a vehicle for promoting a mutual understanding within the industry and with NRC staff of an overall approach with respect to severe accident management. The issue resolution paper also identifies the tasks to be accomplished and expectations for utility implementation. Furthermore, it provides the NRC staff an appreciation of the complexity and scope of the tasks. It is intended to assure the NRC staff that the industry's activities are responsive to the staff's stated objectives and comments. Severe accident management issue resolution will contain a statement of objectives and a discussion of potential impacts of the accident management program development activities. Furthermore it provides an identification of the roles, responsibilities and interfaces between the cognizant industry organizations. Lastly it provides coordination of generic accident management resource document developments that are ongoing within the utility industry. These generic accident management resource documents include: each individual owners group specific accident management guidance, the EPRI/NUMARC Process for Evaluating Accident Management Capabilities, and EPRI's Accident Management Guidance Technical Basis Report. These last two generic documents are discussed below.

\section{A Process for Bvaluating Accident Mansgenent Gapabilities}

The report is being produced under EPRI's direction and NUMARC's coordination and provides a self-evaluation process which provides guidance to electric utilities in identifying enhancements to provisions for accident management for the nuclear power plants that they operate. These provisions 
relate to actions taken during the course of a severe accident to prevent it from progressing further or to mitigate its consequences. The evaluation process outlined in this report is directed at identifying ways in which appropriate advance preparations can be made to ensure that these actions can be carried out effectively if needed. The process includes the evaluation of all relevant phases of a severe accident. The systematic evaluation process provided in this document is one part of the overall plan developed by NUMARC to assist the industry in the closure of severe accident issues. It is important to recognize that individual utilities are not required to use this process. The guidance in this report is provided as a resource to assist utilities in their self evaluation and, therefore, is general rather than prescriptive in nature. The guidelines within it address the objectives and desirable attributes of the evaluation process in the context of five principle steps. The flexibility is retained for each utility to tailor an evaluation process that can be most effectively incorporated into its existing organization and that best fits the technical resources it has available. These goals are also useful when considering the formulation of an evaluation process which may be suitable for the Savannah River production reactors.

This report recognizes that the role of the evaluation process may be different depending upon each utility's individual approach. Specifically, the following objectives for the evaluation process have been identified:

1. For utility's that choose to implement their individual owners group guidance completely, the evaluation will allow a structured review of plant specific aspects important to the assurance of coverage of any unique plant or operational features. The evaluation could also serve as a means of verifying the plans for implementing these specific individual owners group guidance. The evaluation described in this report also covers decision making and organizational aspects that might not be dealt with by the specific individual owners groups.

2. A utility might choose to evaluate the need for specific elements of its specific individual owners group guidance before deciding what portion to adopt, and further use the evaluation to judge what other enhancements might be desirable. 
3. A utility could evaluate their accident prevention capabilities in an accident management framework with more emphasis on defense-in-depth and less reliance on probabilities used in examining their IPE results.

4. An evaluation process will be a useful part of an accident management program development for a utility that decided to develop its own guidance without reliance on a specific individual owners groups products.

5. The outcome of the evaluation process would result in an acciden. management enhancement plan which would be expected to fulfi:l the request in the NRC's upcoming generis letter on accident management.

The process being formulated in this EPRI document assumes the exist. ence of specific individua: owners groups. This could be viewed as a limitation for Savannah River as it it a unique situation which does not have the support of an owners group. Rather a standalone organization is responsible for the Savannah kiver production reactors. The fourth objec- ve in the above list recognizes a situation which applies to the Savannah River site and therefoze implies the validity of considering this proposed evaluation process for Savannah River.

Accident managenent in this document has been defined to encompass the actions taken during the course of an accident to prevent or terminate core damage or to minimize fission product releases. Figure 10 presents the pathways for a potential severe accident, and for accident management strategies that could be taken to arrest or mitigate the accident. Such a pathways figure is an applicable approach for the Savannah River site as well as for the commercial light water reactors to which it is applied in this document. The pathway diagram can be used as a tool for organizing and identifying potintial accident management strategies as well as for communicating such concepts between the different organizations on the project team. The purpose of an accident management program can be viewed as an exercise to identify what actions are needed to arrest or mirigate a severe accident and to assure that available resources are used in the best way to accomplish these actions. Accident management is a success oriented endeavor directed at limiting the continued progression of an accident. The process presented in this EPRI/NUMARC report is aimed at helping utilities 


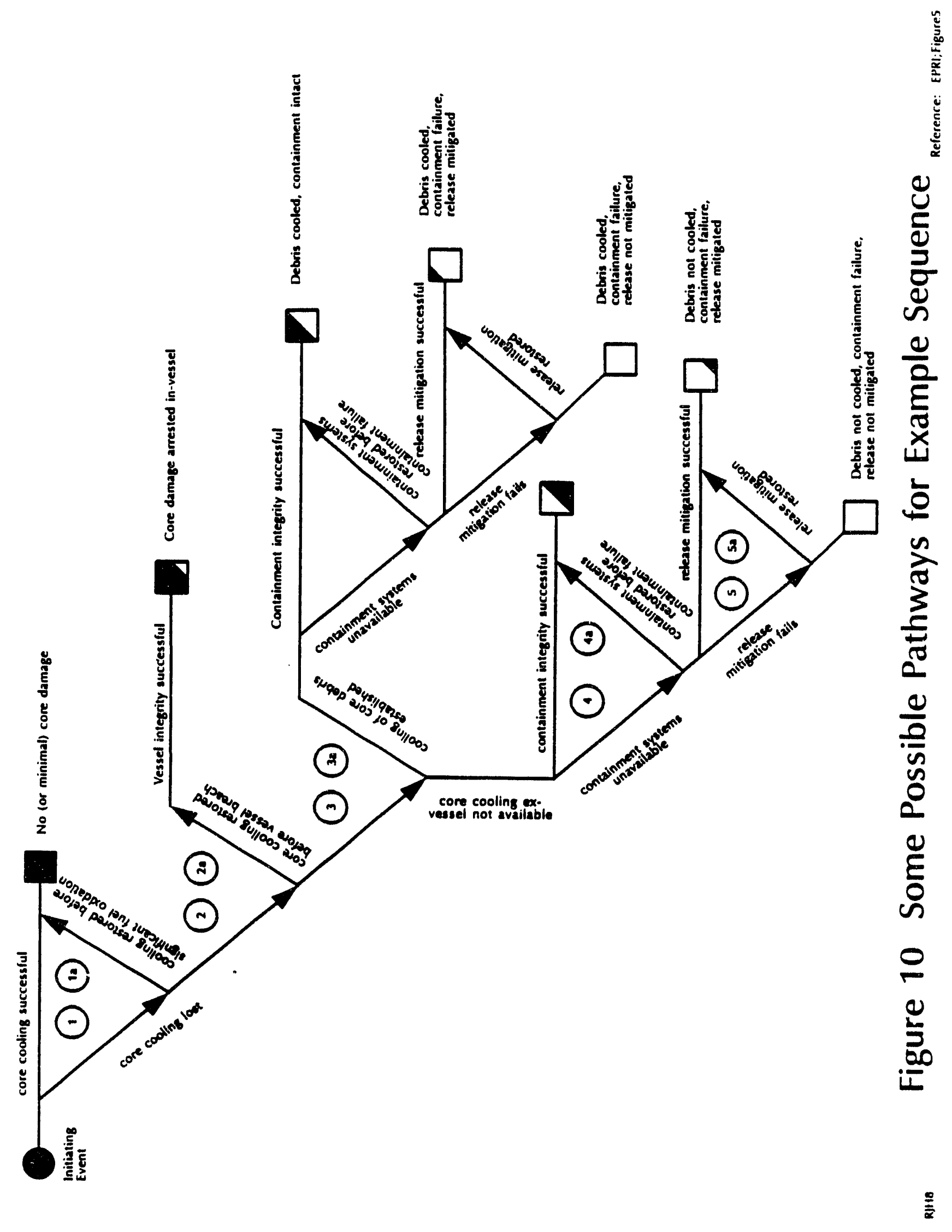


find areas in which existing capabilities for accident management can be enhanced.

Figure 11 provides an overview of the industry guidance for the five step evaluation process. In concept the process could also be considered for the Savannah River Site with the exception of those interfaces that are provided from owners groups as mentioned above. The Savannah River Site could choose to consider for its use, in lieu of the guidance that will be provided by owners group for light water reactors, the information provided in the NRC's "A" strategies or in EPRI's Technical Basis Report once it becomes available. The Savannah River Site could choose to review these documents and use them to convert, delete or define new strategies as needed for their particular design requirements or DOE guidelines. The primary task of step 1 (see Figure 11) is to select a set of accident sequences that can be used most efficiently in the review of the accident management capabilities to be performed in step 2 of this process. Step 1 requires as input the results of an IPE or PRA. The selection process should use functional sequences to group individual action sequences and should ensure that al1 phases of a severe accident are addrossed. Step 2 performs a systematic review of the existing accident management capabilities avallable at the plant being evaluated. The existing accident management capabilities may be embodied in emergency operating procedures, plant drawings, system descriptions, and the conclusions from insights derived from the IPE or PRA for that plant. Figure 12 illustrates the kinds of capabilities that would be assessed. The Savannah River Site may be limited regarding the availability of some of these resources or the extent to which they may have been developed and documented; for example emergency operating procedures. Step 2 is viewed as the principle task of this evaluation process. Questions for each phase of a severe accident and for each category or group of sequences are proposed in order to facilitate the evaluation process. This is similar in form and concept to the approach described above employed by Commonwealth Edison. Commonwealth Edison has developed a set of questions to evaluate each of its individual work products in order to identify insights regarding the plants behavior during severe accidents. Step 3 involves the integration of candidate options identified in step 2. This includes the process of identifying options which are common to multiple accident groups. The 


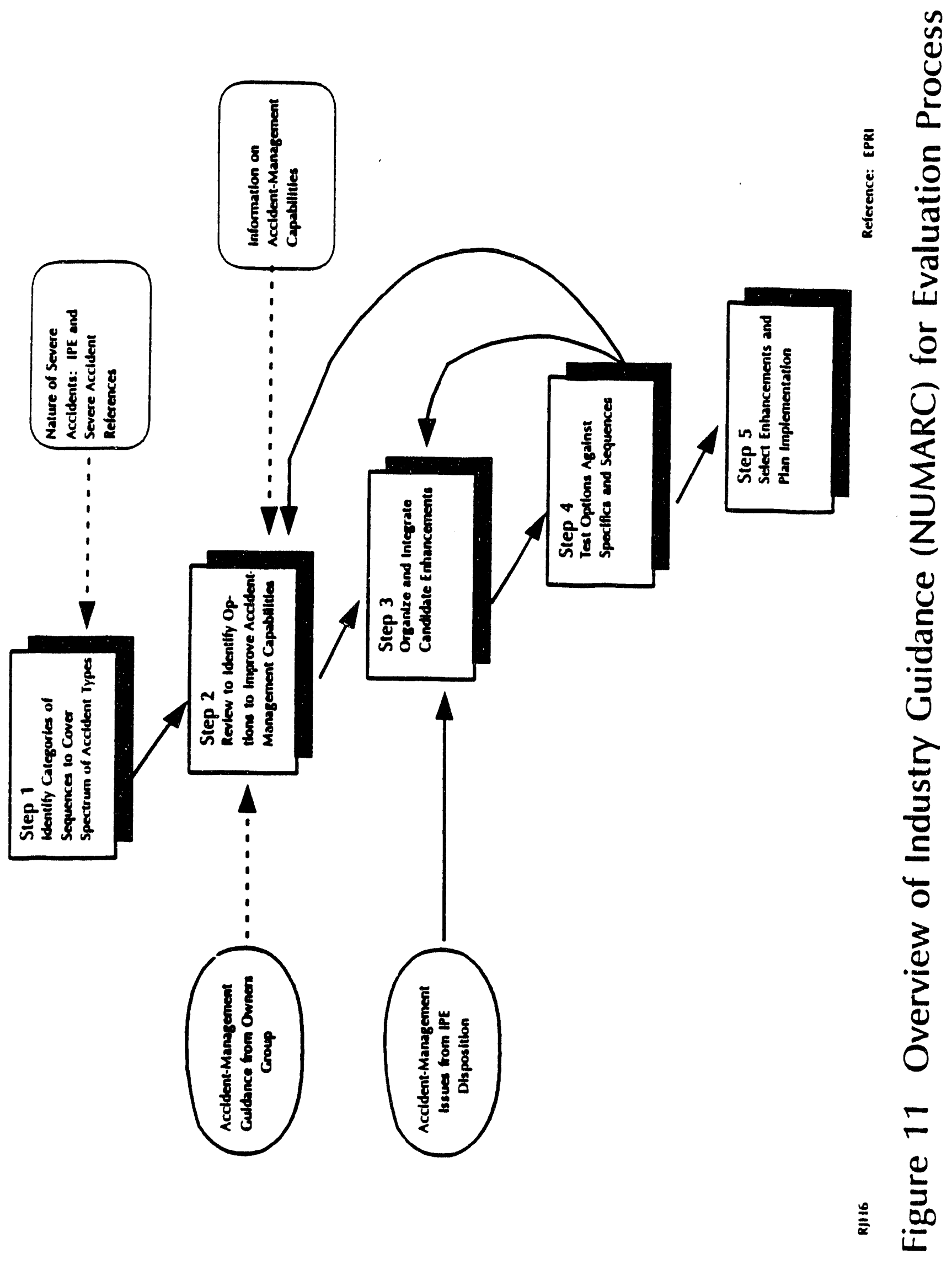




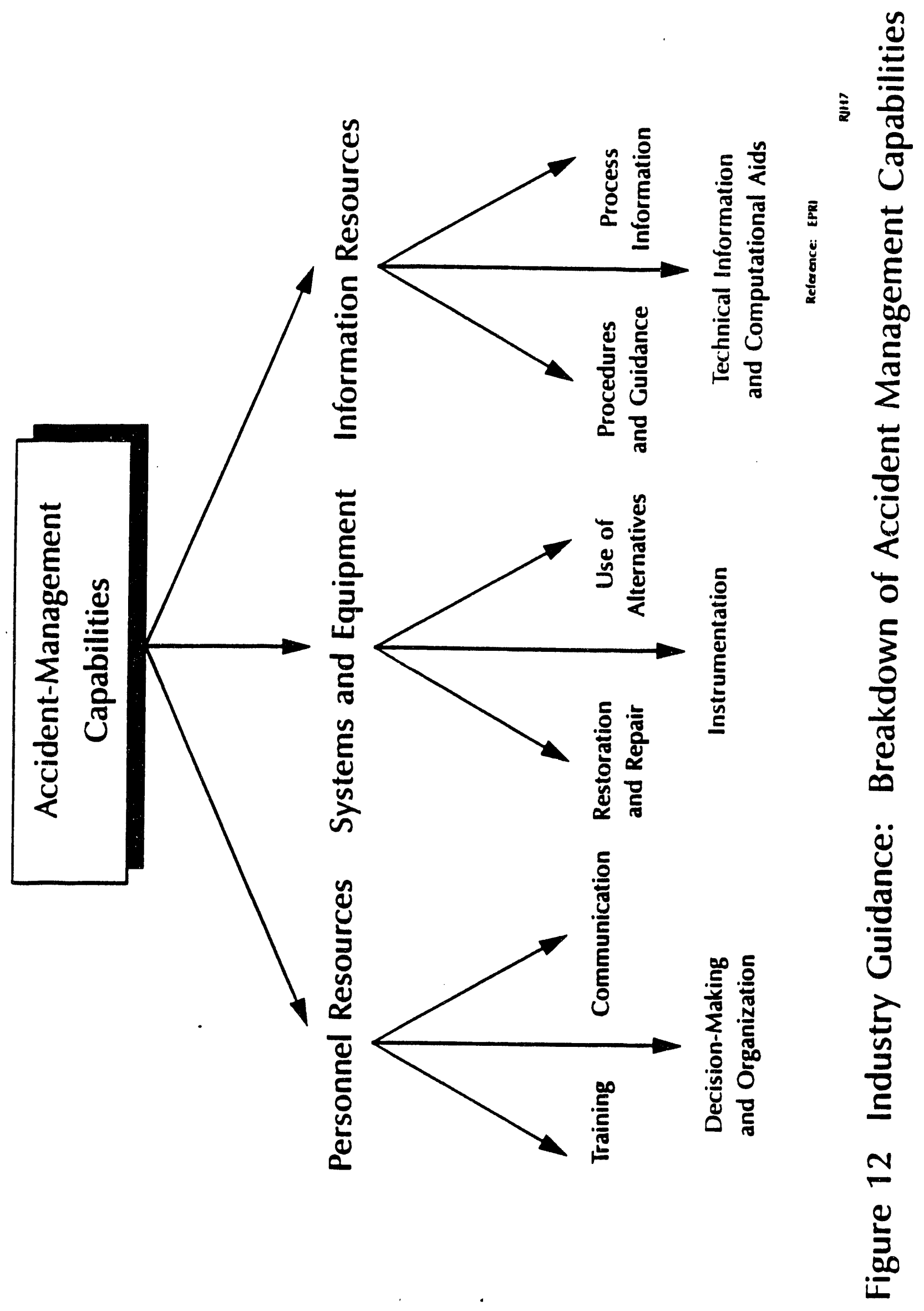


options are screened and organized into candidate enhancements in this step. It is interesting to note that this integration process and screening of options is performed by the "Tiger Team" for Commonwealth Edison as part of its evaluation process. In step 4 the options are tested to assure their feasibility and to check for negative implications should they be implemented. Step 5 is the final step in this evaluation process and it involves deciding what changes to implement and developing plans for carrying out the selected enhancements The implementation process for selected enhancements may involve several aspects: establishing management priorities, identifying responsibility for further effort in defining specific aspects of the proposed enhancement, assigning responsibilities for carrying out the changes to appropriate organization within the utility, and developing a schedule for implementation of selected enhancements. Furthermore training and/or drills may be identified by the utility to review its integrated accident management preparedness.

This EPRI document also provides considerations and recommendations regarding the types and backgrounds of personnel who could make the accident management evaluation most effective. Table 6 summarizes this document's recommendation of personnel resources for accident management evaluation. The summary table identifies the tasks and the corresponding step in this five step evaluation process.

Lastly, the EPRI evaluation process document describes and discusses considerations regarding the documentation necessary to record the evaluation process. Documentation would be provided to maintain a clear and traceable pathway through the evaluation process. Two types of documentation can be envisioned:

1. A plan that lays out the steps the organization intends to take to perform the implementation process and implement its results.

2. Summaries of the data used in the evaluation process and judgements made in carrying out the plan. 
Table 6

SUIAARY OF PERSONREL RESOURCES FOR ACCIDENT-MANAGEAENT EVAUUATION

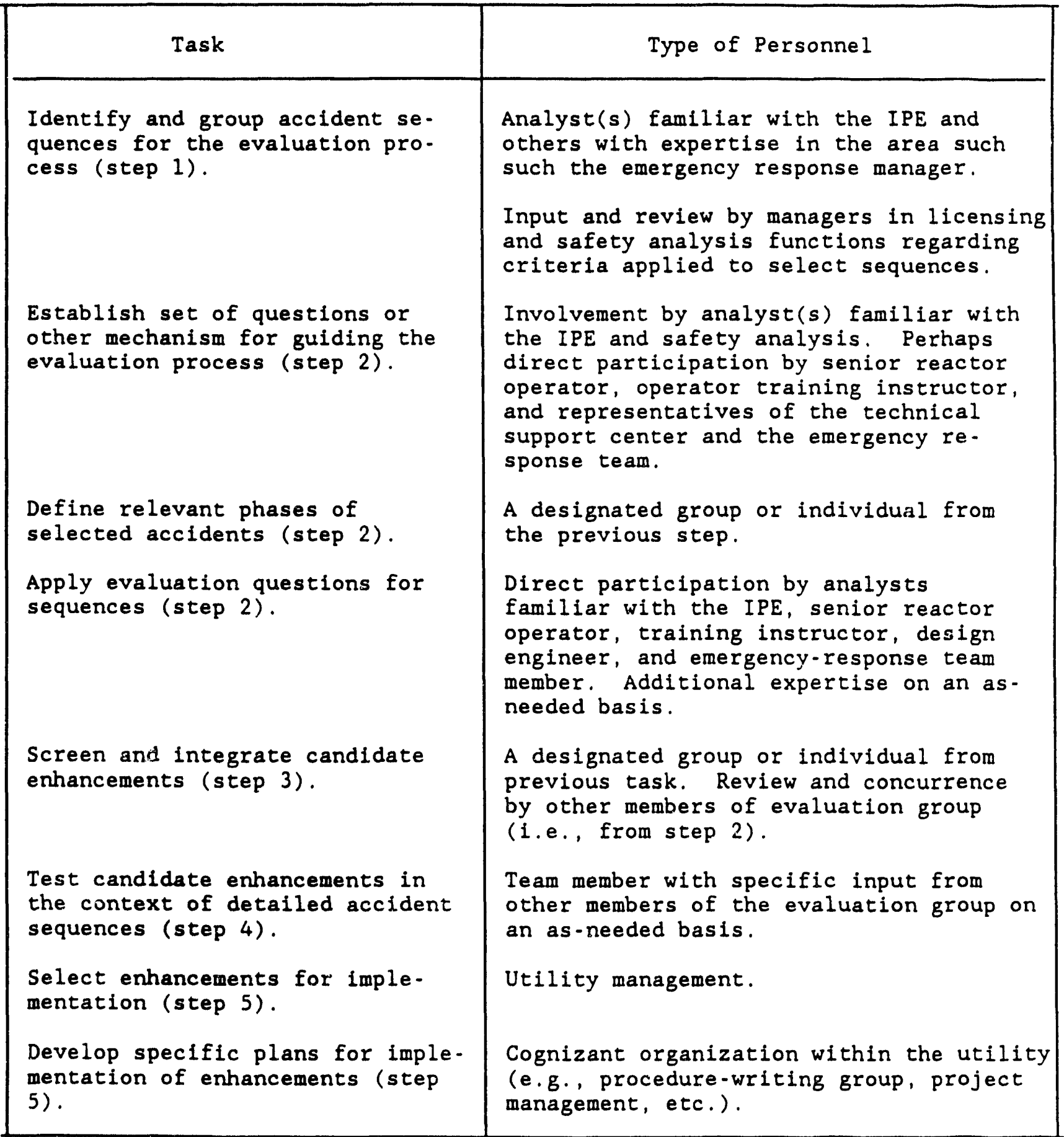


A written plan might be needed to indicate the organization's intentions regarding how the evaluation is to be performed. The plan might include several elements, such as, a statement of the specific philosophy and objectives of the evaluation of accident management capabilities, a summary of the approach to be taken to perform the evaluation, and an indication of criteria that could be used to judge whether or not particular enhancements should be implemented. Such documentation could be used to facilitate a description of the work to be performed by the personnel that are assigned the evaluation process or to demonstrate to regulatory agencies that relevant aspects of the accident management program are being pursued. As an alternative or perhaps a supplement to the actual activities of the evaluation process informal memorandum rather then formal reports could simply be maintained in the organization's files. Formal documentation would then focus principally on the insights from the evaluation and conclusions regarding selected potential enhancements to the accident management capabilities for the plant. In any case it would be prudent to assure that documentation requirements are anticipated at the onset of the evaluation process such that the appropriate information can be collected for use in the final documentation.

\section{RPR Accident Managenent Guidance Technical Basis Report}

The EPRI Technical Basis Report is being prepared as a resource for the individual owners groups as well as the individual utilities. It addresses severe accident phenomena and their significance and impact on both PWR and BWR reactors and containment types. The technical basis report consists of two volumes. Volume 1 contains the identification, description, and objective assessinent of candidate high level actions that could be considered as accident management strategies by individual owners groups or utility members. The objective assessment of each of the candidate high level actions is made for a series of postulated core damage conditions and containment challenges. Each of the candidate high level actions is defined and then its impact for each reactor and containment type and for each potential plant damage condition is described. This description includes both the anticipated beneficial and potentially detrimental responses of the plants to the selected high level action. No conclusions or recommendations 
regarding the selection or suitability of the several candidate high level actions are provided in the Technical Basis Report. Rather the technical basis is simply presented objectively such that the individual owners groups and subsequently the individual utilities may make their own recommendations and reach their own conclusions regarding potential trade-offs associated with selecting various accident management strategies. This document has been drafted and is going through a thorough engineering design review by both EPRI and NUMARC and is expected to be available for the NRC and general information in the fourth quarter of 1991.

Volume 2 of the EPRI technical basis report involves a series of approximately 30 appendices which provide technical bases and descriptions of severe accident technology. The severe accident phenomena associated with the core damage states and containment challenge conditions discussed in Volume 1 are all included in Volume 2. The nature of the current state of knowledge regarding severe accident phenomena, their interactions, their impact on containment performance and fission product performance and mitigation are each discussed. In many cases the appendices on these various topics can serve directly as a calculational aid that may be selected for implementation by the individual owners groups or utilities. In other cases the information provided could serve as a basis for developing additional calculational aids for diagnosing and assessing severe accidents. The information in Volume 2 on severe accident phenomena provides a description of currently available experimental research and analytical assessments on the topics included in volume 2 . Volume 2 of the EPRI Technical Basis Report has been drafted and is going through an engineering design review by EPRI and NUMARC and is anticipated to be available by the first quarter of 1992. Much of the currently available experimental research discussed in Volume 2 is applicable for the Savannah River Site.

In addition to the utility sponsored severe accident research discussed in the previous section the industry has sponsored severe accident research which can benefit the selection and justification of accident management strategies. Therefore, the use of this research to supplement that available from NRC sponsored programs is a prudent approach that should be 
incorporated in the formulation of an accident management program. In particular EPRI conducted and is conducting several research programs in the areas of severe accident phenomena and technology. For example the ACE series of experiments has been useful in studying fission product aerosol behavior and the MACE (Sehgal, 1991) experiments are currently in progress to assess ex-vessel debris coolability. EPRI participated in a series of experiments to assess the vulnerability of BWR Mark I containments to early containment failure due to direct exposure to molten core debris. These experiments helped to quantify the rates of exchange of energy between molten core debris and avallable sources of water. Such fundamental information is of direct use in formulating and assessing potential accident management strategies or calculational aids. This information has been incorporated in the technical basis report Volume 2 appendices discussed above. Furthermore, EPRI is currently supporting experiments to assess the behavior of lower head penetrations during severe accidents. The ability to maintain the integrity of lower head penetrations during a severe accident progression directly impacts the efficacy of using external reactor pressure vessel cooling as an accident management strategy for retarding or preventing lower head fallure. Thus, it is suggested that the entire set of severe accident research as available from NRC programs, utility programs, and industry programs be collected and reviewed for applicability in the technical basis for accident management strategies to be used for the Savannah River Site.

\section{III.4 Accident Mangrenent Bibliography}

This is a bibliography of available references on the subject of accident management which could provide the core library of documents on this topic. These references include contributions from the NRC, utilities, and industry. The references which have been abstracted or reviewed in this report are marked by as asterisk ( $*$ ).

*Bastien, R., Lutz, Jr., R. J., Eliasson, L., Waessman, P. O., 1988, "The Westinghouse "Severe Accident" Procedures as Developed for the Ringhals Unit", Presented at the International Symposium on Severe Accidents in Nuclear Power Plants, Sorrento, Italy. 
*Boyd, G. J., and Lewis, S. R., 1991, "A Process for Evaluating AccidentManagement Capabilities", Rev. 1, SAROS, Inc., Knoxville, Tennessee.

Chen, J. T., et al., 1991, "Procedural and Submittal Guidance for the Individual Plant Examination of External Events (IPEEE) for Severe Accident Vulnerabilities", U.S. Nuclear Regulatory Commission Report NUREG - 1407 .

*Crutchfield, D. M., 1988, "Individual Plant Examination for Severe Accident Vulnerabilities", U.S. Nuclear Regulatory Commission Generic Letter $88-20$, Washington, D.C. .

Deal, L. J., "Severe Accident Insights Report", NUREG/CR-5132.

Hanson, D. J., Ward, Leonard W., Nelson, William R., Meyer, Orville, R., 1990, "Accident Management Information Needs Volume 1 - Methodology Development and Application to a PWR with a Large Dry Containment", NUREG/CR - 5513 .

*Hanson, D. J., Blackman, H. S., Meyer, O. R., Ward, L. W., 1991, "A Systematic Process for Developing and Assessing Accident Management Plans", NUREG-CR-5543, EGG-2595.

Kastenberg, W. E., 1991, Proceedings of a Workshop on Severe Accident Management for PWRs, Los Angeles, California.

Klopp, G. T., Lutz, Jr., R. J., Brown, R. G., 1991, "IPE Insights/Accident Management Program Evolution Guideline", Individual Plant Evaluation Partnership.

*Luckas, W. J., Vanderkieboom, J. J., Lehner, J. R., 1990, "Assessment of Candidate Accident Management Strategies", NUREG/CR-5474.

Lutz, J., R. J., Hammersley, R. J., Brown, R. G., Klopp, G. T., 1991, "Commonwealth Edison's Innovative Approach to Integrating Accident Management with IPE", presented at the American Nuclear Society Nuclear Reactor Safety Division International Topical Meeting, Portland, Oregon.

*NRC, 1985, "Policy Statement on Severe Reactor Accidents", U.S. Nuclear Regulatory Commission, Federal Register, Volume 50, p. 32138 , Washington, D.C.

*NRC, 1988, "Integration Plan for Closure of Severe Accident Issues", U.S. Nuclear Regulatory Commission Report SECY-88-147, Washington, D.C.

NRC, 1989a, "Individual Plant Examination: Submittal Guidance", U.S. Nuclear Regulatory Commission Report NUREG-1335, Washington, D.C.

NRC, 1989b, "Revised Severe Accident Research Program Plan", U.S. Nuclear Regulatory Commission Report NUREG-1365, Washington, D.C.

NRC, 1990, "Status of Accident Management Program and Plans for Implementation", SECY-90-313, U.S. Nuclear Regulatory Commission. 
NRC, 1991, "Individual Plant Examination of External Events (IPEEE) for Severe Accident Vulnerabilities - 10CFR 50.54(f)", Generic Letter No. 88-20, Supplement 4 .

Pratt, W. T., et al., 1988, "Radiological Accidents - Perspectives and Emergency Planning", ANS Topical Meeting, Bethesda, Maryland.

*Stello, Victor, Jr., 1989, "Staff Plans for Accident Management Regulatory and Research Programs", U.S. Nuclear Regulatory Commission Report SECY-89-012, Washington, D.C. 


\section{ASSESSMEANT OF APPROACHES FOR DEVELOPING ACCIDENT MANAGEMIENT PROGRAMS}

\section{IV.1 Regulatory Approach}

As described above in Section III.1, a regulatory approach for a process for evolving an accident management plan has been prepared and is reported in Systematic Process for Developing and Assessing Accident Management Plans (NUREG/CR-5543). This process for evolving an accident management plan is described as a four phase process in that document. NUREG/CR-5543 has recently been issued but has not had the benefit of detailed NRC nor peer review. The first two phases of the envisioned evaluation process and preliminary criteria for assessing accident management plans submitted to the NRC are included in the subject report. Thus, to date there has been no opportunity to apply and test the process identified in this document. It is appropriate to consider it as a preliminary document which may evolve and be revised in the future. Thus, an assessment of the proposed approach must be recognized as also being preliminary.

Step 1 of this proposed approach is the identification of dominant sequences which are then used in a binning type of process in step 2 . The binning type of process suggests that sequence categories be defined along the lines of plant safety functions. No explicit discussion on the use or exploitation of emergency operating procedures is provided in this document. However, by selecting plant safety functions as a mechanism for categorizing sequences, a concept parallel to the EOPs may be argued. However, the selection of sequence categories and the assignment of dominant sequences to them requires judgement. As this is a key step in the process, the judgement employed in this categorization activity has a major impact on the results obtained by implementing this process. This is the case as all subsequent steps depend on the categorization of sequences performed in step 2. In fact a typical sequence is used for each sequence category in the following six steps in this evaluation process. This has a possibility of making the process more sequence than symptom oriented. Furthermore, the evaluation process is applied after the IPE or PRA has been completed. This 
Is the case as it requires the selection of dominant sequences which implies the results of an IPE or PRA are available at the beginning of this accident management program evaluation process. The presumption of availability of IPE or PRA results is common with the evaluation process being proposed by the generic utility guidance (EPRI) but is unlike the guidance being proposed and implemented by Commonwealth Edison. The Commonwealth Edison approach performs the IPE and accident management definition processes in parallel. This does not limit the insights to only the dominant sequences or a typical sequence selected from a categorized group of sequences. In fact perhaps a majority of the insights derived by the parallel process are arrived at even before the event trees and source terms are quantified. The stated purpose of the categorization step in NUREG/CR-5543 is to reduce the number of analyses. This calls to question the completeness of the evaluation. As is frequently the case when a binning process is employed, its success is dependent upon the judgement and experience of the analysts defining the bins and the number of sequences in that bin. This provides an opportunity for missing information. A parallel approach to IPE and accident management development which avoids the need to bin or categorize can also avoid this potential difficulty. Thus, the use of a typical sequence for each category and the subsequent steps of the evaluation process may be viewed as a potential weak point since step 2 in this process can be rather judgmental.

The proposed approach in NUREG/CR-5543 endeavors to identify potential improvements in the complete use of a plant's capabilities for responding effectively to a severe accident event. This is a common goal in all the processes identified to date for evolving an accident management program definition as well as the regulatory guidance described in Section III.1 above. However, as currently written and structured the process provided in this document does not encieavor to identify good practices or plant hardware that provides the plant's capability and robustness recirding potential severe accidents. It is equally important to recognize the features (hardware and/or procedures) that provide the capability to withstand inltiating events which could lead to severe accidents and core damage as it is to identify enhancements to further exploit the severe accident capabilities of the given plant. 


\section{IV.2 Co momealth Edison Approach}

As discussed in Section III.2 above, the approach used by one utility (Comrnonwealth Edison) to evolve its accident management program definition is to perform such an effort in parallel with conducting its individual plant evaluation for each station. In this section we will provide an assessment of the problems and opportunities associated with developing an accjient management program in conjunction with or following the individual plant examination process will be provided.

A potential drawback can be associated with the integrated development of an accident management program definition and the performance of an IPE or PRA, i.e., an increase demand on resources. The development of insights regarding plant vulnerabilities and potential accident management strategies requires additional effort on the part of the individual analysts. Furthermore, as implemented in Commonwealth Edison's approach the activities of both the $: .:$ ident Management Coordinator and the Tiger Team members add to the resource requirements. On the other hand, if it is presumed that both an IPE and and accident management plan will eventually be required, then the generation of insights and an integrated preparation of both the IPE and accident management guidance can prove to be a cost effective means of meeting such dual regulatory requirements. An integrated study which meets both regulatory requirements can provide a substantial overall cost savings. The experience to date on the Commonwealth Edison approach that incorporates integrated activities has not progressed far enough to assess the validity of the potential for cost savings.

The integrated approach can provide a positive result of producing a qualified and experienced staff given that the utility personnel actively participate in the integrated program. By incorporating technical and plant personnel in the process of developing and assessing insights for both plant vulnerabilities and accident management capabilities one develops several positive attributes. The first is an enhanced understanding of severe accident phenomena by a larger portion of the personnel associated with the selected plant. This is a direct benefit that always applies during the active participation of plant personnel as opposed to separate services for 
PRA that are provided by PRA consultants. In addition to an enhanced understanding of severe accident phenomena and PRA as a tool for assessing plant hazards and future modifications direct participation in such an integrated program increases the sense of "ownership" by the plant personnel. The long term utility and benefits to be derived from a plant PRA or IPE may ultimately depend upon the successful implementation and endorsement of the results on the part of the total plant organization. Thus, an integrated program which increases the degree of participation by various plant organizations provides a mechanism for initiating the process of indoctrinating the personnel with the PRA methods, results, limitations and applicability.

The integrated approach including its "top-down/bottom-up" approach results in the need for several new and innovated technical approaches. The integration of accident management also underscores the importance of realism in all the phases of the IPE effort. The development of an accident management program demands that each of the five elements as identified in SECY-89-012 be based on a 'sest and most accurate understanding of plant and operator response during accident conditions. It is possible that conservatisms in the IPE models, assumptions or analyses could lead to the identification of accident management strategies which are not important during an actual accident. A potentially more severe consequence of conservatisms in the IPE models could be that accident management strategies predicated on conservative results could actually have an undesirable impact on the plant performance.

Another innovation in the IPE which results from the integration of the IPE and accident management activities is the development of Plant Response Trees (PRTs) in place of the tradit: onal PRA Level I systems event trees and PRA Level II containment event $t$ :ees. Accident management involves the response of the emergency personnel throughout the entire progression of an accident. This requires that all interactions of the plant and operator response aimed at preventing core damage be carried over to the interactions to prevent containment failure and mitigate fission product releases. Therefore, for all of the integrated IPEs, a total plant response tree has been developed to evaluate the total plani response, including containment 
response and fission product behavior. In addition, since the development of accident management strategies requires that a knowledge of previous operator action successes and system successes be known, key operator actions are distinguished from system response by use of separate top nodes on the plant response trees. This allows accident sequences to be easily sorted for systems and operator fallures which preceed the implementation of possible accident management strategies. This significantly facilitates the identification of optimum accident management strategies.

The effort to perform a realistic assessment of the accident progression for the Commonwealth Edison plants and the impact of systems operation and operator actions has been emphasized in the plant response tree portion of the IPE. Several parts of the plant response tree evaluation have been enhanced to ensure a level of realism that is in concert with the intent of the accident management program:

1) Realistic success criteria, including equipment mission times, have been developed for all system nodes of the PRT, based on plant specific analyses,

2) The accident progression has been matched against the plant specific EOPs and all important operator recovery actions specified in the EOPs are modeled,

3) Realistic time windows have been developed for all operator action nodes in the PRT, based on plant specific analyses and evaluation of the operator progression through the EOPs, and

4) Operator actions which are required to ensure long term (i.e., greater then the traditional 24 hour time period considered in IPE analyses) success for core cooling and containment integrity have been identified and documented as inputs to the plant specific accident management program.

The use of realism or best estimate assessments in an integrated approach improves the understanding of the plant response to accidents, and the impact of operator actions on the accident progression and consequences. This assures that the accident management program guidance is properly focused on optimizing the use of the true plant capability. This avoids the potential conflicts of not using best estimate assessments in a PRA, for example, a Level III PRA may have been conducted that provided conservative 
results for the risk profile. While conservative assumptions may add margin to the assessment of the plant's risk profile, such conservative results may not be compatible with the need for best estimate input as desirable for an accident management program.

An unintended benefit of the integration of accident management into the IPE effort is the ease of identifying and documenting all insights which are relevant to the IPE (i.e., those insights which are not directly applicable to the accident management program). Such insights deal primarily with those aspects of the plant design and operating practices which effect the capability of the plant (as opposed to the plant personnel) to respond to either: a) an event which initiates the accident or b) the progression of an accident. The fundamental desire espoused in the Commonwealth Edison program is to identify and document all these types of insights in addition to those which can provide input to the accident management program. Such insights have been termed "IPE insights". One of the areas which has been stressed in the Commonwealth Edison integrated program is the identification and documentation of the "good" design aspects and operating practices which are found to make a significant contribution to the capability of the plant to prevent core damage or mitigate the consequences of a core damage event. These "good" design insights become areas for which detailed tichnical evaluations must be carried out prior to the implementation of future modifications. This feature of the integrated IPE and accident menagement program being conducted by Commonwealth Edison is viewed to be a very important product of the IPE effort.

An aspect of PRA based assessments that often receives significant scrutiny is the completeness of the PRA. Significant effort is often directed towards assuring that an appropriately exhaustive set of sequences have been captured and quantified in the PRA results. It is recognized that the methodologies employed to conduct PRAs of necessity require elements of judgment, screening, and often binning. The presence of such activities embedded in the PRA methodology may lead to debate regarding the completeness of the results obtained by such a PRA. The use of the integrated approach for the IPE and accident management program definition provides an improvement in the methodology ragarding the question of completeness. The 
Integrated approach assures that all intermediate work products are reviewed by the IPE analysts for potential insights. As mentioned above the insight identification process places an emphasis on identifying both potential enhancements and good practices and plant capabilities. As a form of a check or confirmation on the performance of the integrated approach for developing insights being employed by Commonwealth Edison, a comparison was made of their preliminary results to the "A" strategies identified in the regulatory docunents. When the insights which have been developed only from the work products that proceed the event tree and source term quantification were compared to the "A" strategies, it was observed that the entire set of "A" strategies had been identified by the integrated process. This provided a useful and independent check on the integrated methodology.

The logical-intuitive or "top-down" approach to defining accident management program requirements identified the need for several calculational aids or tools. The benefit of on-line accident management tools to assist Technical Support Center personnel and management in diagnosing and responding to severe accidents was identified. Such accident management tools are being developed and interfaced as part of the Commonwealth Edison integrated program. One tool is called SAMSON and is a artificial intelligent based tool for the rapid identification and diagnosis of severe accidents. The artificial intelligent based SAMSON system relies on a pattern recognition technique that is applied to the observed responses of in-plant instrumentation. The other on-line tool that supplements the emergency procedures and technical support staff is called MARS. The MARS tool performs on-line diagnostic crlculations that track the evolution of the accident and provide faster than real time near term predictions of the plant behavior. Section V.2 provides additional discussion of these accident management tools.

In order to effectively manage, collate, and exploit the large number of insights generated by the integrated approach a relational database was developed by Commonwealth Edison. The relational database will contain the entire set of insights for all of the integrated IPE and accident management program assessments performed for its six stations. The relational database allows for searching of common insights on the basis of plant, system, 
procedures, and phase of the accident progression. The relational database provides a resource for both the Tiger Team which benefits during the IPE anc accident management program and for future applications regarding the living PRA and living accident management activities by the utility.

\section{IV.3 Assegrent of Industry Approach}

The industry (EPRI) proposed process for evaluating accident management capabilities was discussed above in Section III.3. That approach focuses on employing the results of an IPE as a principle input to its evaluation process. The process is proposed to be sequential with an IPE or PRA. This is similar to the evaluation process proposed by the regulators (see Section III.1) but is unlike the integrated approach as selected by Commonwealth Edison (see Section III.2). Table 7 provides a comparison between these two processes, i.e., sequential and integrated development of an accident management program. The systematic evaluation process described in the industry's document has interfaces with the individual LWR owners groups and anticipates owner group produced accident management guidance as input to its evaluation process. The evaluation process is structured in as general an approach as possible so as to afford maximum flexibility during its application by various utilities. As noted previously in this report this framework could be applied to a systematic evaluation for the Savannah River Site. However, some of the anticipated interfaces and inputs to this process would not be available due to the lack of an owners group for the Savannah River production reactors. 
Table 7

SUMAARY OF COMPARISON OF EPRI AND CECO ACCIDENT MANAGEMIENT EVALUATION PROCESSES

\begin{tabular}{|c|c|}
\hline EPRI & CECO \\
\hline $\begin{array}{l}\text { Based on dominant sequences in } \\
\text { IPE. }\end{array}$ & $\begin{array}{l}\text { Based on IPE structure (process) } \\
\text { and quantification. }\end{array}$ \\
\hline Backwards looking. & Forward looking. \\
\hline Captures only enhancements. & $\begin{array}{l}\text { Captures good practices and en- } \\
\text { hancements. }\end{array}$ \\
\hline $\begin{array}{l}\text { Requires judgement in selecting } \\
\text { representative accident sequences. }\end{array}$ & Covers all accident sequences. \\
\hline $\begin{array}{l}\text { Focuses on additional capabilities } \\
\text { required. }\end{array}$ & $\begin{array}{l}\text { Focuses on enhancing existing } \\
\text { capabilities. }\end{array}$ \\
\hline $\begin{array}{l}\text { Insights developed from quanti- } \\
\text { fication. }\end{array}$ & $\begin{array}{l}\text { Insights develloped from "structure", } \\
\text { i.e., IPE process. }\end{array}$ \\
\hline $\begin{array}{l}\text { Likely to identify } 1 \text { or } 2 \text { major } \\
\text { items. }\end{array}$ & $\begin{array}{l}\text { Likely to identify many smaller en- } \\
\text { hancements, which together form a } \\
\text { major item. }\end{array}$ \\
\hline $\begin{array}{l}\text { Likely to find only additions to } \\
\text { plant capabilities. }\end{array}$ & $\begin{array}{l}\text { Likily to find deletions from } \\
\text { current design/practices as well as } \\
\text { enhancements. }\end{array}$ \\
\hline $\begin{array}{l}\text { Testing of options (enhancements) } \\
\text { and implementation of plan. }\end{array}$ & $\begin{array}{l}\text { Beyond the scope of CECo's evalu- } \\
\text { ation process. }\end{array}$ \\
\hline
\end{tabular}




\section{SEVERE ACCIDENT TECHNOLOCY DEVELOPATANTS}

The purpose of this section is to review and sumarize current NRC, utility, and industry technology developments regarding severe accidents in the areas of computational tools, severe accident predictive tools, diagnos. tic aids, and severe accident training and simulation. It should be noted that since the LWR industry in general has not yet completed its IPE efforts nor focused its efforts on accident management that only a limited number of developments regarding severe accident technology developments currently exist. The possible direct or modified application to the Savannah River production reactors will be identified.

\section{V.1 RRC Technology Developents}

Through the literature survey and direct conversation with the NRC (Palla, 1991), two activities in the area of accident management related computational tools or diagnostics have been identified.

The Nuclear Plant Analyzer (Palla, 1991) has been developed as a computational tool through work at the Idaho National Engineering Laboratory for the NRC. This computational tool utilizes the SCDAP/RELAP 5 computer code to perform severe accident sequence simulations. This is intended to be a fast operating version of this code combination. To date the Nuclear Plant Analyzer has been put in place in the NRC regions and used for training NRC regional personnel in severe accidents. An assessment of the applicability of the Nuclear Plant Analyzer to the Savannah River Site has not been attempted as part of this work.

The second diagnostic or calculational aid identified as part of ongoing NRC sponsored work is the Reactor Safety Assessment System (RSAS) code (Sebo, 1986). This is an expert system designed for U.S. NRC emergency response. RSAS is intended for use at the NRC Operations Center during serious incidents at licensed nuclear power plants and during emergency response drills. It is an heuristic classification system which converts parametric data from a power plant into plant status information which is 
useful to NRC emergency response personnel. The NRC Operations Center serves as the operational communication center for the NRC. A key NRC function during incidents is to provide an independent technical assessment of existing and expected plant status, offsite consequences and licensee actions. The RSAS expert system is a tool that is used for assessing the current and anticipated status of the nuclear power plant, particularly those aspects of plant status that could lead to offsite radioactivity releases. This expert system uses as input parametric data which the NRC phone talker obtains from the plant. Typically twenty to thirty values of temperatures, pressures, radiation readings, etc. are provided at 15 minute intervals. RSAS produces three types of conclusions based on this input data. First, diagnoses are produced when appropriate. An example of such a diagnosis would be that a steam generator is dry if its pressure is significantly below the saturation pressure corresponding to primary system temperatures. A second type of conclusion reached by this expert system points out important relationships between parameters and plant specific setpoints. An example of such a conclusion would be that the system notes relationships between a reactor system pressure and ECCS serpoints or between pressure and reactor temperatures. The third type of conclusion that may be reached regarding the input data is about the significant behavior of individual parameters such as high heatup or cool down rates. Furthermore, in addition to producing conclusions regarding the internal consistency and preliminary interpretation of the data, the system has ranges for plant instruments and is able to do limited error checking for the inputted signals. A graphic display of selected input parameters is available from this system. The direct applicability of this tool to the Savannah River Site would require the production of a rule set and separate setpoint files for the Savannah River Site. Such a capability could be used as part of the diagnostic and signal conditioning aspects of a larger more inclusive accident management tool.

In addition to the computational tools described above, the NRC has developed a diagnostic aid in the form of a Response Technical Manual (McKenna, 1991). The manual contains procedures to be used by the NRC when responding to accidents. The manual is designed to cover a spectrum of accidents including severe accidents and considerations for recovery and 
relaxing protective actions. Figure 13 provides an Assessment Tool overview which depicts the typical sequence in which the major procedures would be used by the NRC relative to the phases of an accident. Table 8 provides a summary of the procedures included in the Consequence Assessment while Table 9 provides a summary of the procedures in the Protective Action Assessment. As illustrated in Figure 13, the Assessment Tool provides a logical process for classifying accidents, assessing the conditions in the core and containment, for estimating the plume dose and source term, and for identifying protective actions for the general population including time intervals following the termination of the release of fission products. This document is structured in the form of checklists and charts to facilitate its use during an actual event. This is a useful format and worthy of consideration in other applications including potential applications at the Savannah River Site. NRC personnel receive training on the use of this Assessment Tool before being authorized to employ it. Volume 2 of the Assessment Tool report includes training materials applicable to its use.

\section{V.2 Utility Technology Developents}

Some utility's have initiated efforts to produce accident management tools which are capable of diagnosing and predicting severe accidents and are anticipated to be made available in support of utility personnel as a tool or an aid during an actual severe accident. In particular Northeast Utilities, Commonwealth Edison, and overseas utility organizations have initiated efforts to employ the MAAP accident analysis program developed under IDCOR and maintained by EPRI in such an accident management tool. The MAAP Accident Response System (MARS) is a calculational tool that has been structured to provide a mechanistic predictive capability to establish a realistic representation of a severe accident state and progression with a minimum of computer time and minimal reliance of understanding on controversial issues. A key feature of MARS is that it directly uses on-line plant data to identify and track the accident, to identify the accilent's cause, and to predict the plant's response for a variety of potential accidents or situations. The MARS system performs extremely fast assessments of mass and energy balances on the plant and includes a trending capability. 


$\begin{array}{ccc}\begin{array}{c}\text { Accident } \\ \text { Phase }\end{array} & \text { Consequence } & \text { Protective } \\ & \text { Assessment } & \text { Action } \\ & \text { Assessment }\end{array}$

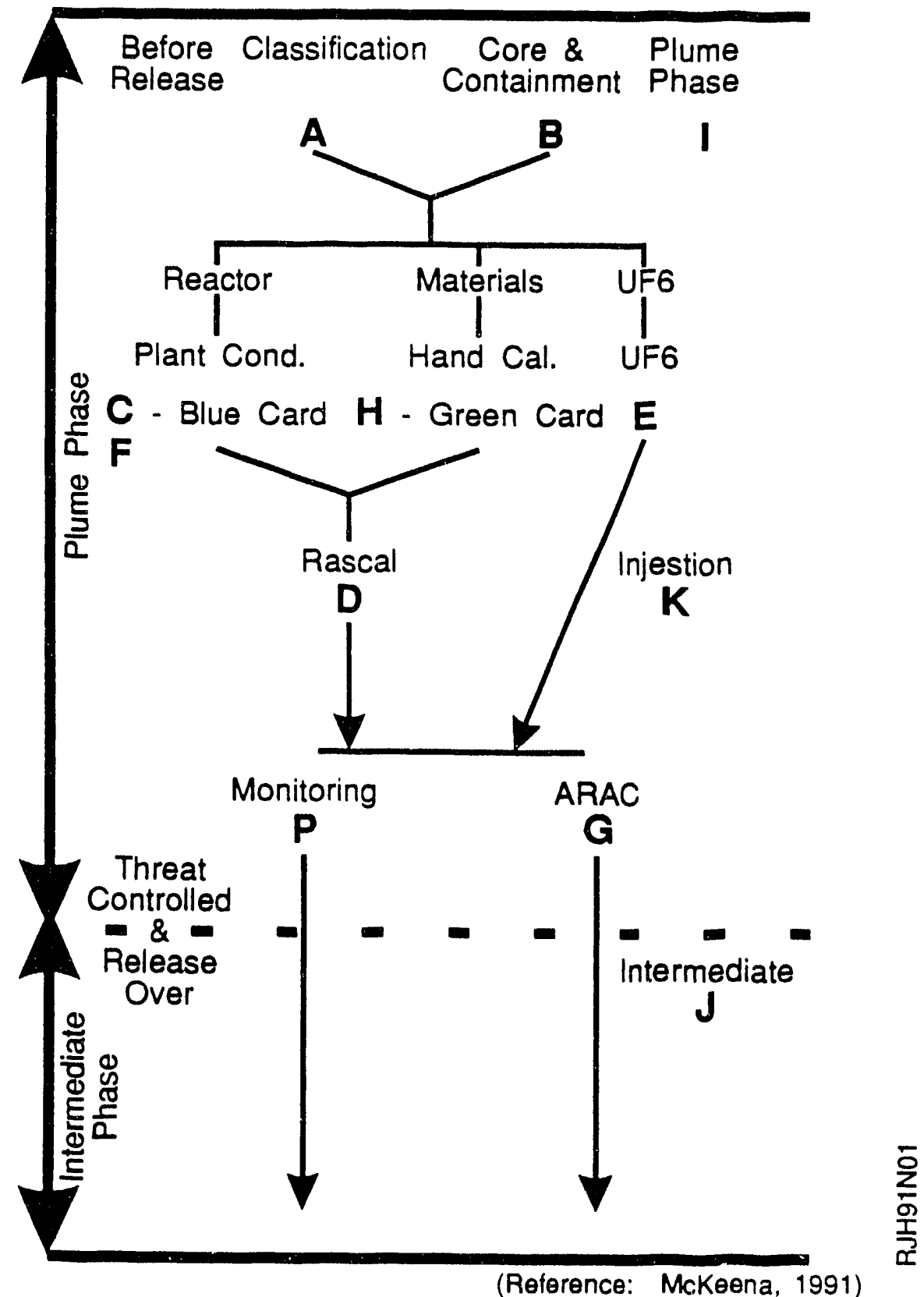

Figure 13 NRC Assessment Tool Overview 
Table 8

NRC CONSEQUENCE ASSESSKIENT PROCEDURE OVERVIEN

Section A, Classification Assessment

Differentiate accidents requiring immediate protective actions (general emergencies) from those that can wait for further assessments (e.g., field measurements).

Section B, Core and Containnent Assesswent

Aids in assessing core and containment conditions.

Section C, Reactor Accident Consequence Assessnent Based on Plant Conditions or Blue Card

Initially bound consequences (health effects and EPS PAG comparisons) based on possible reactor accident conditions.

Section D, Use of RASCAL

Standard NRC accident consequence / dose projection model (reactor conditions and isotopic releases.

Section E, UF6 Release Assessment

Assessment of consequence and protective actions for a UF6 accident.

Section F, Long Distance, Elevated Release and Rain Dose Projections for Severe Reactor Accidents

Dose projections out to great distances for severe reactor accidents that show the influence of elevated releases and rain.

Section G, Use of ARAC

Advanced transport model. Requires about an hour to produce end result and we wust specify source term (release information). Can project to great distances.

Section H, Plume Dose and Source Term Hand Galculation or Green Card

Calculate dose or source term from field measurements.

Section P, DOE Radiological Field Measurenents Assistance

How to get DOE field monitoring assistance. Use ASAP.

(Reference: McKeena, 1991) 


\title{
Table 9
}

NRC PROTECTTVE ACTION ASSESSMENTT PROCEDURE OVERVIET

\begin{abstract}
Section I, Plume Phase General Population Protective Action Assessment
Immediate actions taken before or shortly after a release. Actions to protect the population from the plume - prevent early health effects and reduce dose above EPA PAGs.
\end{abstract}

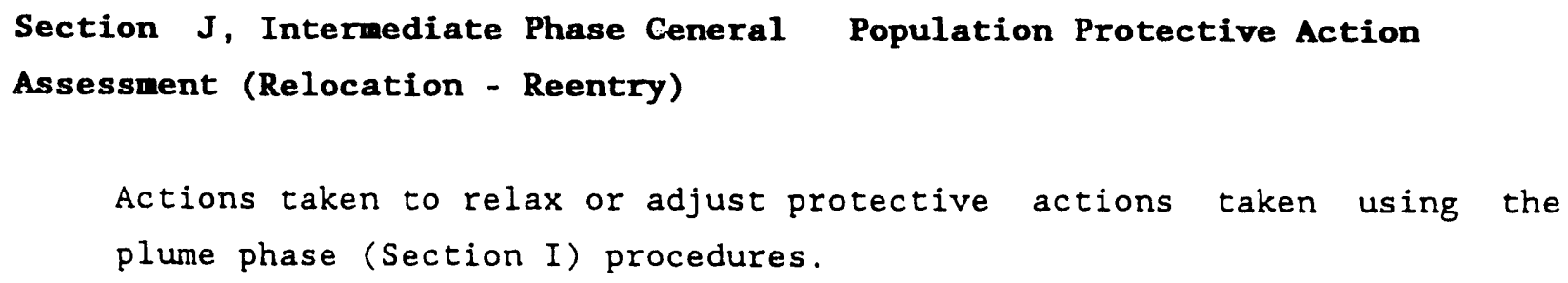

Section K, Ingestion Pathway Protective Action Assessment

Actions to protect the public from injection of contaminated food or water. 
MARS analyzes (diagnoses) all the reported information from the plant every time the data is transmitted, including severe accident states. The plant data is searched for inconsistencies, specifically regarding validity of any of the instrument readings. The trending evaluation derives information from major parameters such as water levels, pressures, and temperatures. The diagnostic mode assesses the fundamental cause of the accident and provides potential insights regarding the accidents root cause which can provide a mechanism for assuring the proper steps required to terminate an accident. Additionally, MARS performs a tracking function to assure that the response system predictions are current with the plant input data and the plant state within the accuracy of the data transmitted from the plant. The tracking function assures that the MARS system is continually consistent with the measured plant state such that future predictions (faster then real time) are initialized to the actual plant behavior. The mechanistic predictions of future plant response can be used to assess the potential outcome if no actions are taken, the potential outcome if the emergency operatirg procedures are followed, or the potential outcome of candidate accident management strategies being implemented. The near term future predictions will be very helpful to utility management personnel responsible for accident management and decision making.

The MARS system is currently being developed and implemented both at Northeast Utilities and overseas in Japan. Commonwealth Edison also plans to implement the MARS system. Commonwealth Edison is also supporting the development of an artificial intelligence based accident management tool called SAMSON. This tool uses a neural network approach to perform pattern recognition on plant signals to assess the state of the plant and estimate time until key severe accident events. The SAMSON system and MARS system will be complimentary to each other and operate in parallel to provide guidance and serve as tools in support of the severe accident management team. The SAMSON system has been implemented and tested in two demonstration phases and is currently being "trained" based on a series of plant specific MAAP runs. The SAMSON system like the MARS system is capable of identifying failed sensors or questionable plant parameters. The SAMSON system is able to identify failed sensors incorporated in the plant data for multiple channels and selected parameters. Since the SAMSON approach which 

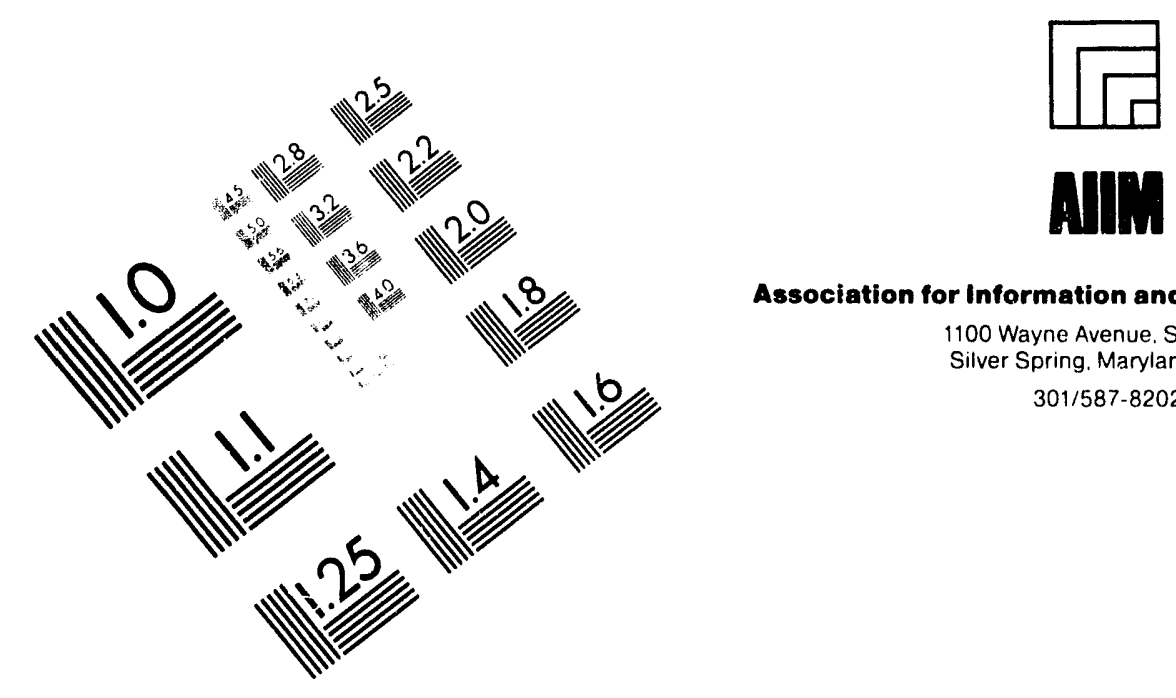

Association for Information and Image Management

1100 Wayne Avenue. Suite 1100

Silver Spring. Maryland 20910 301/587-8202

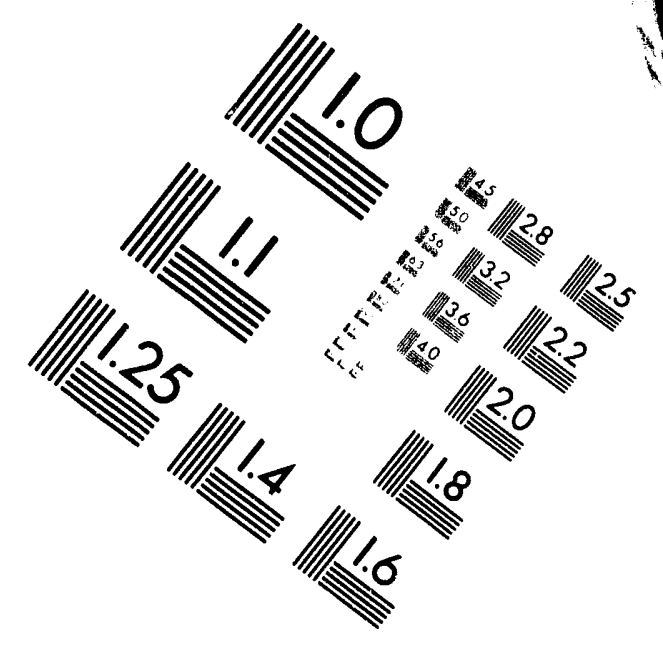

\section{Centimeter}

$\begin{array}{llllllllllllllll}1 & 2 & 3 & 4 & 5 & 6 & 7 & 8 & 9 & 10 & 11 & 12 & 13 & 14 & 15 & \mathrm{~mm}\end{array}$

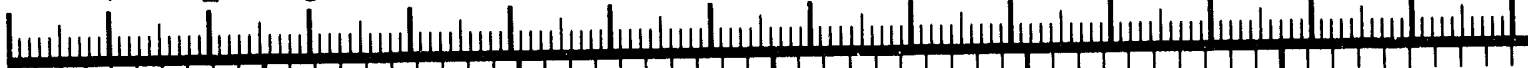

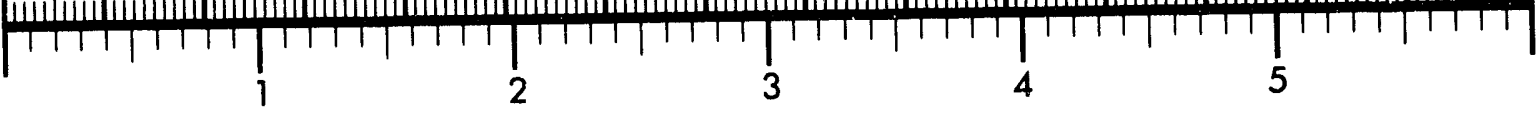
Inches
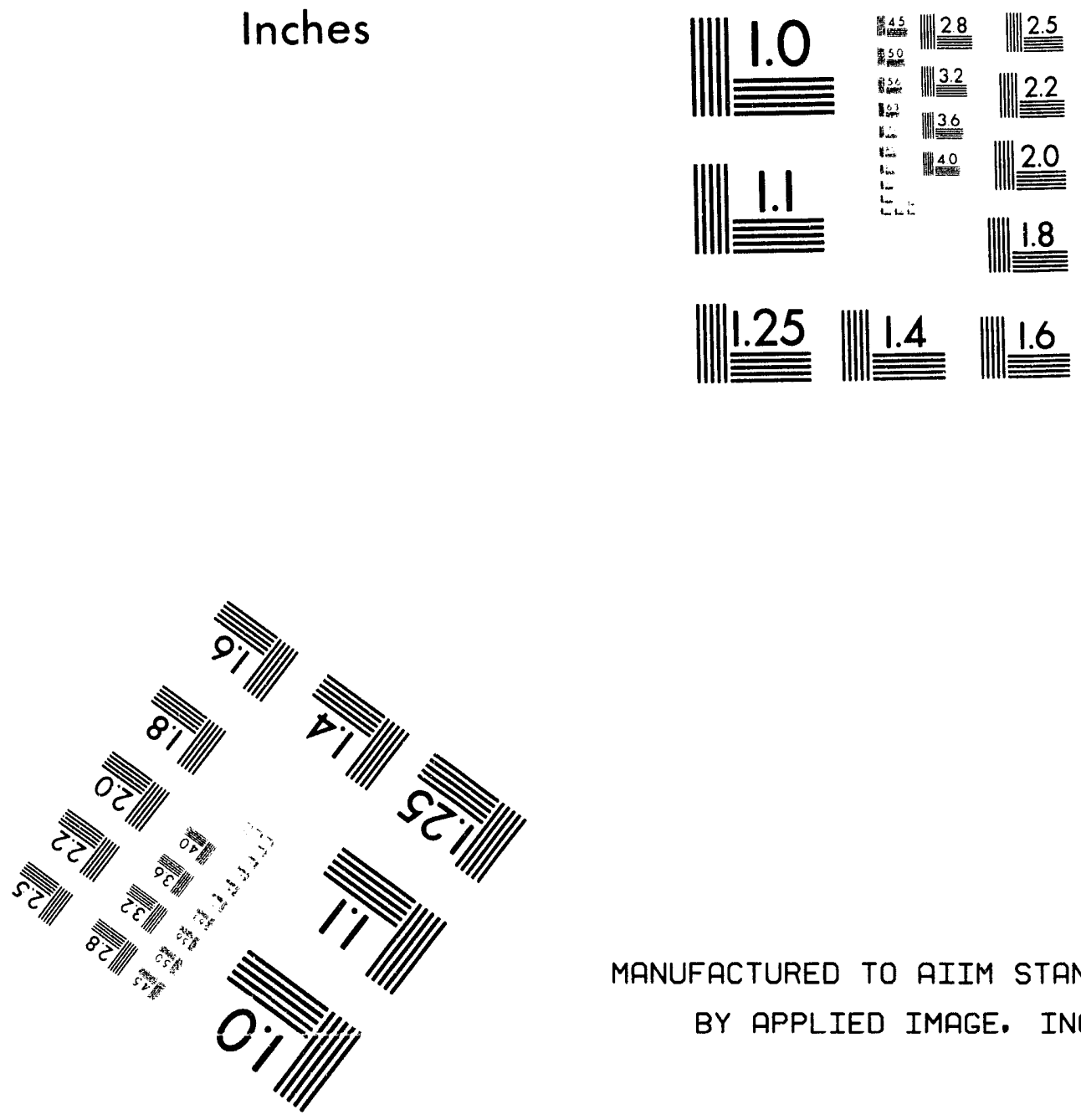

MANUFACTURED TO AIIM STANDARDS BY APPLIED IMAGE. INC.

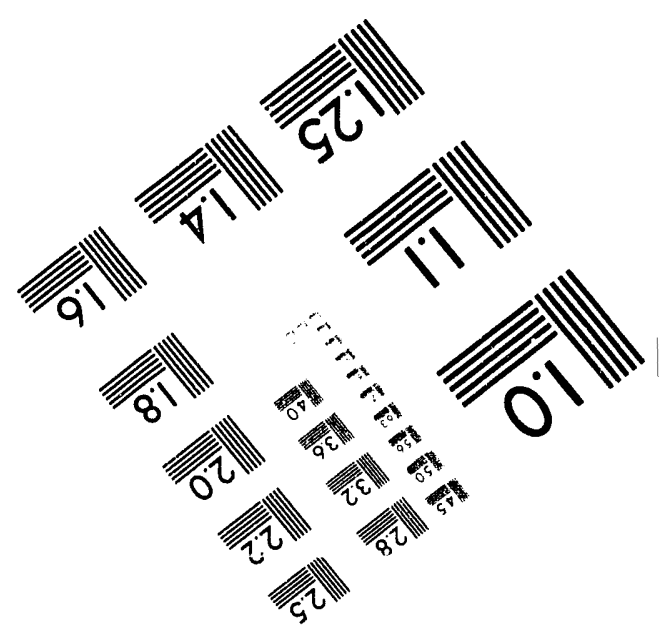



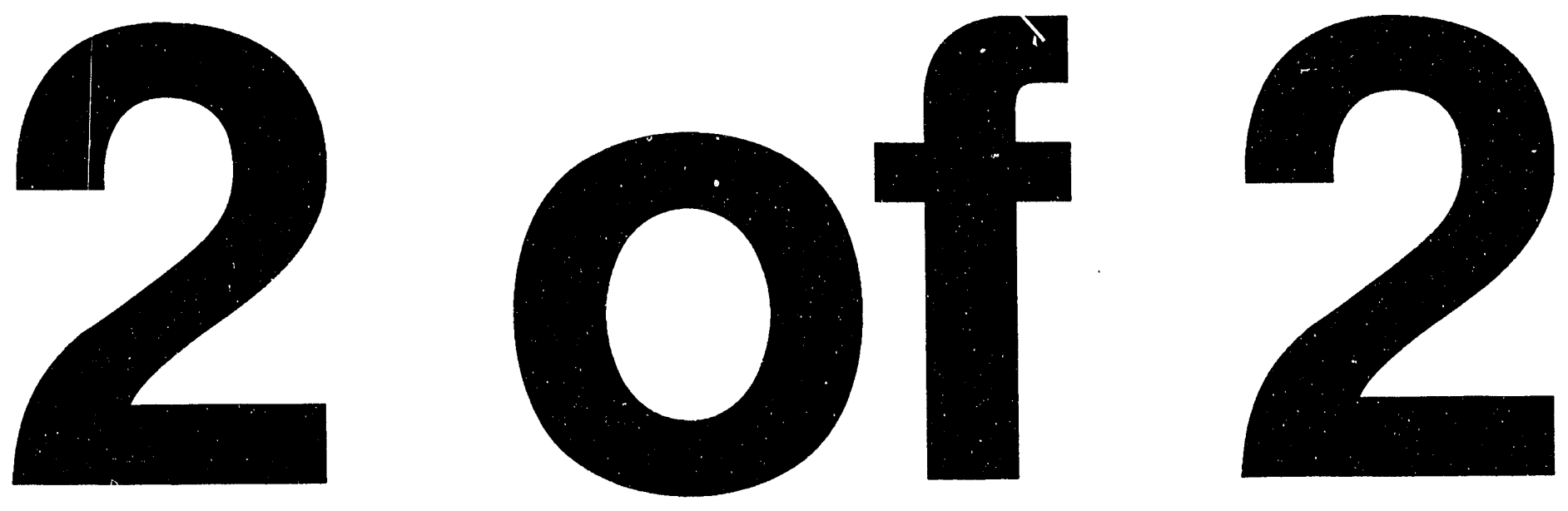
MARS analyzes (diagnoses) all the reported information from the plant every time the data is transmitted, including severe accident states. The plant data is searched for inconsistencies, specifically regarding validity of any of the instrument readings. The trending evaluation derives information from major parameters such as water levels, pressures, and temperatures. The diagnostic mode assesses the fundamental cause of the accident and provides potential insights regarding the accidents root cause which can provide a mechanism for assuring the proper steps required to terminate an accident. Additionally, MARS performs a tracking function to assure that the response system predictions are current with the plant input data and the plant state within the accuracy of the data transmitted from the plant. The tracking function assures that the MARS system is continually consistent with the measured plant state such that future predictions (faster then real time) are initialized to the actual plant behavior. The mechanistic predictions of future plant response can be used to assess the potential outcome if no actions are taken, the potential outcome if the emergency operating procedures are followed, or the potential outcome of candidate accident management strategies being implemented. The near term future predictions will be very helpful to utility management personnel responsible for accident management and decision making.

The MARS system is currently being developed and implemented both at Northeast Utilities and overseas in Japan. Commonwealth Edison also plans to implement the MARS system. Commonwealth Edison is also supporting the development of an artificial intelligence based accident management tool called SAMSON. This tool uses a neural network approach to perform pattern recognition on plant signals to assess the state of the plant and estimate time until key severe accident events. The SAMSON system and MARS system will be complimentary to each other and operate in parallel to provide guidance and serve as tools in support of the severe accident management team. The SAMSON system has been implemented and tested in two demonstration phases and is currently being "trained" based on a series of plant specific MAAP runs. The SAMSON system like the MARS system is capable of identifying failed sensors or questionable plant parameters. The SAMSON system is able to identify failed sensors incorporated in the plant data for multiple channels and selected parameters. Since the SAMSON approach which 
is a neural network employs pattern recognition as a technique for identifying plant condition, it can provide a very rapid response for accident diagnosis. The rapid diagnosis complements the diagnostic capability of MARS since MARS uses mechanistically based predictive capabilities. As discussed in the previous section of this report, these tools or computational aids have been identified as useful contributions as part of CECo's integrated IPE and accident management development program. The SAMSON system has been demonstrated to the NRC and at the 19 th Water Reactor Safety Information Meeting and received a positive initial reaction.

Another simulation capability has been derived from MAAP which is called MAAP-GRAAPH. MAAP-GRAAPH provides an interactive graphical display of various light water reactor containment types, primary system, and ECCS systems and water sources. The MAAP generated prediction of the transient behavior of pressures, temperatures, water levels, and hydrogen concentrations are visually displayed in this graphical representation. The user of the MAAP-GRAAPH system may change the status of valves and pumps in these various systems by the use of a "mouse". This simulation tool provides directly accessible technology that is available to training personnel as well as members of an accident management team. It provides a means of performing general transfer technology regarding severe accidents and their impact on the plant. Furthermore, such a simulation tool provides a mechanism for identifying and testing potential accident management strategies as well as developing realistic emergency response drills. The MAAP-GRAAPH capability is currently in place at several utility's in the United States, in Sweden and in Japan and is currently being pursued in several other countries.

The current design basis for control room simulators in the United States does not include the capability to address severe accidents. The potential uses and advantages of including severe accident capabilities in control room simulators is being studied and discussed (Hammersley, 1990). Technology for including severe accident models in control room simulators is being actively pursued overseas, in particular, in Sweden and Finland (see Section III.2). The development of such simulation capabilities would provide a convenient and familiar setting for training by operators. The 
pro's and con's of incorporating severe accident models in control room simulators are being evaluated by the U.S. nuclear industry as well as its regulators.

As discussed in Section III.2 (Northeast Utilities sub-section), an online calculation aid has been produced to support technical personnel's diagnoses and assessment of an accident. A set of plant specific information and interactive calculation algorithms are available via a menu. This represents one example of a severe accident management "tool box" as further discussed below in Section V.3.

The calculational aids discussed above including MARS, MAAP-GRAAPH and SAMSON and those discussed in Section III.2 (see Duke Power and Northeast Utilities sub-sections) are all potential candidates for application for the Savannah River Site production reactors. A prerequisite for the modification and implementation of MAAP dependent tools at Savannah River would be a revision of the severe accident modeling capability (MAAP) to reflect the specific geometry and systems incorporated in the Savannah River production reactors. Thus, such tools currently being developed for LWR designs are not directly applicable for Savannah River but could be modified to provide useful tools as part of the Savannah River accident management program. Tools formatted like Duke's severe accident sequence histories notebook, Northeast Utilities on-line calculation aids, or the NRC's assessment tool could be directly applicable at the Savannah River site.

\section{V.3 Industry Technology Developent}

As discussed above in Section III.3, a Technical Basis Report is being produced under the sponsorship of EPRI. Volume 2 of this document includes a series of appendices which provide a technical basis and calculational methods for assessing various severe accidents, responses for the primary system, and responses of the containment and its systems. These methodologies in some cases may serve directly as computational tools that can benefit accident management or in other cases provide a technical basis from which tools may be derived. To date calculational aids have not been developed or implemented based on the guidance provided in the Technical 
Basis Report. Rather, this document is nearing completion and will serve as a key input to the individual utility owners groups and then individual utilities. These organizations will develop and implement the actual calculational tools. A perspective on the elements that may benefit from analysis during accident management is included in Figure 14 (Oehlberg, 1991). The organization described by this figure is based on the perception that the focus of accident management is on making the maximum use of existing plant capabilities. Hence, it can be anticipated that tools will be used to assist in interpreting plant instrumentation which may be performing beyond its design basis, interpreting plant status based on available information, interpreting plant response to accident management actions and anticipating accident progression. In order to be practical such tools should be simple to use, simple to interpret and not excessibly dependent upon precise knowledge of phenomenological factors which can influence the accident progression. The elements of an accident management "toolbox" as described in Figure 14 are applicable for assessing similar needs at the Savannah River production reactors. 


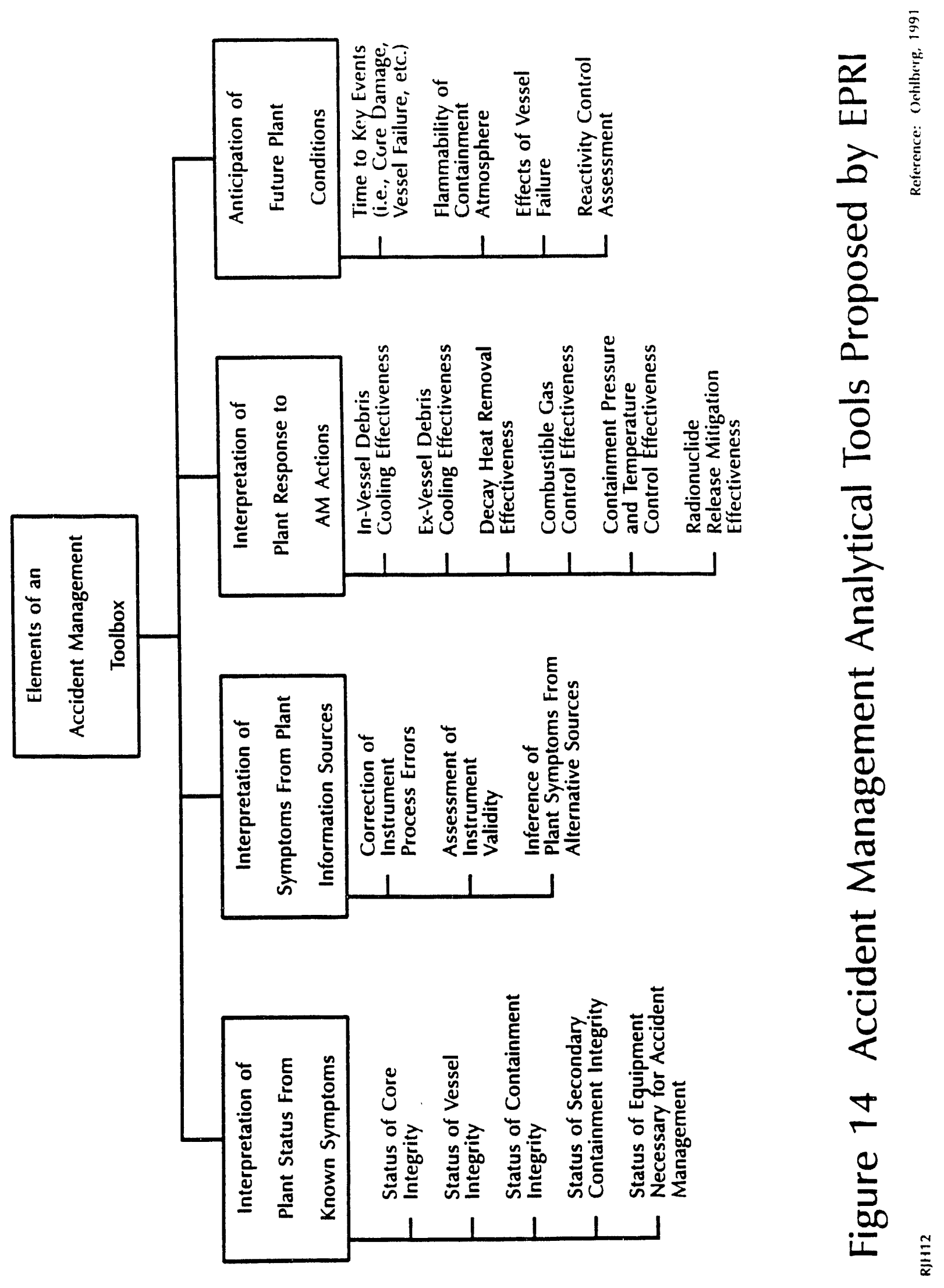




\section{REFERENCES}

Barrett, M., Duke Power, Personal Communication, November 11, 1991.

Bastien, R., et a1., 1988, "The Westinghouse "Severe Accident" Procedures as Developed for the Ringhals Unit", Presented at the Internationa.l Symposium on Severe Accidents in Nuclear Power Plants, Sorrento, Italy'.

Debes, M., 1991, "Incident and Accident Management in PWR Plants, 'The French Approach" ", Proceedings of the International Topical Meeting on Safety of Thermal Reactors, Portland, Oregon.

Haas, P., Mitche11, H., Norkus, J., Bell, D., 1990, Accident Management Program for SRS Reactors, Safety Analysis Group, Savannah River Laboratory (viewgraphs).

Hammersley, R. J., 1990, "On the Use of Training Simulators for Accident Analysis and Training", EMC 1990 Eastern Multiconference, April 23-26, Nashville, Tennessee.

Henry, R. E., Hammersley, R. J., Klopp, G. T., 1991a, "Direct Containment Heating Experiments in a Zion-Like Geometry", Presented at 27th National Heat Transfer Conference, July 29 - August 7, 1991, Minneapolis, Minn.

Henry, R. E., et al., 1991b, "Cooling of Core Debris Within the Reactor Vessel Lower Head", Presented at 1991 ANS Annual Meeting, June 2-6, 1991, Orlando, Florida.

Klopp, G. T., 1988, "Industry Program Needed for Nuclear Accident Management", Power Engineering, May.

Klopp, G. T., 1990, "Accident Management Program Evolution at Commonwealth Edison", Nuclear Plant Journal, September-October.

Klopp, G. T., 1991, Transactions of the Nineteenth Water Reactor Safety Information Meeting.

Lutz, J., R. J., Hammersley, R. J., Brown, R. G., Klopp, G. T., 1991, "Commonwealth Edison's Innovative Approach to Integrating Accident Management with IPE", Proceedings of the International Topical Meeting on Safety of Thermal Reactors, Portland, Oregon.

Malinovic, B., Henry, R. E., 1989, "Experiments Relating to Drywell ShellCore Debris Interaction", EPRI report presented at the AIChE Heat Transfer Conference, Philadelphia.

McKeena, T., et al., 1991, "RTM-91 Response Technical Manual", NUREG/BR0150, U.S. NRC. 
Oehlberg, R. N., Henry, R. E., Ture, D. E., 1991, "Practical Considerations in Accident Management", Proceedings of the International Topical Meeting on Safety of Thermal Reactors, Portland, Oregon.

Palla, R., USNRC, Personal Communication, July 29, 1991.

Post, J. S., et al., 1983, "BWR Emergency Procedure Guidelines", Proceedings 1983 ANS Topical Meeting on Anticipated and Abnormal Plant Transients in Light Water Reactors.

Sebo, D. E., Bray, M. A., King, M. A., 1986, "An Expert System for USNRC Emergency Response", Transactions of the Fourteenth Water Reactor Safety Information Meeting.

Sehgal, B. R., et al., 1991, "ACE Program Phases C\&D: Molten Corium Concrete Interaction (MCCI) Experiments and Corium Melt Coolability Experiments (MACE)", Transactions of the Nineteenth Water Reactor Safety Information Meeting.

Surman, R. C., et al., 1983, "Guidance for Control Room Emergency Operations", Proceedings 1983 ANS Topical Meeting on Anticipaced and Abnormal Plant Transient.s in Light Water Reactors.

Tuomisto, H., Theofanous, 1991, Proceedings 1991 Specialist Meeting on Severe Accident Management, Rome, Italy. 

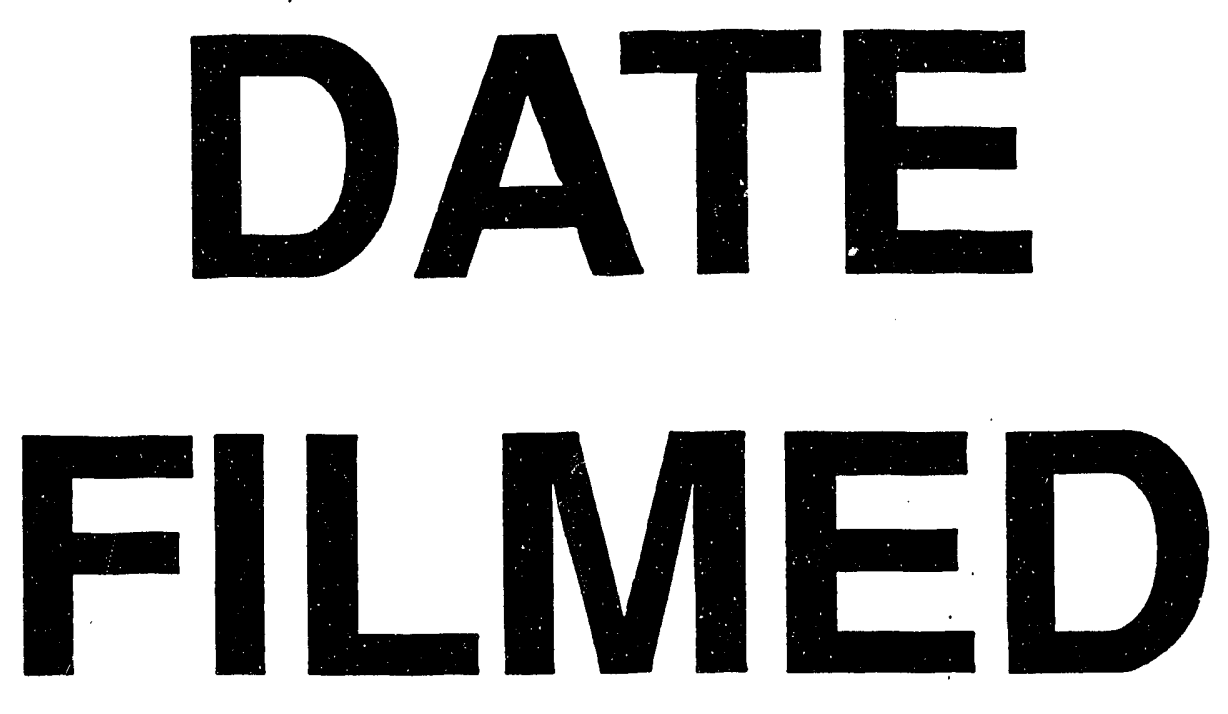

$9 / 10 / 93$
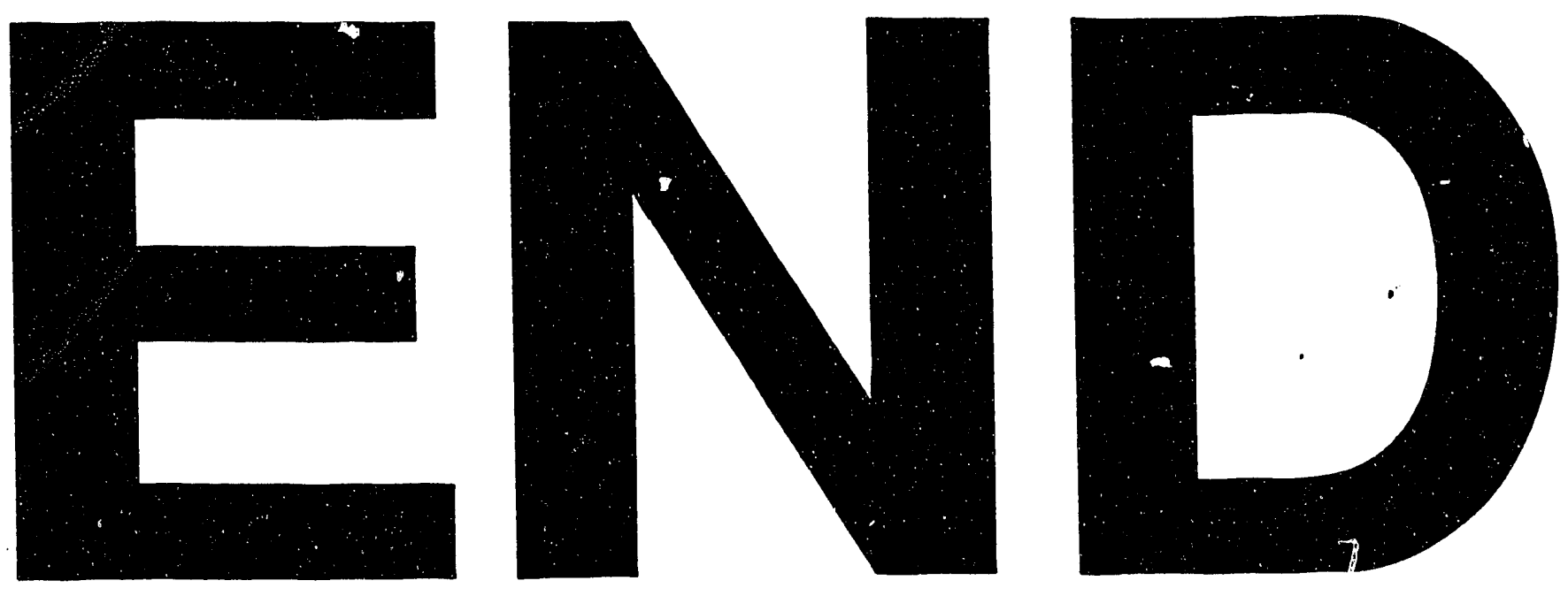
